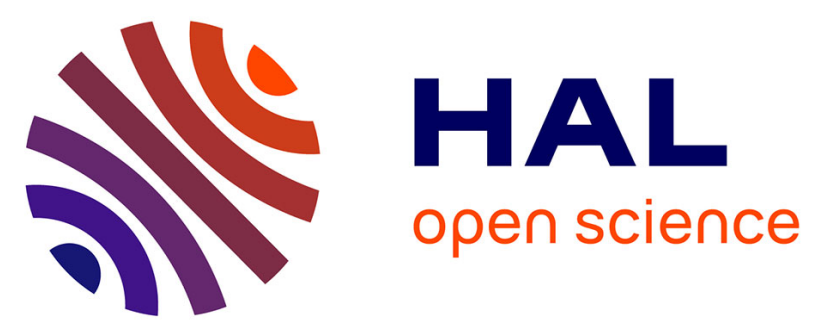

\title{
Potential encoding of coupling between Milankovitch forcing and Earth's interior processes in the Phanerozoic eustatic sea-level record
}

Slah Boulila, Bilal U Haq, Nathan Hara, R. Dietmar Dietmar Müller, Bruno Galbrun, Guillaume Charbonnier

\section{- To cite this version:}

Slah Boulila, Bilal U Haq, Nathan Hara, R. Dietmar Dietmar Müller, Bruno Galbrun, et al.. Potential encoding of coupling between Milankovitch forcing and Earth's interior processes in the Phanerozoic eustatic sea-level record. Earth-Science Reviews, 2021, 220, pp.103727. 10.1016/j.earscirev.2021.103727 . hal-03284099

\section{HAL Id: hal-03284099 https://hal.science/hal-03284099}

Submitted on 12 Jul 2021

HAL is a multi-disciplinary open access archive for the deposit and dissemination of scientific research documents, whether they are published or not. The documents may come from teaching and research institutions in France or abroad, or from public or private research centers.
L'archive ouverte pluridisciplinaire HAL, est destinée au dépôt et à la diffusion de documents scientifiques de niveau recherche, publiés ou non, émanant des établissements d'enseignement et de recherche français ou étrangers, des laboratoires publics ou privés. 
Earth-Science Reviews, 2021

DOI:https://doi.org/10.1016/j.earscirev.2021.103727

Received date: 5 April 202. Revised date:9 June 202. 1Accepted date: 22 June 2021

\title{
Potential encoding of coupling between Milankovitch forcing and Earth's interior processes in the Phanerozoic eustatic sea-level record
}

\author{
Slah Boulila a,b, ${ }^{*}$, Bilal U. Haq ${ }^{\mathrm{a}, \mathrm{c}}$, Nathan Hara ${ }^{\mathrm{d}}$, R. Dietmar \\ Müller $^{\mathrm{e}}$, Bruno Galbrun ${ }^{\mathrm{a}}$, and Guillaume Charbonnier ${ }^{\mathrm{a}}$ \\ a Sorbonne Université, CNRS, Institut des Sciences de la Terre Paris, ISTeP, F-75005 Paris, France. \\ ${ }^{b}$ ASD/IMCCE, CNRS-UMR8028, Observatoire de Paris, PSL University, Sorbonne Université, 77 \\ Avenue Denfert-Rochereau, 75014 Paris, France. \\ ${ }^{c}$ Smithsonian Institution, Washington DC, USA \\ ${ }^{d}$ Département d'astronomie, Université de Genève, 51 Chemin de Pegasi b, 1290 Versoix, Suisse. \\ ${ }^{e}$ EarthByte Group, School of Geosciences, University of Sydney, Sydney, New South Wales 2006, \\ Australia.
}

*Corresponding author: slah.boulila@sorbonne-universite.fr

\begin{abstract}
The driving mechanisms of Earth's climate system at a multi-Myr timescale have received considerable attention since the 1980's as they are deemed to control largeamplitude climatic variations that result in severe biogeochemical disruptions, major sea-level variations, and the evolution of Earth's land- and seascapes through geological time. The commonly accepted mechanism for these changes derives from the evolution of Earth's coupled plate-mantle system. Connection between Earth's interior and external climate drivers, e.g., Milankovitch insolation forcing, has not been investigated at multi-Myr timescale, because tectonics and astronomical influences at these longer timescales have long been thought as independent pacemakers in the evolution of the Earth system.

Here we have analyzed time-series from multiple geological datasets and found common periodicities of 10 and 35 Myr. Additionally, we have highlighted the modulation in amplitude of the $10 \mathrm{Myr}$ cycle band by the $35 \mathrm{Myr}$ cyclicity in sedimentary sea-level data. We then demonstrate the same physical amplitude modulation relationship between these two cyclicities in astronomical (Milankovitch) variations, and establish correlation between Milankovitch and sea-level variations at these two frequency bands. The 10 and $35 \mathrm{Myr}$ cycles are prominent in the geological records, suggesting either unresolved fundamental Milankovitch periodicities, or reflecting a sedimentary energy-transfer process from higher to lower Milankovitch frequencies, as argued here via amplitude modulation analysis in both astronomical and sea-level data.

Finally, we find a coherent correlation, at the $35 \mathrm{Myr}$ cycle band, between Milankovitch, sea-level and geodynamic (plate subduction rate) variations, hinting at a coupling between Earth's interior and surface processes via Milankovitch paced climate. Thus, our findings point to a coupling between Milankovitch and Earth's internal forcings, at
\end{abstract}


10 to 10 s of Myr. The most likely scenario that could link insolation-driven climate change to Earth's interior processes is Earth's interior feedbacks to astro-climatically driven mass changes on Earth's surface. We suggest that Earth's interior processes may drive largeamplitude sea-level changes, especially during greenhouse periods, by resonating to astroclimatically driven Earth's surface perturbations.

Keywords: Earth's climate, sea level, Milankovitch, tectonics, multi-million year timescales.

\section{Introduction}

The link between Earth's interior and surface processes at longer geological timescales has fascinated Earth science community because their combined effect shapes the Earth's surface (e.g., Raymo et al., 1988; Molnar and England, 1990; Raymo and Ruddiman, 1992; Lamb and Davis, 2003; Lagabrielle et al., 2009; Whipple, 2009; Cloetingh and Haq, 2015).

That solid Earth responds to or resonates with the Earth's surface perturbations induced by climate and environmental changes has been suggested at short timescales on the diurnal to annual band. Tidal forcing of the micro-seismic and volcanic activity has been argued based on several datasets (Johnston and Mauk, 1972; McNutt and Beavan, 1981; Emter, 1997; Petrosino et al., 2018; Dinger et al., 2019, among many others). Also, correlations are well established between volcanic eruptions and diurnal to annual temperature and atmospheric pressure, suggesting that the hydrological cycle plays a crucial role in volcanism via water-mass transfer from oceans to continents and the resulting pressure changes on the upper mantle (see e.g., McNutt and Beavan, 1987; Neuberg, 2000; Mason et al., 2004).

Processes reflecting Earth's interior dynamics have been linked to climate change at millennial timescale (Rampino et al., 1979; McGuire et al., 1997; Huybers and Langmuir, 2009, 2017; Lund and Asimow, 2011; Kutterolf et al., 2012; Crowley et al., 2015; Tolstoy, 2015; Schindlbeck et al., 2018; Cerpa et al., 2019). In particular, the detection of shorter Milankovitch climate periodicities in global volcanic activity (Rampino et al., 1979; Schindlbeck et al., 2018) and in the seafloor abyssal bathymetry suggest links between astro-climate and Earth's interior processes (Crowley et al., 2015; Tolstoy, 2015). Such potential connections have been investigated by others, e.g., Olive et al. (2015) and Goff et al. (2018), who have suggested that Milankovitch forcing of sea-level (and thus seafloor abyssal hills) should not be taken at face value, and that only slow-spreading rates would favor such expression of Milankovitch periodicities in the bathymetric data. For fast- to intermediate-spreading rates, Olive et al. (2015) favor a tectono-magmatic model for the abyssal hill fabrics that considers normal faulting as an important element. This model differs from that based only on the magmatic and volcanic outputs at mid-ocean ridges to explain the fabric of the abyssal hills (Crowley et al., 2015; Tolstoy, 2015). Interestingly, Olive et al. (2015) suggested that the lithosphere and seafloor-shaping processes may act as a lowpass filter on variations in magma supply, damping Milankovitch periods shorter than about 100 kyr.

Another line of evidence for the potential connection between Earth's interior processes and external climate forcing, but at multi-Myr timescales, comes from a striking correlation between orbitally paced 9.5 Myr climatic cyclicity (from deep-sea stable oxygenisotopic records, e.g., Zachos et al., 2001), and geodynamically-induced (tectonics, volcanism) oceanic-climatic events of the past $115 \mathrm{Ma}$ (Boulila, 2019).

Major tectonic plate motions that occur at very slow, Myr to multi-Myr timescales, drive the evolution of land- and seascapes (Cloetingh and Haq, 2015), dictate changes in biomass evolution and turnovers, and drive biogeochemical and sea-level cycles. One of the 
major manifestations of long-term tectonic forcing is global sea-level eustatic variations through geodynamically-induced changes in the volume of the ocean basins (Vail et al., 1977; Haq et al., 1987; Miller et al., 2005a; Müller et al., 2008; Simmons, 2012; Conrad, 2013; Simmons et al., 2020). The recognition of similar periodicities in sea-level, climate and Milankovitch variations has led some researchers to suggest potential correlation between Milankovitch and tectonic forcings at multi-Myr timescales (Boulila, 2019; Boulila et al., 2020). Thus, the detection of correlatable Myr to multi-Myr scale variations in tectonic, biogeochemical, climate and sea-level proxy data (Vail et al., 1977; Haq et al., 1987; Boulila et al., 2011, 2012, 2018, 2020; Boulila, 2019) could provide further constraints for the link between Earth's interior and surface processes.

Here we review cyclicities of tens of Myr in astronomical and geological data. We focus on sedimentary inferred sea-level record and geodynamic data/models, and compare them with stable oxygen isotopes and astronomical (Milankovitch) variations. Given that Milankovitch variations exhibit modulation in amplitude and frequency, we performed amplitude modulation analysis (see Section 2.3) on Earth's orbital eccentricity variations to investigate the record of longer cyclicities of tens of Myr. Then, we performed amplitude modulation analysis on Phanerozoic sea-level data. Finally, we compared sea-level, climate and Milankovitch variations with geodynamic data for potential linkages.

\section{Data and methods}

\subsection{Geological data}

The eustatic sea level curve for the Phanerozoic was constructed based on sequence-stratigraphic studies of the marine sedimentary sections around the world. Correlations are based on the available marine biostratigraphic markers, and if a sea-level change can be demonstrated to be present in a number of non-contiguous sections, it is considered wide-spread and therefore eustatic. The details of these methodologies are described in Haq et al. (1987) for the Meso-Cenozoic and in Haq and Schutter (2008) for the Paleozoic. The Ceno-Mesozoic eustatic curve (Haq et al., 1987) was revised through a comparison with the Arabian Platform records (Haq and Al-Qahtani, 2005). The compiled Ceno-Mesozoic and Paleozoic eustatic curves (Phanerozoic, 0 to $542 \mathrm{Ma}$ ) were recalibrated to recently updated geological timescale (Gradstein et al., 2020, Fig. 1A).

Variations in Earth's interior processes can be inferred from data modeling of midocean spreading and plate subduction processes. Well-constrained plate tectonic and carbon cycle models of the Meso-Cenozoic interval have been constructed (e.g., Müller et al., 2016; Müller and Dutkiewicz, 2018). Cyclicities of tens of Myr were detected in these models. In particular, spectral analysis of spreading rate data detects a main cyclicity of 25 to $26 \mathrm{Myr}$ (e.g., Cogné and Humler, 2006; Müller and Dutkiewicz, 2018). Here we have focused on cyclicities of tens of Myr in both spreading and subduction data for potential correlations with sea-level data. We used tectonic data of the most recent global plate model of Müller et al. (2019) that is updated from the earlier model of Müller et al. (2016). This newer model additionally includes plate deformation along major rifts and orogens since rifting of Pangea started in the Early Triassic (240 Ma). It also considers the evolution of the age-area distribution of ocean floor. This model provides mid-ocean spreading and plate subduction data as well as the total variations in the crustal production and destruction rates through time. We have also analyzed the equivalent data of the previous model (Müller et al., 2016) to see to what extent the cyclicities we find are affected by the differences in plate tectonic models. 

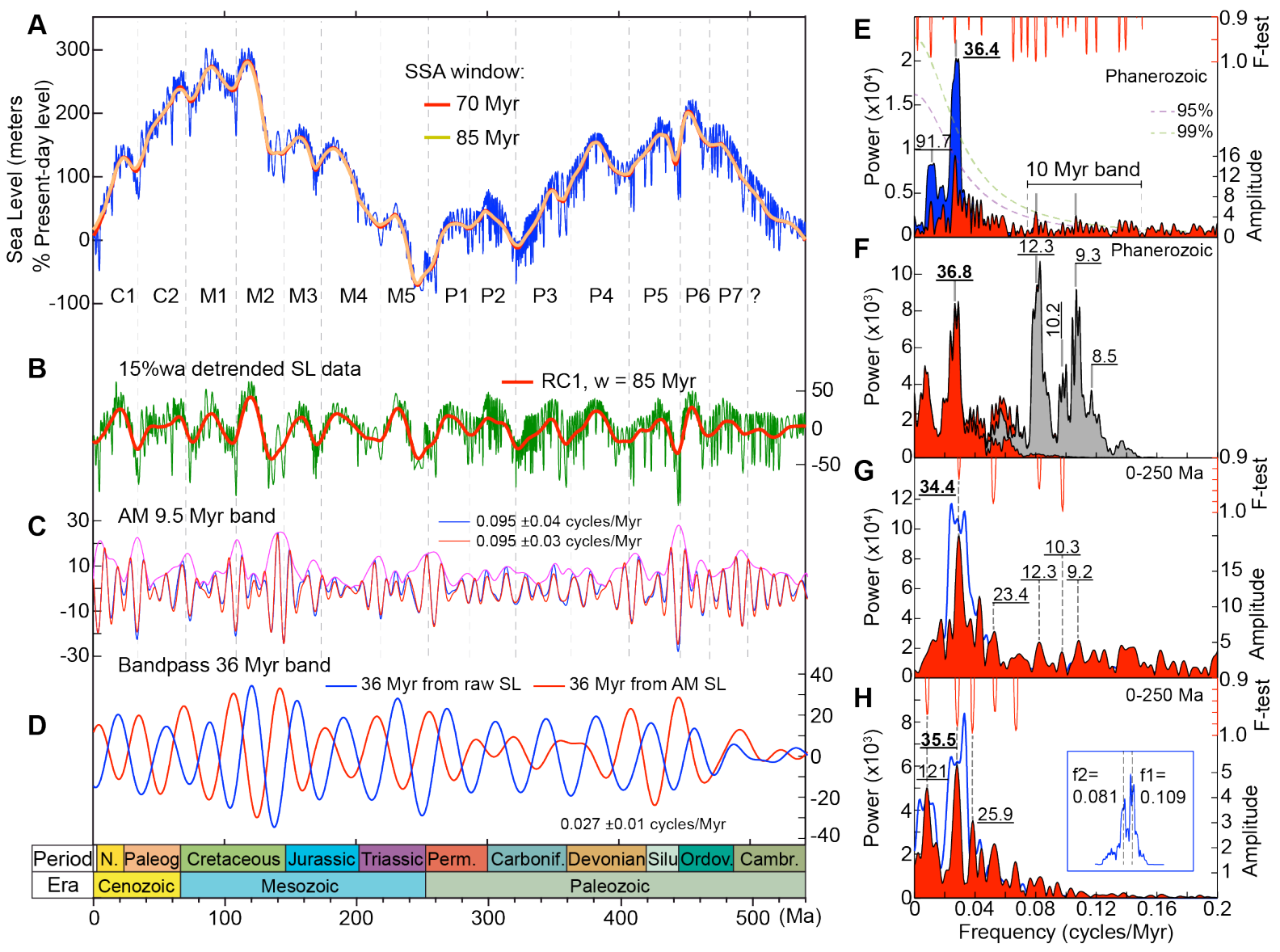

Figure 1: Amplitude modulation analysis of Phanerozoic sea-level data. (A) Raw sea-level data (detail on reference sources is provided in Section 2.1), along with SSA lowpass filtering (RC1 with different windows indicated). (B) Detrended Phanerozoic sea-level data (Wilson cycles removed, 15\% weighted average removed), along with SSA RC1. (C) 10 Myr bandpass filtering and amplitude modulation envelopes of the detrended sea-level data in 'A'. (D) $35 \mathrm{Myr}$ bandpass filtering from sea-level data in ' $A$ ', and from amplitude modulation envelopes in 'B'. (E) Power and amplitude spectra of the detrended Phanerozoic sea-level data. (F) Power spectra of 10 Myr bandpass filtered (0.095 \pm 0.04 cycles/Myr) sea-level data in grey and of its amplitude modulation envelope curve in red. (G) Power and amplitude spectra of the detrended sea-level data over the interval 0-250 Ma. (H) Power and amplitude spectra of sea-level amplitude modulation envelope curve of the $10 \mathrm{Myr}$ band $(0.095 \pm 0.04 \mathrm{cycles} / \mathrm{Myr})$ for the interval 0-250 Ma. Inset: Power spectrum of the $10 \mathrm{Myr}$ bandpass filtered data to show the two beating frequencies $\mathrm{f} 1=0.081(12.3 \mathrm{Myr})$ and $\mathrm{f} 2=0.109(9.2 \mathrm{Myr})$ that produce the $35 \mathrm{Myr}$ cycle. Results on the interval 0-250 Ma are shown for comparison with the astronomical data (Figs. 7 and 8). The antiphase relationship between the $35 \mathrm{Myr}$ cycle from $10 \mathrm{Myr}$ amplitude modulation band and that from the original data in ' $D$ ' is explained in Section 3.2.

\subsection{Astronomical data}

An important feature of the Earth's orbital parameter variations is that they display modulations in amplitude and frequency. The significance of certain amplitude modulation cycles was first described by Laskar (Laskar, 1990, 1999; Laskar et al., 1993), and an extensive review was later presented by Hinnov (2000). The most well known long-period modulation cycles are those of eccentricity ( 2.4 Myr) and obliquity ( 1.2 Myr).

Lower-frequency orbital variations (e.g., 2.4 and $4.7 \mathrm{Myr}$ ) are characterized by lower amplitudes when compared to higher-frequency variations (e.g., Laskar et al., 2004). 
However, several studies have shown strong expression of long-period orbital cycles in the sedimentary record (e.g., Beaufort, 1994; Zachos et al., 2001; Pälike et al., 2006; Mitchell et al., 2008; Boulila et al., 2010, 2011, 2012, 2014, 2020; Huang et al., 2010; Sprovieri et al., 2013; Boulila, 2019). Energy-transfer process from higher to lower astronomical frequencies is also a common feature in the sedimentary record (Boulila et al., 2012; Li et al., 2018). Our strategy for the extraction of low-frequency orbital amplitude modulation envelopes was based on choice of the strongest eccentricity ( $405 \mathrm{kyr}, \mathrm{g} 2-\mathrm{g} 5$, where g2 and g5 are related to the precession of the perihelions of Venus and Jupiter) and its surrounding terms, the interference of which would produce longer terms of 2.4, 4.7 and 9.5 Myr (Boulila et al., 2012, 2020; Boulila, 2019). Subsequently we bandpass filtered the $9.5 \mathrm{Myr}$ band from these 400 kyr amplitude modulation envelopes for eventual, serial modulation by even longer eccentricity terms. The phase of the $9.5 \mathrm{Myr}$ cycle band was rectified for correlation with sealevel data (Section 3.3). We used all available astronomical data, which cover the past 250 Ma: the La2004 model (Laskar et al., 2004), and La2010a,b,c and d models (Laskar et al., 2011). Only La2004 and La2010d data show coherent cyclicities with sea-level data, and therefore only their respective amplitude modulation results were shown (Section 3.3). The robustness of La2010d with respect to other La2010 versions has already been demonstrated via a correlation with carbon-cycle data (Boulila et al., 2012). A persuasive correlation at the $9.5 \mathrm{Myr}$ cycle band between carbon-cycle and La2004 astronomical data was also shown for the past $60 \mathrm{Ma}$ (Boulila et al., 2012 their figure 1).
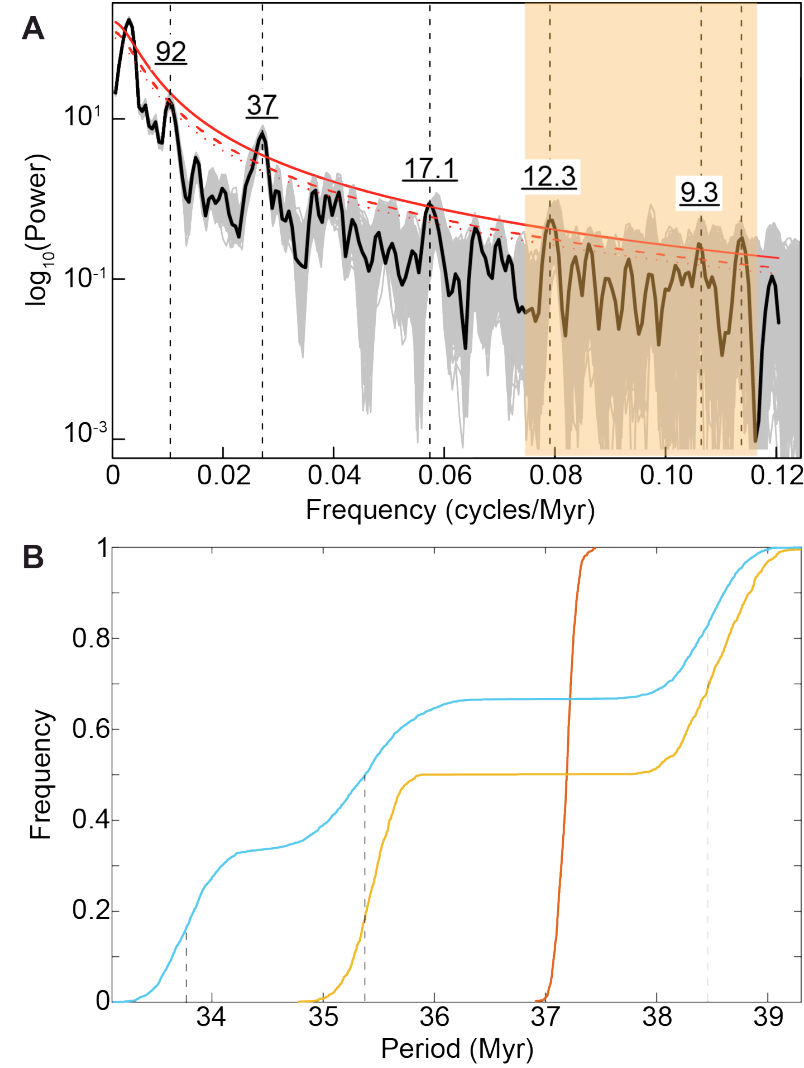

Figure 2: Power spectra of Phanerozoic sealevel data, and quantification of the $37 \mathrm{Myr}$ cyclicity per intervals (from Boulila et al., 2018). (A) Power spectrum of the raw sea-level data and confidence levels of $90 \%, 95 \%$ and $99 \%$. Grey-colored spectra are 1000 Markov Chain Monte Carlo (MCMC) simulations to test the impact of timescales on the recorded periods. Light orange shaded interval indicates the 10 Myr cycle band. (B) Experimental cumulative distribution function of the $37 \mathrm{Myr}$ period of sea-level data over three time intervals: the entire sea-level data, sea-level data split into two equal time intervals, sea-level data split into three equal time intervals. 

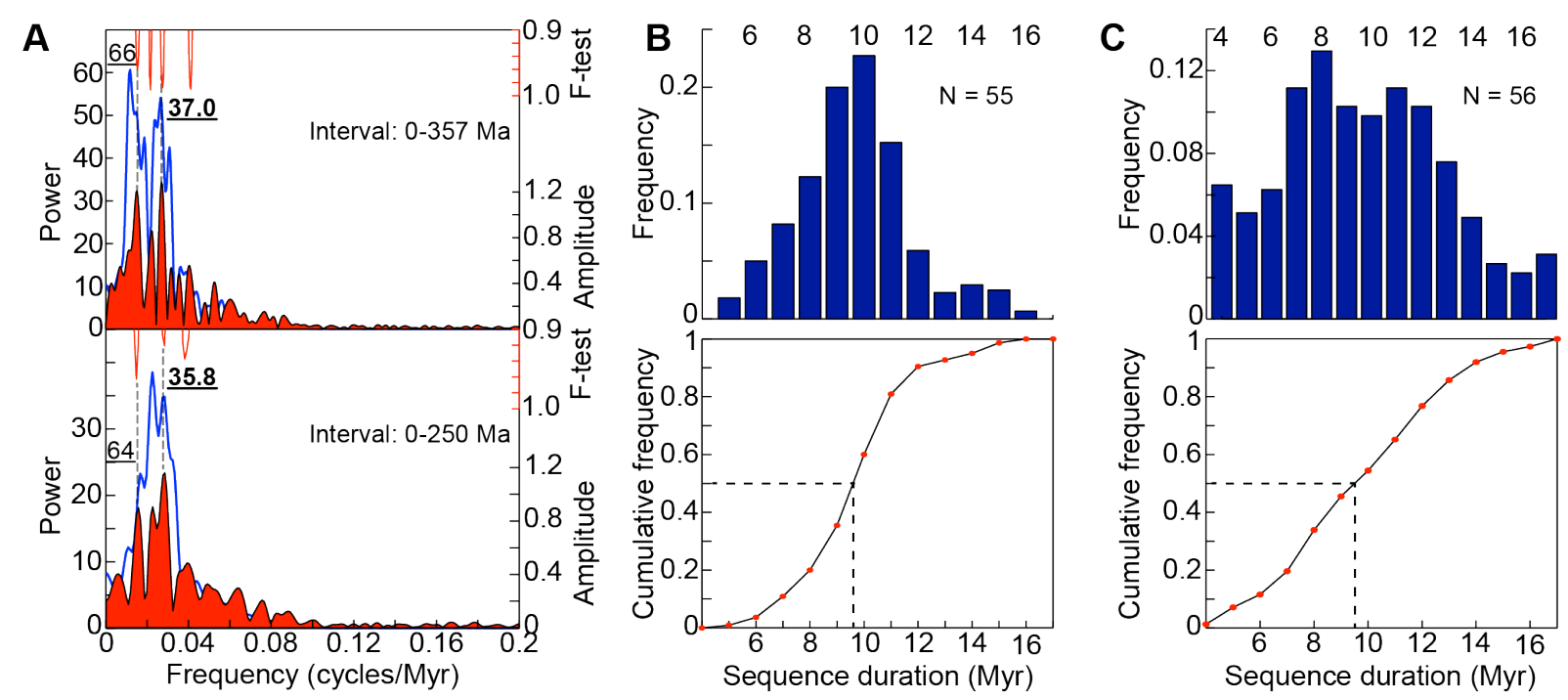

Figure 3: Power spectra and statistics of the duration of 10 Myr scale eustatic cycles (medium-1 second-order sequences, Boulila et al., 2018, see Table 1). (A) Power spectra of the evolution of duration of 10 Myr eustatic sequences through time (data are from the sea-level reference chart, see Section 2.1 for the original references). (B) Histogram and cumulative distribution function of the duration of $10 \mathrm{Myr}$ scale cycles from the reference eustatic curve. (B) Histogram and cumulative distribution function of the duration of $10 \mathrm{Myr}$ scale cycles from the Canadian sequences (data are from Embry et al., 2019, see Supplementary Fig. S1). For comparison between histograms of the reference and Canadian sea-level data, durations of the reference sequences were rounded to $1 \mathrm{Myr}$ as for the canadian sequences.

\subsection{Time-series analysis}

The Phanerozoic sea-level data are influenced by long-term Wilson megacycles, which were measured and subtracted by a $15 \%$ weighted average of the series (Fig. 1A,B). Following this detrending, the data were analyzed via the Thomson's multitaper spectral method (MTM, Thomson, 1982) with three windows, together with the harmonic F-test and the classical red noise, as implemented in the Acycle freeware packages (Li et al., 2019). We conjointly used MTM amplitude (i.e., harmonic) and power spectra since the harmonic analysis allows a fine frequency decomposition, while the power spectra would average frequencies (e.g., Ghil et al., 2002). For cross-spectral analysis and correlations, we used the cross-MTM method in the Matlab routine of Peter Huybers (e.g., Huybers and Denton, 2008).

Furthermore, we perform an exploratory search for periodicities with new methods. We compute the phase distance correlation periodogram (PDCP, Zucker, 2018), which searches for periodicities without assumptions on the shape of the periodic signal, through a measurement of statistical independence between the data and an angle varying with a certain frequency. The data is phase-folded at the detected periodic features, and the shape of the periodic signals is approximated with a fitted low-order polynomial with a derivability constraint. The estimated periodic signal is then subtracted from the data and the PDCP is applied to the residuals, this procedure is repeated in an iterative manner. We further explore the fitting of non strictly periodic signals through orthonormal polynomials and Gaussian processes (Rassmussen and Williams, 2006) with quasi-periodic kernels.

We focused on both $\sim 10$ and $\sim 35$ Myr cyclicities (Boulila et al., 2018), in particular on their potential physical (modulation) link (Fig. 1C-H). To this end, we extracted amplitude envelopes of the $10 \mathrm{Myr}$ cycle band looking for the $35 \mathrm{Myr}$ modulator cyclicity. We applied this approach in three steps: (1) we first bandpass filtered the 10 Myr-scale spectral peaks detected in the raw data $(0.11 \pm 0.04$ cycles/Myr), using a Gaussian filter (Paillard et al., 
1996), (2) then we applied a Hilbert transform to the filtered time series to extract the amplitude envelopes, (3) finally we compared the recovered amplitude envelopes with lowfrequency variations in the raw data. For textural simplification, we refer to the above three steps as amplitude modulation analysis (see for e.g., Hinnov, 2000; Boulila et al., 2012). The illustrations of such method can be seen in figures 10 and 11 . The $40 \mathrm{kyr}$ obliquity cycle band (black curve in figure 10B) is modulated in amplitude by the 1.2 Myr cycle (red curve in figure 10B). The $100 \mathrm{kyr}$ eccentricity cycle band (blue curve in figure 11B) is modulated in amplitude by the $400 \mathrm{kyr}$ cycle (green curve in figure 11B), and the $400 \mathrm{kyr}$ eccentricity cycle band (black curve in figure 11C) is modulated in amplitude by the 2.4 Myr cycle (red curve in figure 11C).

Lowpass filtering was performed using the Singular Spectrum Analysis (SSA) method (Ghil et al., 2002). SSA method separates signals from noise in a sequence of signal components (reconstructed components, RCs, e.g., Fig. 1A,B) that are statistically independent, at zero lag, and based on signal strength (variance).

\section{Results}

\subsection{Time-series analysis of Phanerozoic sea-level data}

Spectral analysis of Phanerozoic sea-level data shows five significant peaks of $\sim 92$, $\sim 37, \sim 17, \sim 12.3$ and $\sim 9.3$ Myr (Figs. 1E,F and 2). The 92 and 37 Myr peaks were statistically highlighted in Boulila et al. (2018). The 17 Myr peak was discussed in Boulila (2019) and Boulila et al. (2020) in potential eccentricity terms. However, the 12.3 and $9.3 \mathrm{Myr}$ in Phanerozoic sea-level data were not been examined in depth by Boulila et al. (2018). Here we show that the beating of 9.3 and 12.3 Myr frequencies may produce the 37 Myr cycle (Fig. $1 \mathrm{C}, \mathrm{F})$. Amplitude modulation output of the $10 \mathrm{Myr}$ cycle band shows a dominant spectral peak of 36.8 Myr (Fig. 1F), which is very close to the 36.4 Myr peak detected in the original sea-level data (Fig. 1E). This result was further supported by independent geological data from the Canadian Basin where the variations of the duration of 10 Myr sedimentary sequences are modulated by the $37 \mathrm{Myr}$ cyclicity (see below). Hereafter we refer to the $\sim 37$ Myr periodicity, which is the mean period over much of the Phanerozoic Eon (Fig. 2), as the $35 \mathrm{Myr}$ cycle, and the shorter periods of 9.3 and $12.3 \mathrm{Myr}$ as the 10 Myr cyclicity.

Correlation of the 35 Myr amplitude modulation envelopes of the 10 Myr band with 35 Myr cyclicity extracted directly from the original sea-level data show a strong coherence (Fig. 1D). Such correlation points to a physical link between the 10 and 35 Myr cyclicities, and implies that they could have a common causal mechanism (see Section 3.3).

The exploratory statistical search also yields detection of $\sim 92$ and 35 Myr periodicities with evidence of non-strict periodic behavior. We also found signals at $\sim 17, \sim 12.3, \sim 9.3 \mathrm{Myr}$, as well as $2.56 \mathrm{Myr}$ (Supplementary Information).

Although potential uncertainties in the timescales (e.g. in the Triassic, see Haq, 2018) preclude the application of the frequency modulation method, examination of durations of shorter second-order sea-level sequences (e.g., Haq et al., 1987; Boulila et al., 2018) through time provides some evidence for frequency modulation of the $10 \mathrm{Myr}$ cycle band by the $35 \mathrm{Myr}$ cyclicity (Fig. 3). Spectral analysis of variations of the $10 \mathrm{Myr}$ periodicity through time detects a spectral peak of $36.3 \mathrm{Myr}$, which is very close to that detected in the raw sealevel data (Fig. 3A).

This frequency modulation result is further supported by independent sea-level data from the Canadian High Arctic Basin. Time-series analysis of variations of the duration of the major Canadian 10 Myr sedimentary (sea-level) sequences through time (Embry et al., 2019) faithfully captures a cyclicity of $35 \mathrm{Myr}$, matching the eustatic cycle of the reference chart (Supplementary Fig. S1). Such cyclicity in the Canadian sea-level data has been extensively studied by Rampino and Caldeira (2020) using other methods of spectral analysis. The detection of the $35 \mathrm{Myr}$ periodicity in the variations of duration/frequency of the 10 Myr cycles 
(Fig. 3B) from the Canadian and reference sea-level data provides additional evidence that the 35 Myr cyclcity modulates the 10 Myr cycles.
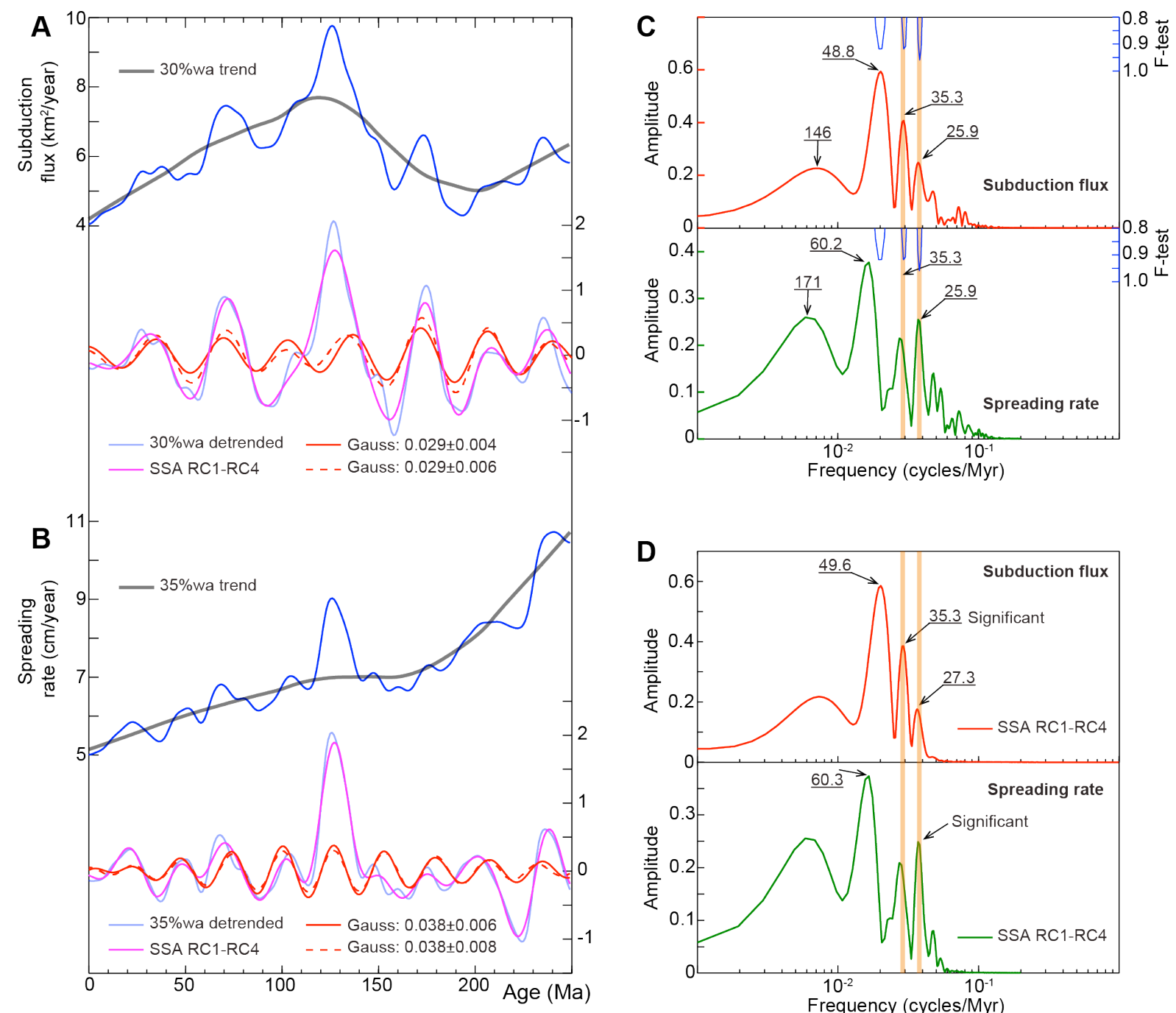

Figure 4: Time-series analysis of plate subduction and mid-ocean spreading data of Müller et al.'s (2019) model. (A) Raw specific subduction flux, i.e., plate surface deplacement per time unit (blue curve) along with weighted average (wa) smoothing (grey curve) used to detrend the raw data shown below with similar color codes, along with SSA first components RCs (pink curve) and a $35 \mathrm{Myr}$ bandpass filter (in cycles/Myr) depicted in bold and dashed red lines. Note that $35 \mathrm{Myr}$ filter outputs strongly fit most of the time series, one exception is the interval of ca. 85-140 Ma, where a 50 Myr trend overwhelmingly dominates this interval (detected by the 48.8 Myr peak). (B) Raw seafloor spreading data (blue curve) along with weighted average (wa) smoothing (grey curve) used to detrend the raw data shown below with similar color codes, along with SSA first components RCs (pink curve) and a $26 \mathrm{Myr}$ bandpass filter (in cycles/Myr) depicted in bold and dashed red lines. Note that $26 \mathrm{Myr}$ filter outputs strongly fit the raw data for the interval ca. 0-175 Ma, beyond there is no record of the 26 Myr cycle, instead there is a shorter cyclicity of $21 \mathrm{Myr}$. (C) $2 \pi-\mathrm{MTM}$ spectra of detrended subduction flux (upper panel) and mid-ocean spreading data (lower panel) showing a stronger $35 \mathrm{Myr}$ peak in subduction and a stronger $26 \mathrm{Myr}$ peak in spreading data (indicated by light, orange-colored vertical bars). (C) $2 \pi-M T M$ spectra of lowpass SSA filter outputs (RC1 through RC4 of detrended data) of subduction flux (upper panel) and spreading data (lower panel). Visual inspection and filtering highlights the dominance of $26 \mathrm{Myr}$ cycle in spreading data, and the $35 \mathrm{Myr}$ cycle in subduction data (Supplementary Fig. S20). 

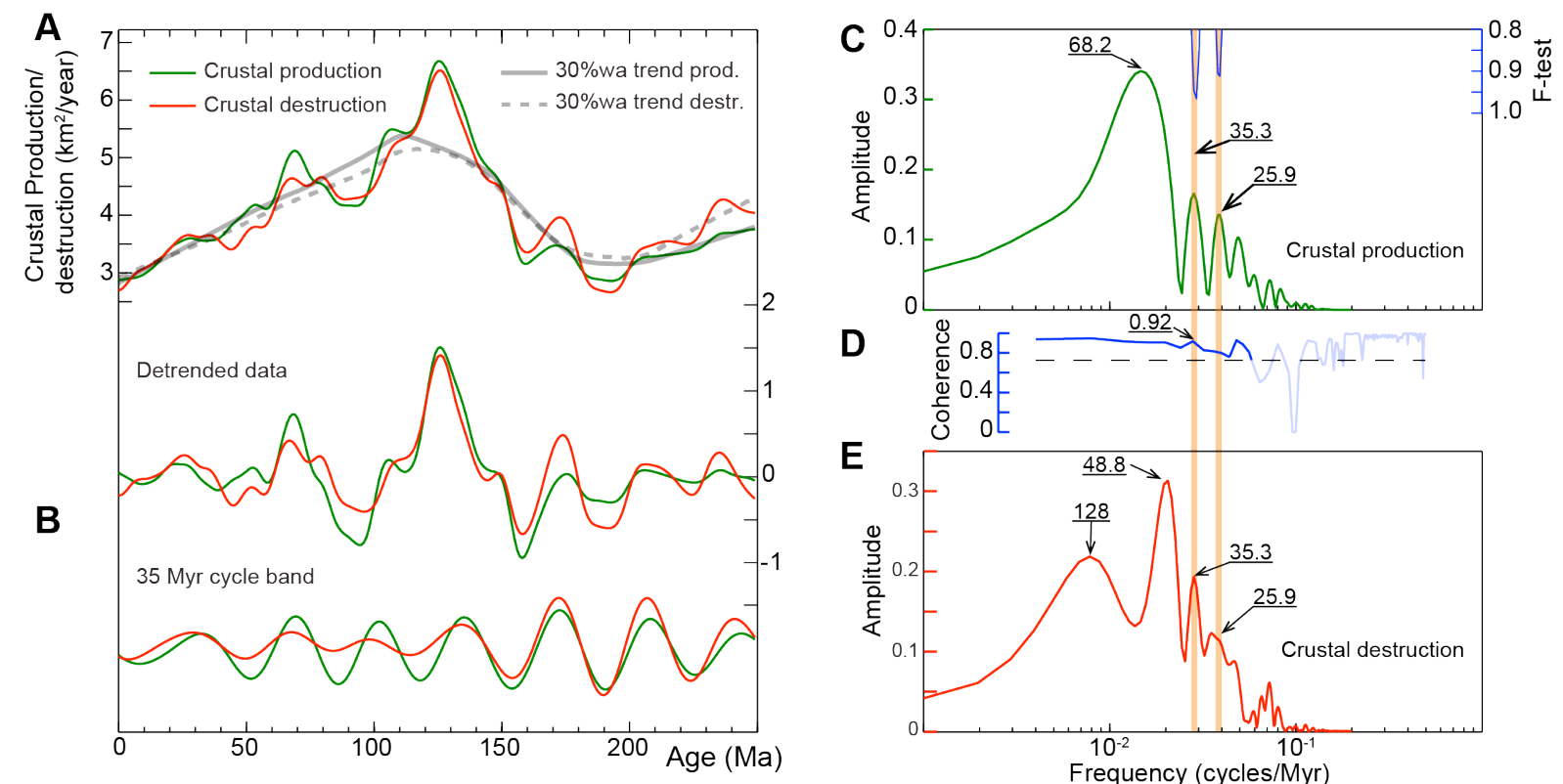

Figure 5: Time-series analysis of crustal production and crustal destruction data of Müller et al.'s (2019) model. (A) Raw data, in green crustal production and in red crustal destruction, along with weighted average (wa) smoothed data (grey curve) showing the long-term trends. (B) Detrended data by removal of the trends shown in 'A', and 35 Myr bandpass filters $(0.029 \pm 0.006$ cycles/Myr) using similar color codes as in 'A'. (C) Amplitude spectrum of crustal production data. (D) Spectral coherence between crustal-production and crustal-destruction data. The higher frequency $(<20 \mathrm{Myr})$ part of the spectrum is not significant, hence we indicated it by the light color. (E) Amplitude spectrum of crustal destruction data.

\subsection{Time-series analysis of geodynamic data}

Spectral analysis of subduction data reveals that the 35 Myr cycle that spans much of the time series (Fig. 4). Another apparently significant peak is centred on a period of $\sim 26$ Myr. However, this peak disappears when we exclude the $95-158 \mathrm{Ma}$ interval from the time series, thus negating the regularity and significance of a 26 Myr cyclicity in subduction data. This result is reinforced by visual inspection and filtering of the subduction time series, where the 26 Myr bandpass filter does not match the original data (Supplementary Fig. S20).

Spectral analysis of data for crustal production rates along mid-ocean ridges (the product of seafloor spreading rates and ridge length) also shows the two peaks of 26 and 35 Myr (Fig. 4). The $26 \mathrm{Myr}$ is more regular and continuously recorded. However, the $35 \mathrm{Myr}$ trends are intermittently recorded. Thus, the $35 \mathrm{Myr}$ is a dominant cyclicity in the subduction data (this study), while the $26 \mathrm{Myr}$ is dominant in the spreading data. Cross spectral analysis of subduction and spreading data (not shown) provides no coherence, neither at the $26 \mathrm{Myr}$ nor at the 35 Myr bands.

Spectral analysis of crustal production and crustal destruction rate data (Fig. 5) further supports the above results. The 26 Myr cycle is well expressed in the crustal production rate data, and somewhat in the crustal destruction rates. The $35 \mathrm{Myr}$ cycle is highly coherent between crustal production and crustal destruction datasets. Additionally, the crustal destruction data exhibit higher-frequency cyclicity of $\sim 14$ Myr focused mainly within the interval ca. 0-90 Ma. Nevertheless, the statistical F-test fails in the detection of the 26 and 35 Myr in the crustal destruction data, pointing to the non-cyclic nature of subduction rate variations and/or because of the detected cyclicities do not span the entire time series, such as the above mentioned $\sim 14$ Myr cyclicity. The exploratory statistical search also yields detection of the $\sim 35 \mathrm{Myr}$ periodicity in subduction and crustal production data (Supplementary Information). 
In summary, the 35 Myr periodicity is particularly well expressed in the global subduction rate data (Fig. 4), indicating that this cyclicity may originate from the episodicity in slab rollback and advance. Some supporting evidence for this connection is found in 2D numerical subduction models that have revealed slab rollback/advance periodicities of $\sim 30$ Myr (Čížková and Bina, 2015). This process would involve profound rhythmic changes in subduction deepwater cycling, and thus could explain the $35 \mathrm{Myr}$ sea-level cyclicity inferred from the sedimentary record (see Discussion). The potential impact of deep mantle water recycling on sea-level oscillations has been pointed out by Cloetingh and Haq (2015) and Karlsen et al. (2019). Even though seafloor spreading and subduction processes ought to be be coupled, the dominance of the $26 \mathrm{Myr}$ cycle in spreading and $35 \mathrm{Myr}$ cycle in subduction data suggests that these two operating periodicities are not tightly related. This reflects the influence of continental crustal deformation through time, changing the continental/oceanic crustal area ratio and thus modulating subduction flux.

The 26 Myr spreading cycle reflects mantle convection processes and far-field plate driving forces, while the 35 Myr subduction cycle is a consequence of the time dependence of slab buoyancy and slab-mantle interaction, modulated by the trench-orthogonal migration of overriding plates, which partly reflects the deformation of overriding plates. We should also note, as mentioned above, that crustal production data record the two cyclic components of 26 and 35 Myr. The 26 Myr periodicity is potentially intrinsic to spreading processes, while the $35 \mathrm{Myr}$ periodicity may reflect a dependent component to subduction processes.

Finally, detailed time-series analysis of the geodynamic data of the previous model (Müller et al., 2016) further supports the existence of a dominant 26 Myr cyclicity in seafloor spreading data and a 35 Myr cyclicity in subduction data (Supplementary Information). Additionally, we have noted short-term oscillations of a periodicity around $10 \mathrm{Myr}$ in both spreading and subduction data (Supplementary Figs. 16B and S17B).

\subsection{Time-series analysis of astronomical (Milankovitch) data}

We tested amplitude modulation of the $10 \mathrm{Myr}$ eccentricity band in all available astronomical models covering the past 250 Myr. Only La2004 and La2010d models reveal the 35 Myr cycle (Figs. 6 and 7). Amplitude modulation output of La2004 model shows a dominant spectral peak centred on the period of 34.5 Myr (Fig. 7A). Amplitude modulation output of La2010d model detects a broader peak centered on 35.6 Myr, including two main periods of 29.4 and 45.4 Myr in the amplitude spectra, averaging the 35.6 Myr period (Fig. 7A). The $35 \mathrm{Myr}$ spectral peak persists even when considering different analyzed time intervals or different passbands (Fig. 7A). Thus, amplitude modulation analysis of Earth's orbital eccentricity variations indicate the modulation of the $\sim 10$ Myr cycles by the $\sim 35$ cyclicity.

Increasing evidence for $\sim 10$ Myr orbital (Milankovitch) pacing of sea-level change and other geological processes, and the amplitude modulation relationship between the 10 and 35 Myr bands detected in sea-level record (Sections 3.1 and 4.1) and herein Milankovitch data, further supports the link between geological and Milankovitch variations at these longer timescales. Spectral analysis and amplitude modulation results of the equivalent time interval (i.e., 0-250 Ma) in the sea-level record highlight a close periodicity of $35 \mathrm{Myr}$ (Fig. 1G,H). A strong correlation between sea level and astronomical variations at the 10 and $35 \mathrm{Myr}$ bands (Fig. 6C,E,F) provides a compelling evidence for a link between the two.

The seeming antiphase relationship between sea-level and astronomical variations at the $10 \mathrm{Myr}$ band (Fig. 6C,E,F) is related to the inverted phase of the $\sim 10$ Myr orbital cyclicity due to its extraction from $400 \mathrm{kyr}$ amplitude modulation envelopes (Fig. 8A,C). This feature is analogous to the $2.4 \mathrm{Myr}$ cyclicity extracted from amplitude modulation of the $400 \mathrm{kyr}$ band, which is characterized by an inverted phase with respect to the fundamental $2.4 \mathrm{Myr}$ component in the raw eccentricity (Fig. 9, see also Laskar et al., 2011 for more detail about 
the corrected phase of the 2.4 Myr band). Accordingly, the actual phase of the $10 \mathrm{Myr}$ orbital cycle should be rectified (inverted) for correlation with sea-level data.

The $35 \mathrm{Myr}$ amplitude modulation envelopes in the eccentricity and that in sea-level data have the same phase (Fig. 6E,F), implying an identical amplitude modulation relationship between the 10 and 35 Myr cyclicities, analogous to the $2.4 \mathrm{Myr}$ versus $10 \mathrm{Myr}$ eccentricity modulations. The $\sim 10$ Myr cyclicity from 2.4 Myr eccentricity has the same phase as that extacted from the inverted 2.4 Myr eccentricity (Supplementary Fig. S2). Similarly, the 35 Myr cyclicity extracted from amplitude modulation of $\sim 10$ Myr cycles and that extracted from amplitude modulation of inverted $\sim 10$ Myr cycles are characterized by a similar phase.

Thus, sea-level cyclicities share a similar phase relationship with Earth's orbital eccentricity. The $35 \mathrm{Myr}$ cycle extracted directly from bandpass filtering of sea-level record is antiphased with respect to that retrieved from amplitude modulation envelopes of the $10 \mathrm{Myr}$ sea-level band (Fig. 1D). This is again the same amplitude modulation physical relationship between the $400 \mathrm{kyr}$ and $10 \mathrm{Myr}$ or between the $400 \mathrm{kyr}$ and $2.4 \mathrm{Myr}$ eccentricity cycles (Figs. 8 and 9, Laskar et al., 2011). In more detail, because the long-term nodes of the 400 kyr signal are a truncated function at minimal eccentricity values, which is typical for the orbital motion of a body in an eccentric trajectory. Thus, filtering of $400 \mathrm{kyr}$ nodes results in amplitude modulation maxima envelopes, whereas filtering of $400 \mathrm{kyr}$ maxima results in amplitude modulation minima envelopes (Fig. 9). This is different to the oscillations of the Earth's axial tilt, the values of which are not truncated at minimal (or mean) values, thus filtering of these variations retrieves the actual phase of their amplitude modulation envelopes (Fig. 10).

Sea-level data at the $35 \mathrm{Myr}$ cycle band has a similar feature as that of a truncated function at minimal values. Filtering to the 10 Myr band yields $35 \mathrm{Myr}$ envelopes that are in opposite of phase with respect to the $35 \mathrm{Myr}$ cycles in the original data. This additional physical analogy between sea-level record and Earth's orbital eccentricity may provide additional argument for sea-level modulation by Earth's orbital eccentricity at the $35 \mathrm{Myr}$ band. Minima of eccentricity corresponds to minima of sea-level and vice versa (Section 4.4).

Furthermore, the sea-level data support theoretical modeling that predicts the validity of astronomical models up to $45 \mathrm{Ma}$. Likewise, we show that the La2004 astronomical model provides the best fit with sea-level record compared to the more recent La2010d model. In particular, a good correlation between sea-level and La2004 astronomical data is not only observed up to $50 \mathrm{Ma}$ at $10 \mathrm{Myr}$ cycle band, but also nearly up to $150 \mathrm{Ma}$ at $35 \mathrm{Myr}$ cycle band, pointing to the robustness of La2004 model. The efficacy of La2004 model has already been demonstrated by correlation with other geological proxy records (carbon cycle), with a coherent phase relationship up to $\sim 60 \mathrm{Ma}$ (Boulila et al., 2012).

Finally, we further investigated such serial amplitude modulation of La2004 eccentricity within the most constrained time interval (0-30 Ma, Fig. 11) to seek for the multiMyr variations and the origin of their modulating components (see also Boulila, 2019; Boulila et al., 2020). The 1.6, 2.4 and 4.7 Myr eccentricity cycles (Fig. 11E; Boulila, 2019) are associated to the resonant angle $\theta$ (Boulila et al., 2020, libration period $\mathrm{P} \theta=4.7 \mathrm{Myr}$ of the resonant angle $\theta$ ). The 2.4 Myr cycle band presents three beating frequencies of $\sim 2.1, \sim 2.4$ and 2.7 Myr (Fig. 11F) providing the resulting $\sim 10$ and $\sim 18$ Myr cycles (Boulila, 2019). The 4.7 Myr cycle band shows two periods of $\sim 4.3$ and $~ 5.3$ Myr (Fig. 11E,F), which may also provide the $\sim 18 \mathrm{Myr}$ cycle. The $\sim 10 \mathrm{Myr}$ cycle is equally detected, although the analyzed time interval is too short for such cyclicity. By analogy with well-known Milankovitch cyclicities, such as the 2.4 Myr eccentricity term, we suggest that the 10 and 35 Myr cycles may correspond to some unresolve fundamental terms, and also arise from the modulation of shorter eccentricity terms as shown in the present study. 


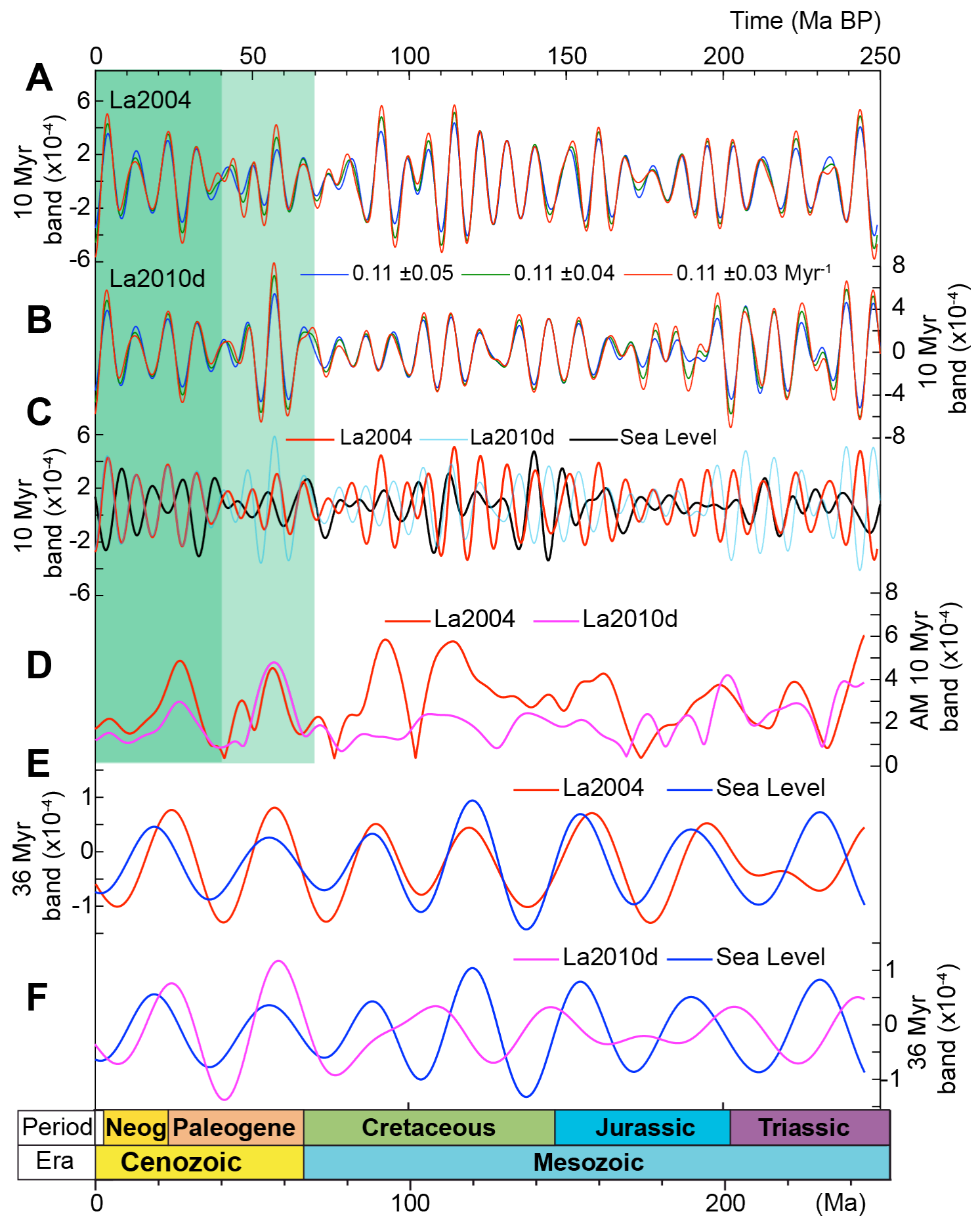

Figure 6: Amplitude modulation analysis of the astronomical data and correlations with sea-level data at the $\sim 10$ and $\sim 35 \mathrm{Myr}$ cycle bands. (A) $9.5 \mathrm{Myr}$ extracted cycles from bandpass filtered $400 \mathrm{kyr}$ amplitude modulation envelopes in the La2004 model. (B) 9.5 Myr extracted cycles from bandpass filtered $400 \mathrm{kyr}$ amplitude modulation envelopes in the La2010d model. (C) Correlation at the $10 \mathrm{Myr}$ cycle band between sea-level, and La2004 and La2010d astronomical data. (D) Amplitude modulation envelopes of the $10 \mathrm{Myr}$ band in La2004 and La2010d astronomical models. (E) Correlation at the 35 Myr cycle band between sea-level and La2004 astronomical data. (F) Correlation at the $35 \mathrm{Myr}$ cycle band between sea-level and La2010d astronomical data. See Fig. 7 for the spectra of $9.5 \mathrm{Myr}$ amplitude modulation envelopes in the astronomical models, and compare with spectra of sea-level data in Fig. 1G,H for the same time interval $(0-250 \mathrm{Ma})$. Note the intriguing correlation between sealevel and La2004 astronomical data till nearly $150 \mathrm{Ma}$. The inverted phase of the $10 \mathrm{Myr}$ cycle from $400 \mathrm{kyr}$ amplitude modulation band is explained in Section 3.3. 

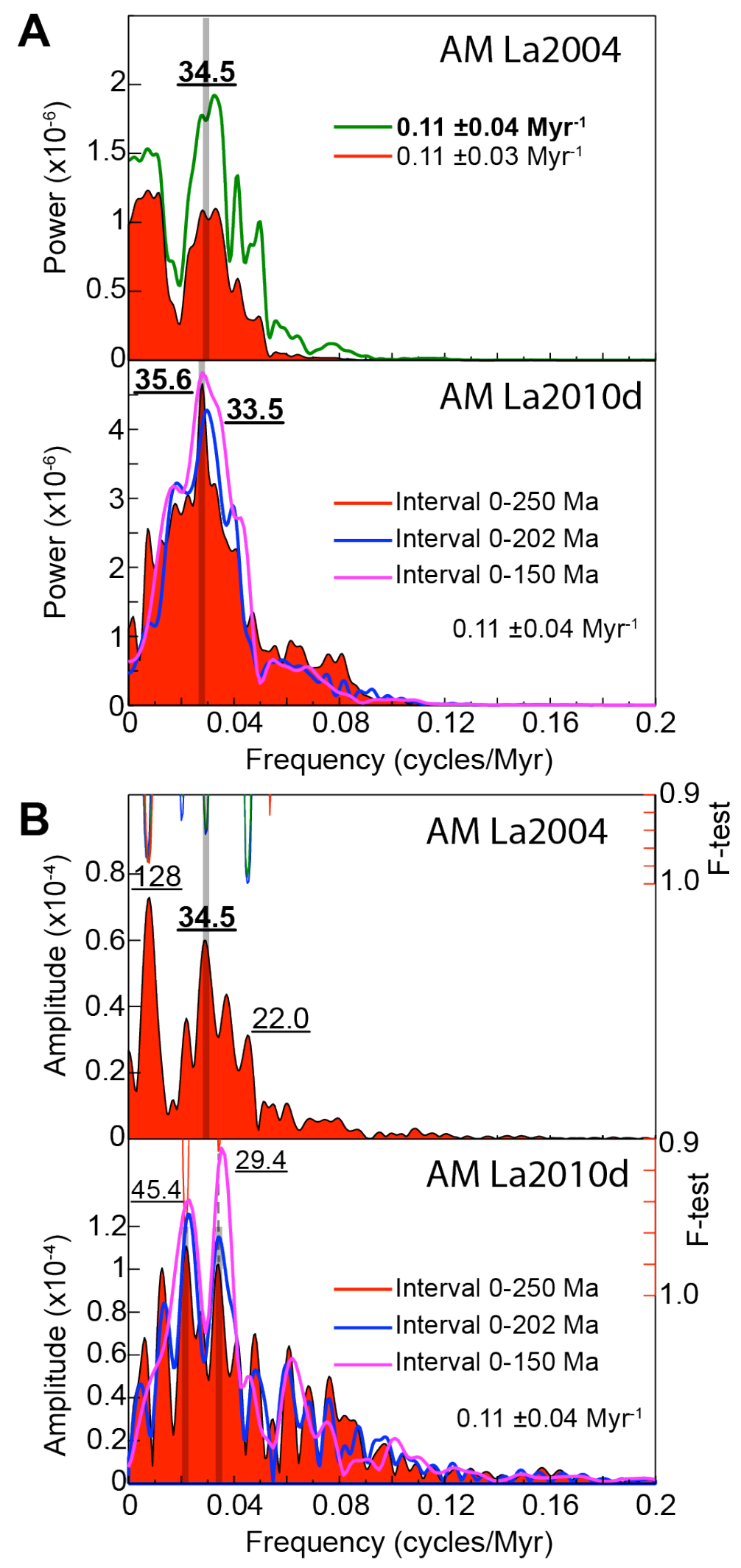

Figure 7: Amplitude and power spectra of $10 \mathrm{Myr}$ amplitude modulation envelopes in Earth's orbital eccentricity variations. (A) Power spectra. (B) Amplitude spectra. Note the high variability of the 35 Myr mean periodicity, resulting in a broad spectral peak, which is splitted into two peaks in the amplitude spectrum of La2010d model, of periods of 29.4 and 45.4 Myr averaging the 33.5 to 35.6 Myr period. 


\section{Discussion}

\subsection{Two distinct frequency bands of tens of Myr in the geological data}

Geologically detected cyclicities of tens of Myr, ranging from ca. 25 to ca. $38 \mathrm{Myr}$, have long been thought to be within the same frequency band, and differences in the detected mean periodicity are related to the quality of geological data, especially to the different timescales employed, and to the methods used for time-series analysis. However, by employing a consistent timescale for the past 240 Myr we show here that subduction data encode the 35 Myr cycle, while mid-ocean spreading data capture the 26 Myr cycle. Thus, there are two distinct frequency bands in the geological data. The mean periods of these two cyclicities could vary, depending on the analyzed time interval (see for e.g., Fig. 2B) - the mean values of these two cyclicities, over the past $200 \mathrm{Myr}$, are within the narrow ranges of 25-26 Myr and 33-35 Myr, respectively. For textural simplification, we hereafter refer to the former as the 26 Myr cycle, and to the latter as the 35 Myr cycle.

The 35 Myr cyclicity in subduction data correlates with its time equivalents in sea level, stable oxygen isotopes and Earth's orbital eccentricity (Section 4.2, Fig. 13). This cyclicity has been well documented in the geological record (reviewed in Sections 4.2 and 4.3). Also, the 26 Myr cyclicity in seafloor spreading data has previously been detected (Cogné and Humler, 2006; Müller and Dutkiewicz, 2018), and supported by our study. Indeed, the 26 Myr cyclicity has been studied since 1980s, especially in the biodiversity data of the extinction of marine families for the past 260 Myr (e.g., Raup and Sepkoski, 1984, 1988), albeit its regularity and statistical significance have been the subject of a long debate (e.g., Stigler and Wagner, 1987, 1988; Bailer-Jones, 2010). Later studies using updated biodiversity data and more recent geological timescales have further supported the existence of the 26 Myr cycle (Lieberman and Melott, 2007; Melott and Bambach, 2010, 2014; Rampino and Caldeira, 2015).

At the 26 Myr frequency band, studies have suggested a link between biomass extinction events, crater impacts and/or Earth's interior dynamics (e.g., Rampino and Stothers, 1984, 1988; Rich et al., 1986; Napier, 1988; Rampino and Caldeira, 1993; Courtillot and Renne, 2003). More recently, the $26 \mathrm{Myr}$ cycle has been recorded in updated impactcratering data, and correlated to biological extinction events over the past $260 \mathrm{Myr}$ (Rampino and Caldeira, 2015). From these studies, it would seem that the 26 Myr periodicity is statistically significant, and characteristic of mid-ocean seafloor spreading processes and the resulting flood basalt provinces, biomass extinction, and potentially also impact cratering (Rampino and Caldeira, 1993, 2015; Cogné and Humler, 2006; Rampino, 2010; Müller and Dutkiewicz, 2018). Strong evidence of flood basalt volcanism control of biomass extinctions comes from a striking correlation between CAMP eruptions and bioextinction of the endTriassic Extinction Event (Whiteside et al., 2010). It is quite likely that the astronomical and geological events (e.g., crater impacts, bioevents, eustatic lows and highs, etc) that have been employed to look for such cyclicities of 26 and 35 Myr bands (e.g., Rampino and Caldeira, 2015) correspond to amplitude extremes of these cycles. Boulila (2019) showed that the major known climate-ocean events of the past $115 \mathrm{Ma}$ strikingly match the $35 \mathrm{Myr}$ extreme cycling. Further studies need to focus on time-series analysis of these cyclicities in both discrete geological events and continuous geological datasets.

\subsection{The 35 Myr eustatic cycle: an historical overview}

The 35 Myr cyclicity is a striking feature of the reference Phanerozoic eustatic sealevel curve based on data in Haq et al. (Haq et al., 1987; Haq and AI-Qahtani, 2005; Haq and Schutter, 2008, Fig. 1). A comparable cyclicity was already recognized in sea-level data a long time ago by Grabau (1936), who noticed several pervasive 32 Myr scale major transgressive phases during the Paleozoic (Fig. 12), which he extended to the Phanerozoic, 
calling them as transgressive pulses (Grabau, 1940). Dorman (1968) suggested a $30 \mathrm{Myr}$ cycle in global temperatures inferred from $\delta^{18} \mathrm{O}$ proxy data of Cenozoic mollusks. Damon (1971) found a periodicity of about $36 \mathrm{Myr}$ in Phanerozoic tectonic (magmatism) data, and correlated it to major marine transgressive-regressive phases. Wise (1974) constructed sealevel curves for the Phanerozoic, suggesting a 36 Myr periodicity for regression phases, which is identical to the period determined by Damon (1971), albeit using different sea-level datasets.

A similar 32 Myr cycle spanning the Meso-Cenozoic had then been extensively reviewed by Fischer and Arthur (1977) on the basis of sedimentological proxy data (e.g., biogenic silica, deep-sea carbonates, black shales, etc), pelagic biodiversity, and paleotemperatures and carbon-cycle derived from $\delta^{18} \mathrm{O}$ and $\delta^{13} \mathrm{C}$ of benthic and planktonic foraminifera. The main conclusion of these authors was that several geological processes were climatically linked to the $32 \mathrm{Myr}$ cyclicity, especially the vertical and latitudinal temperature gradient (and oxygenation) in the ocean, sea-level fluctuations, and marine biomass evolution. All these processes are sensitive to fluctuations in influx of solar energy, which modulates climate changes. Fischer and Arthur (1977) evoked two mechanisms for the $32 \mathrm{Myr}$ cycle, the incident solar energy and Earth's interior processes.

The finding of the 32 Myr cycle of Fischer and Arthur (1977) in multiple geological proxy datasets is the precursor for several later studies since 1980's, that have suggested similar periodicity in the rate of extinction (Raup and Sepkoski, 1984; Kitchell and Pena, 1984) or in the occurrence of comet showers (Davis et al., 1984; Rampino and Stothers, 1984). Rampino and Stothers (1984) inspired by the Fischer and Arthur went on to demonstrate a $33 \pm 1$ Myr periodicity in the Meso-Cenozoic sea-level data of Vail et al. (1977). Baker and Flood (2015) found a cyclicity of $31 \mathrm{Myr}$ in Late Cretaceous to Miocene sea-level data of Kominz et al. (2008). Boulila et al. (2018) demonstrated a mean cyclicity of 36 to 37 Myr over the Phanerozoic eon based on sea-level data of Haq et al. (1987), Haq and AlQahtani (2005) and Haq and Schutter (2008). They have also shown that this cyclicity is shorter in the Mesozoic and Cenozoic eras, thus supporting previous estimates (e.g., Fischer and Arthur, 1977; Rampino and Stothers, 1984). They have also tested the impact of evolving geological timescales on the record of such cyclicity, and concluded the persistence of such cyclicity in global sea-level data.

In parallel, increasing stratigraphic resolution has allowed the record with high fidelity of the 35 Myr cyclicity in $\delta^{18} \mathrm{O}$ data (Shackleton and Imbrie, 1990; Kaiho and Kaito, 1994; Svensmark, 2006; Boulila et al., 2018; Boulila, 2019). The record of similar $35 \mathrm{Myr}$ scale cyclicity in sea-level and $\delta^{18} \mathrm{O}$ data (Dorman, 1968; Fischer and Arthur, 1977) reveals the climatic control of sea-level change (Fischer and Arthur, 1977; Boulila et al., 2018). However, tectonic processes are also able to force climate and sea-level changes at this timescale (e.g., Raymo et al., 1988; Lamb and Davis, 2003; Lagabrielle et al., 2009; Whipple, 2009), thus the $35 \mathrm{Myr} \delta^{18} \mathrm{O}$ cyclicity also reflects tectonically-driven climatic changes (Shackleton and Imbrie, 1990; Kaiho and Kaito, 1994; Zachos et al., 2001).

In summary, since 1980's a number of studies have focused on the 25-40 Myr geological cyclicity and its causal mechanism in biomass extinctions, comet impacts, orogenic events, ocean anoxic events and sea-level changes. Regarding the potential drivers the views are split between the tectonic forcing hypothesis (e.g., Damon, 1971; Shackleton and Imbrie, 1990; Kaiho and Saito, 1994; Abreu et al., 1998; Bond and Grasby, 2017), and external galactic cosmic-ray or comet showers from the vertical motion of the solar system in the Milky Way galaxy (e.g., Rampino and Stothers, 1984; Rampino and Caldeira, 1993, 2015; Stothers, 1998; Svensmark, 2006, 2007; Medvedev and Melott, 2007; Randal and Reece, 2014; Baker and Flood, 2015; Rampino, 2015; Boulila et al., 2018). In Section 4.5, we propose a model that reconciles the tectonic and astroclimate (Milankovitch) hypotheses but without invoking the galactic impact (Boulila et al., 2018), unless Milankovitch (insolation) and galactic (cosmic ray) drivers are coupled (Boulila, 2019). 


\subsection{Evidence for the 10 and $35 \mathrm{Myr}$ cyclicities in astroclimate and tectonic archives}

Amplitude and frequency modulation analysis of the 10 Myr cycle band in the reference sea-level data indicates a main cyclicity of a period close to $35 \mathrm{Myr}$. This result is supported by independent data from the Canadian High Arctic Basin (Fig. 13C, Section 3.1), that record global sedimentray sequences (Embry et al., 2019, Supplementary Fig. S2). Collectively, these results provide a compelling evidence for the modulation of the $10 \mathrm{Myr}$ band by the 35 Myr cyclicity in sea-level data (Figs. 13 and 14).

A number of studies have shown the existence of $\sim 10$ Myr periodicity in Milankovitch orbital variations (Boulila et al., 2012, 2020; Sprovieri et al., 2013; Boulila, 2019). The 10 Myr orbital cyclicity can be retrived either from the precession of perihelia or from the precession of nodes (Boulila et al., 2012, 2020; Boulila, 2019), i.e., it exists in the eccentricity and obliquity time series. Here we further support the presence of such cyclicity in Earth's orbital eccentrcity, and in particular we demonstrate that it is modulated by a longer cyclicity of $\sim 35$ Myr. These orbitally related $\sim 10$ and $\sim 35$ Myr cyclicities have been noticed in paleoclimate proxy data, in deep-sea $\delta^{18} \mathrm{O}$ record (Boulila, 2019).

The 35 Myr cyclicity is dominant in the subduction data (Section 3.2). However, the dominant cyclicity in spreading data is 25-26 Myr (Cogné and Humler, 2006; Müller and Dutkiewicz, 2018). The 10 Myr cyclicity is expressed in both subduction and mid-ocean spreading data (Section 3.2). Although such cyclicity should be considered with caution, our current knowledge seems to indicate that it is modulated by the 25-26 Myr cycle.

The 10 Myr cyclicity has previously also been reported from highly resolved geodynamic modeling data. A dominant 10 Myr cyclicity was detected in global intra-plate volcanism during the Cenozoic (Mjelde et al., 2010). In addition, a secondary 5 Myr cyclicity was detected in these data (Mjelde et al., 2010), which is close and potentially equivalent to the 4.7 Myr orbital cyclicity (Boulila et al., 2020). The 10 and 5 Myr tectonic cycles were attributed to global fluctuations in core-mantle interaction, involving periodic heating of the core and subsequent heat release to the mantle and increased global plume activity from the edges of the lower-mantle anomalies (Mjelde et al., 2010). A 10-15 Myr cyclicity has more recently been recorded in continental back-arc process (Wolfram et al., 2019). An extensive review of variations in global magmatic systems brought out cyclicities ranging from 5 to 10 Myr (Mitchell et al., 2019), further supporting tectonic fluctuations at these timescales.

The $35 \mathrm{Myr}$ is generally well preserved in geodynamic data because of its stronger amplitude and fewer errors on its estimate from modeling resolution and temporal uncertainties. A prominent cyclicity of 25-50 Myr has also been recognized in the western American Cordilleras (DeCelles et al., 2009). The record of 25-26 Myr in mantle convection and $35 \mathrm{Myr}$ in subduction remains unresolved. We tentatively hypothesize that the interference of these two cyclicities may result in the 92 Myr cycle $(1 / 26-1 / 36)$ seen in sealevel data (Fig. 2). The $92 \mathrm{Myr}$ cycle has equally been recorded in other very long geological datasets including tectonics (Puetz and Borchardt, 2015; Puetz et al., 2018; Wiemer et al., 2018).

\subsection{Driving mechanisms of Myr to multi-Myr eustatic cycles}

The well-known driving mechanism of sea-level changes is glacioeustasy in icehouse periods, i.e. change in seawater volume by waxing and waning of continental ice sheets. Such mechanism would generate larger sea-level oscillations of magnitude reaching 120 to $130 \mathrm{~m}$ below present-day sea-level as during the Last Glacial Maximum, ca. 27 to $20 \mathrm{ka}$ (e.g., Peltier and Fairbanks, 2006; Austermann et al., 2013; Miller et al., 2020). The $100 \mathrm{kyr}$ Quaternary glacial cycles have an amplitude of 100-150 m of glacioeustatic change (e.g., Miller et al., 2005a; Siddall et al., 2010). Estimates from deep-sea $\delta^{18} \mathrm{O}_{\text {benthic }}$ and 
backstripping suggest Myr-scale variations of 20 to $50 \mathrm{~m}$ driven by ice-volume variations during pre-Pliocene Cenozoic icehouses (John et al., 2004; Miller et al., 2005a, 2020).

The Earth during the Phanerozoic witnessed long-lasting greenhouse periods without ice sheets or with ephemeral continental ice sheets (Miller et al., 2004, 2005b; Haq and Schutter, 2005; Royer et al., 2004; Bornemann et al., 2008; Galeotti et al., 2009; Boulila et al., 2011), against shorter icehouse periods with extended, well-developed ice sheets (Fig. 1). Glacial conditions have been episodically recorded over the Phanerozoic eon, in the Late Ordovician-Early Silurian, the Late Devonian, through much of the Carboniferous and Permian, the Late Paleogene-Neogene (e.g., Fisher, 1984; Frakes et al., 1992; Deynoux et al., 1994; Zachos et al., 2001; Haq and Schutter, 2008), and potentially in the Late Cretaceous during the ephemeral Antarctic ice phases (Matthews, 1984; Stoll and Schrag, 1996, 2000; Miller et al., 2003, 2005b; Bornemann et al., 2008, among others). During the Meso-Cenozoic, Myr-scale sea-level cycles of a few to several tens of meters (Miller et al., 2005a; Kominz et al., 2008) have been argued to be paced by Milankovitch orbital forcing via glacioeustasy (Boulila et al., 2011). During the Paleozoic, the magnitude of shorter (Myrscale, Boulila et al., 2011) sea-level cycles were assessed at a few tens of meters up to 125 $\mathrm{m}$, the most prominent ones were related to glacioeustasy (Haq and Schutter, 2008). Although the Paleozoic sea-level sequences are in generally less precisely dated, when compared to the Ceno-Mesozoic sequences (Haq and Schutter, 2008), careful examination of several glacio-eustatic sequences points to Myr-scale sea-level sequences matching Milankovitch orbital band (Fig. 15, Boulila et al., 2011, see Supplementary information for detailed comments on Fig. 15). Some lines of evidence for icehouse conditions throughout the Earth's history have been reported, suggesting that sea-level oscillations were largely glacio-eustatically driven (Matthews, 1984; Stoll and Schrag, 1996, 2000; Abreu et al., 1998; Immenhauser, 2005; Miller et al., 2003, 2005b; Bornemann et al., 2008; Matthews and AlHusseini, 2010; Boulila et al., 2011, among others).

The other alternative mechanism for sea-level fluctuations at Myr to multi-Myr timescales is tectono-eustasy from Earth's interior processes and plate tectonic motions. It is considered as the main candidate to explain the high-amplitude eustatic variations, especially during the so-called greenhouse periods when there were no extensive ice sheets on Earth (e.g., Vail et al., 1977; Haq et al., 1987). Tectonic processes driving sea-level and their operating timescales were recently reviewed by Conrad (2013). The main process is the change in the volume of global ridge system via mantle convection (e.g., Pitman, 1978; Harrison, 1990; Miller et al., 2005a; Cogné et al., 2006; Cogné and Humler, 2008; Müller et al., 2008; Cloetingh and Haq, 2015), which involves the creation of new ridges within the ocean basins as well as spreading rates which when accelerates tends to flatten the ridge system, raises the depth of the seafloor and elevates global sea level (Pitman, 1978; Graffin, 1987). Global ridge-system process could account for several meters of sea-level changes in only a few Myr, to $\sim 50 \mathrm{~m}$ in approximately 20 to $30 \mathrm{Myr}$, and to $\sim 200 \mathrm{~m}$ at 100 to $200 \mathrm{Myr}$ timescales (Conrad, 2013). At similar timescales, the production of seafloor should be compensated by subduction process, where older lithospheric plates tend to subduct to satisfy solid Earth's mass conservation - however, the average age and depth of subducting seafloor changes through time, while the age and depth of newly produced seafloor does not change. The fluctuations in the age of subducting seafloor are a reflection of the changing age-area distribution of seafloor through time (Wright et al., 2020) resulting in long-term sea level fluctuations. In addition, seawater gain from convection and seawater loss in subduction (Conrad, 2013) contributes to this process. At very long timescales (Gyr), convection and subduction processes result in an imbalance of the ocean's water exchange with the deep mantle (Conrad, 2013). 
A

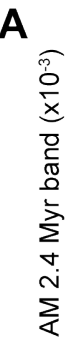

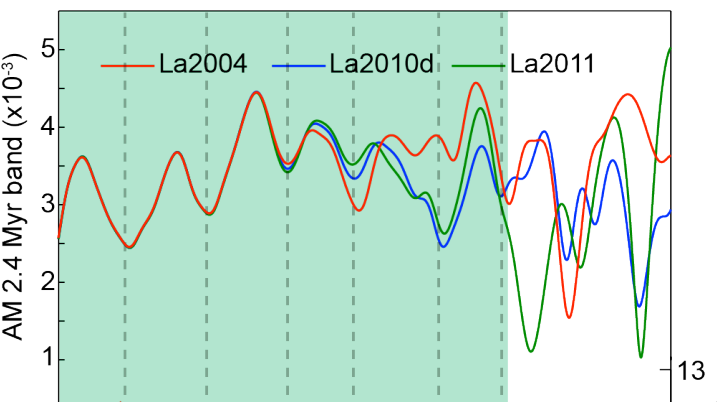

B
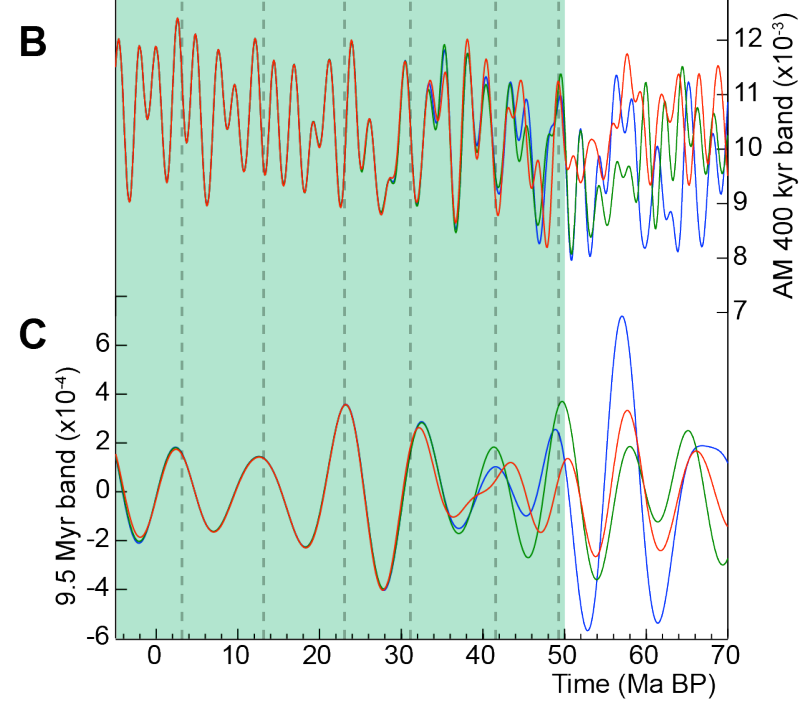
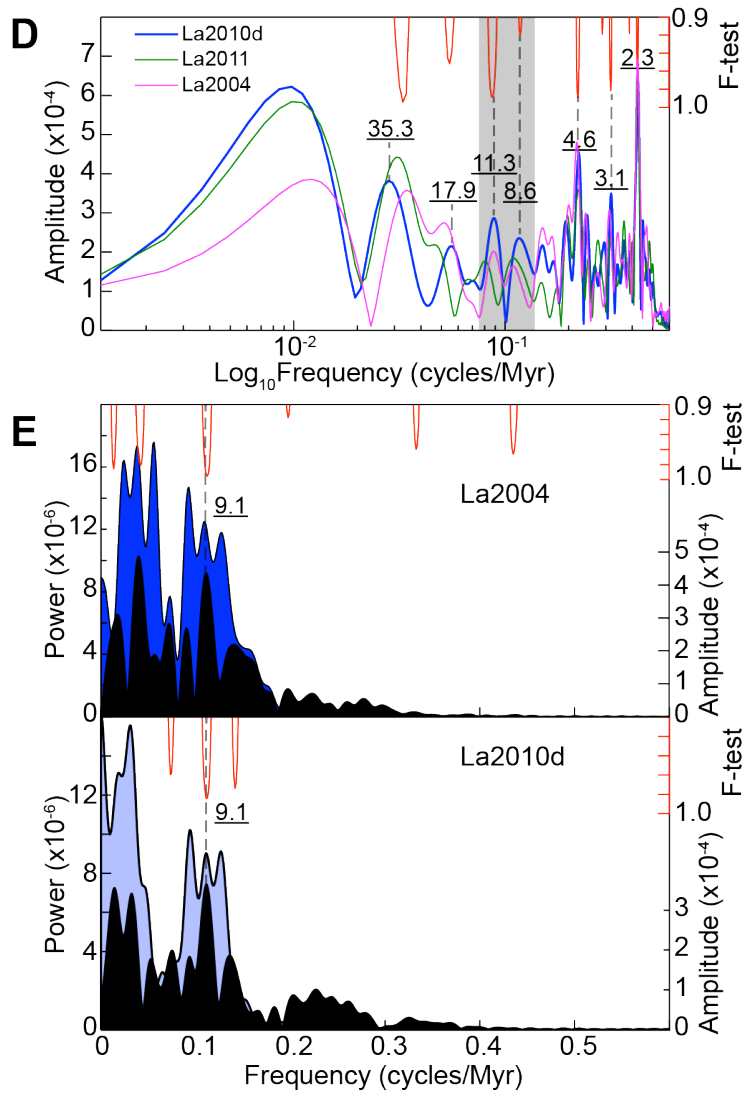

Figure 8: Amplitude modulation analysis of the astronomical data (details on reference sources of La2004, La2010d and La2011 astronomical models are provided in Section 2.2). (A) Amplitude modulation of the $2.4 \mathrm{Myr}$ cycle band, $0.43 \pm 0.15$ cycles/Myr (as in Boulila et al., 2012). (B) Amplitude modulation of the $400 \mathrm{kyr}$ cycle band $(2.465 \pm 0.4 \mathrm{cycles} / \mathrm{Myr})$. (C) Bandpass filtered 9.5 cycle band (0.11 $\pm 0.05 \mathrm{cycles} / \mathrm{Myr}$ ) from $400 \mathrm{kyr}$ amplitude modulation envelopes in 'B'. Green-dashed area roughly indicates the validity interval of astronomical data. (D) Amplitude spectra of $400 \mathrm{kyr}$ amplitude modulation envelopes. (E) Amplitude and power spectra of 2.4 Myr amplitude modulation envelopes.

Mantle flow and the resulting upwellings and downwellings generate so-called dynamic topography at relatively long wavelengths (Gurnis, 1993; Conrad and Gurnis, 2003). This process would generate lateral and vertical motions on lands and seas, deflecting seafloor bathymetry and modifying the volume of the ocean basins (Gurnis, 1993; Conrad et al., 2004; Spasojevic and Gurnis, 2012; Flament et al., 2013; Cloetingh and Haq, 2015). The impact of dynamic topography on sea-level change is estimated to be in the range of 100-200 $\mathrm{m}$ since the Late Cretaceous (Conrad, 2013), and may have also played an important role in high-frequency (third- and higher orders) sea-level cycles, of up to $50 \mathrm{~m}$ (Lovell, 2010; Petersen et al., 2010). The vertical motions associated to the dynamic topography could also generate local uplift and subsidence patterns (e.g., Gurnis, 1993; Moucha et al., 2008; Braun, 2010; Lovell, 2010), including those along continental margins (Müller et all, 2018), which were suggested as the main driver of second-order (10 Myr) sea-level sequences (e.g., Embry et al., 2019).

Spectral analysis of subduction data from most a recent plate tectonic models (Müller et al., 2016, 2019) shows evidence of 33 to 35 Myr cyclicity over the past 200 Myr (Fig. 13I and Supplementary File). A close cyclicity is also detected in sea-level, $\delta^{18} \mathrm{O}$ and Milankovitch variations (Fig. 13F-J). Interestingly, cross-spectral analysis highlights a strong correlation between the subduction, sea-level, $\delta^{18} \mathrm{O}$ and eccentricity variations at the $35 \mathrm{Myr}$ cycle band (Fig. 14), suggesting a link between Earth's interior and surface processes, mediated by 
external Milankovitch forcing (Section 4.5). Subduction lags sea-level change by only $\sim 0.5$ Myr (phase $=-175^{\circ}$ at $34 \mathrm{Myr}$, coherence $=0.96$, Fig. 14). Thus, higher subduction leads to lower sea levels. This would imply that the episodicity in slab advance would generate a loss in seawater (Conrad, 2013; Karlsen et al., 2019), inducing minima in the $35 \mathrm{Myr}$ sea-level cycle. A potential scenario to link tectono-eustatically driven sea-level to external (Milankovitch) climate forcing of Earth's suface processes is provided below in Section 4.5. Other, relatively minor contributions to sea-level change during icehouse and greenhouse climates also need to be considered, such as the thermal expansion of seawaters (thermoeustasy), and terrestrial water storage and groundwater-driven eustasy called aquifereustasy (e.g., Jacobs and Sahagian, 1993, 1995; Lombard et al., 2005; Föllmi, 2012; Wagreich et al., 2014; Sames et al., 2016, 2020; Wendler et al., 2016; Wendler and Wendler, 2016; Ray et al., 2019; Davies et al., 2020). For instance, the impact of aquifer-eustasy on short-term (400 kyr to $3 \mathrm{Myr}$ ) sea-level change is increasingly advocated, especially during the Cretaceous greenhouse period (e.g., Föllmi, 2012; Sames et al., 2016; Wendler et al., 2016; Wendler and Wendler, 2016; Sames et al., 2020). Nevertheless, the larger magntitude sea-level cycles of up to $65 \mathrm{~m}$ assessed for the Cretaceous challenge the aquifer-eustasy hypothesis, and favor the glacio-eustasy hypothesis even during greenhouses (e.g., Miller et al., 2005b; Boulila et al., 2011; Ray et al., 2019; Davies et al., 2020; Simmons et al., 2020). The interplay of the above processes, aquifer-, glacio-, thermo-, and tectono-eustasy to sealevel change is likely (e.g., Simmons et al., 2020) at shorter and longer timescales (Section 4.5).

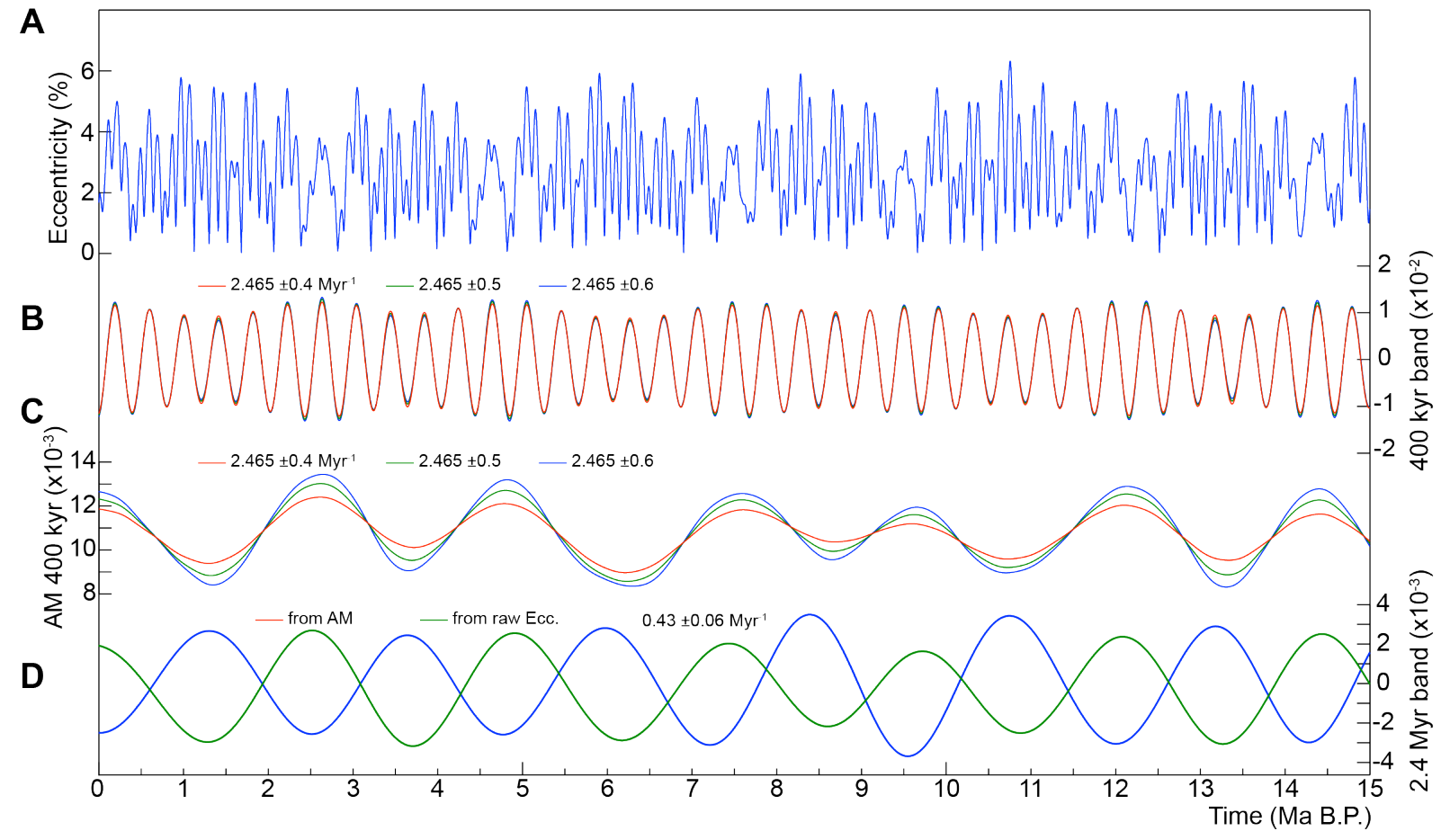

Figure 9: 2.4 Myr eccentricity phasing. (A) La2004 raw eccentricity time series (Laskar et al., 2004). (B) 400 kyr eccentricity bandpass filtering (indicated frequency bands are in $\mathrm{Myr}^{-1}$ ). (C) Amplitude modulation envelopes of the $400 \mathrm{kyr}$ bandpass filterd time series. (D) Comparison of $2.4 \mathrm{Myr}$ filtered eccentricity cyclicity $\left(0.43 \pm 0.06 \mathrm{Myr}^{-1}\right)$ from $400 \mathrm{kyr}$ amplitude modulation envelopes in ' $\mathrm{C}$ ' and that from the original eccentricity data in ' $A$ '. 


\subsection{A coupled climate-tectonic model for the 10 and 35 Myr eustatic cycles}

Astronomically forced sea-level hierarchy spans a large temporal band from millennial precession period to multi-Myr orbital modulations (Table 1). Strong evidence of a $20 \mathrm{kyr}$ precession to 1.2 and $2.4 \mathrm{Myr}$ orbital modulation of sea-level changes has been found throughout the Phanerozoic (Strasser et al., 2006; Boulila et al., 2011; Fang et al., 2015; Liu et al., 2019). Longer orbital periods of 4.7 and $10 \mathrm{Myr}$ have also been suggested to pace long-term geological processes including sea-level (Boulila et al., 2012; Sprovieri et al., 2013; Boulila, 2019; Boulila et al., 2020). Our finding of $35 \mathrm{Myr}$ modulation of the $10 \mathrm{Myr}$ cycles in eccentricity and sea-level data further extends such a hierarchical link between Milankovitch and sea-level cycles (Table 1). The 10 and 35 Myr periodicities have similarly been detected in tectonic data (Sections 3.2 and 4.3).

The most likely phenomenon that may link insolation-climate to Earth's interior processes is climatically driven mass changes on Earth's surface (e.g., Métivier et al., 2010; Rietbroek et al., 2012). Thus, the potential link between external and Earth's interior processes would manifest as interactions and feedbacks (Boulila, 2019), rather than a direct orbital forcing of the solid Earth.

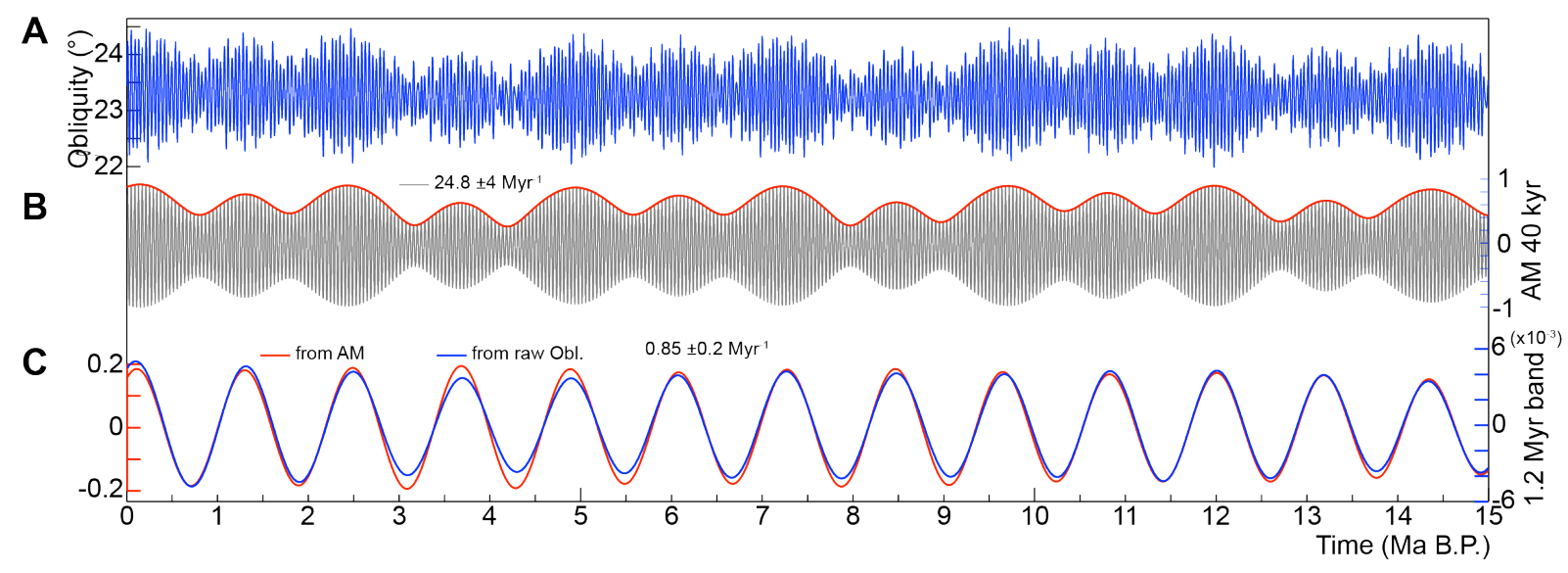

Figure 10: 1.2 Myr obliquity phasing. (A) La2004 raw obliquity time series (Laskar et al., 2004). (B) 40 kyr bandpass filtering $\left(24.8 \pm 4 \mathrm{Myr}^{-1}\right)$ and amplitude modulation envelopes (red curve). (C) Comparison of $1.4 \mathrm{Myr}$ filtered obliquity cyclicity $\left(0.85 \pm 2 \mathrm{Myr}^{-1}\right)$ from $40 \mathrm{kyr}$ amplitude modulation envelopes in ' $B$ ' and that from the original obliquity data in ' $A$ '. Note: a larger band in ' $C$ ' of, for example, $0.85 \pm 0.4 \mathrm{Myr}^{-1}$ would integrate other longer obliquity periods, such as the $799 \mathrm{kyr}$ and 2.4 Myr components. Therefore, an appropriate band of $0.85 \pm 0.2 \mathrm{Myr}^{-1}$ is more conservative to restore the actual phase of the 1.2 Myr cyclicity.

It has long been argued that the change in the shape of Earth's surface via the redistribution of Earth's water masses would distort the entire Earth system by deplacing its barycenter (e.g., Haskell, 1935; Mitrovica and Peltier, 1993; Conrad and Hager, 1997; Nerem and Wahr, 2011; Roy and Peltier, 2011). Redistribution of water mass on Earth's surface would induce elastic and viscous deformations of the solid Earth, and these two modes of deformation deflect the seafloor as well as the gravitational equipotential (geoid) surface that defines sea-level; both processes affect relative and global sea-level, but at different timescales (Haskell, 1935; Farrell, 1972; Walcott, 1972; Farrell and Clark, 1976). Elastic deformation operates at 1 to 100 years timescales, while the viscous deformation acts at longer timescales of 1 to $100 \mathrm{kyr}$ (see Conrad, 2013 for a review). Although the mechanically deformed Earth's surface due to glaciation/deglaciation could be local and over shorter timescales, such elongation is susceptible to propagate outside the deformation site, thus affecting sea-level at larger scale (Farrell and Clark, 1976; Mitrovica and Peltier, 1991; 
Conrad, 2013), and its low-frequency modulation via the hydrological cycle (e.g., Mason et al., 2004) is very likely (see below). It has even been demonstrated that seawater ocean loading causes a similar viscous response along coastlines that leads to changes in the global eustatic sea level (Mitrovica and Milne, 2002). Such a mechanism has long been recognized (Walcott, 1972; Clark et al., 1978; Nakada and Lambeck, 1989; Mitrovica and Peltier, 1991).
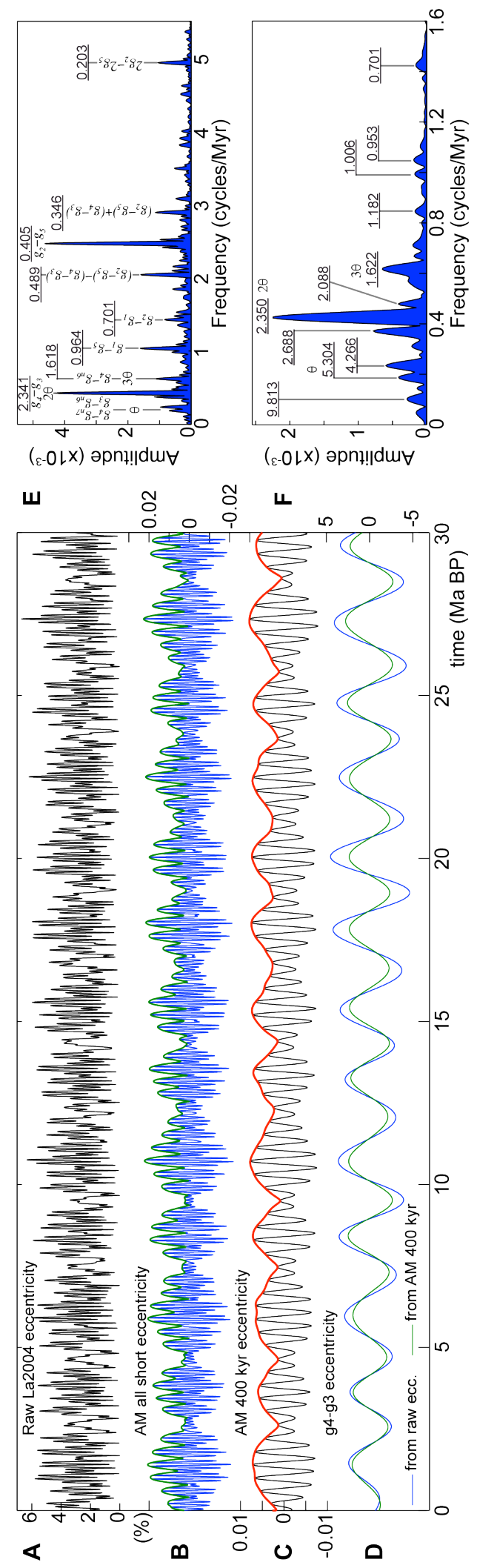
Figure 11: Amplitude modulation of the orbital eccentricity. (A) La2004 raw eccentricity. (B) Amplitude modulation of the short eccentricity (bandpass: $0.009 \pm 0.003$ cycles $/ \mathrm{kyr}$ ). (C) Amplitude modulation of the $400 \mathrm{kyr}$ eccentricity (bandpass: $0.00247 \pm 0.001 \mathrm{cycles} / \mathrm{kyr}$, applied to amplitude modulation envelopes in 'B'). (D) Bandpass (0.0004256 \pm 0.002 cycles/kyr) filtered g4-g3 from amplitude modulation envelopes in ' $C$ ' (green curve) and from the raw eccentricity in ' $A$ ' (blue curve). (E) Amplitude spectrum of amplitude modulation of short eccentricity band (green curve in 'B'). (E) Amplitude spectrum of amplitude modulation of 400 kyr eccentricity band (red curve in ' $C$ ').

These perturbations of Earth's surface from ice-mass and seawater ocean loading/unloading could be transferred to the deep solid Earth system. Observations of the match between orbitally paced Quaternary glacial cycles and global volcanic eruption has led to linkage between Earth's surface and interior processes at the orbital timescale (e.g., Rampino et al., 1979; McGuire et al., 1997; Huybers and Langmuir, 2009, 2017; Lund and Asimow, 2011; Schindlbeck et al., 2018). Large eruptions have been correlated to $100 \mathrm{kyr}$ glacial cycles at Mount Mazama (Bacon and Lanphere, 2006), Western Europe (Nowell et al., 2006), and the South Eastern United Sates (Jellinik et al., 2004). It is thus suggested as a causal link between loading and removal of ice on and from continents and the resulting general perturbations of the lithosphere and upper mantle (e.g., Nowell et al., 2006; Huybers and Langmuir, 2009). Orbitally-paced glacial cycles could modify the pressure exerted on the upper mantle, causing in turn the change in magma production and thus the global volcanic activity (e.g., Maclennan et al., 2002; Jellinek et al., 2004; Huybers and Langmuir, 2009; Kutterolf et al., 2013; Crowley et al., 2015; Tolstoy, 2015; Conrad, 2015; Schindlbeck et al., 2018). In particular, Crowley et al. (2015) highlighted a correlation between abyssal hill fabrics along mid-ocean ridges and the glacial cycles, suggesting cyclic magmatic response to changes in sea level. In addition, at Milankovitch time scales and longer, it was postulated that magmatic variation could cause climate change via volcanic emissions of greenhouse gases, impacting in turn Earth's surface processes including sea-level changes (Sternai et al., 2020). The interplay between tectonics, climate and Earth's surface processes was also suggested to explain the evolution of mountain building (Pesek et al., 2020).

Likewise, it has been hypothesized that annual, seasonal and tidal cycles are fingerprinted in seafloor volcanic variations, suggesting that tidal to annual changes in sealevel and environments (tides) would govern deformation of Earth's surface, and thus pace the global volcanic activity (e.g., Emter, 1997; Mason et al., 2004; Jupp et al., 2004). Milankovitch periodic parameters (precession, obliquity and eccentricity) modulate the annual and seasonal cycles (e.g., Berger et al., 2006; Huybers and Curry, 2006; Hinnov, 2013). In other words, any change in the amplitude/frequency of the shorter cycles (seasonal/annual) would be transferred to the longer cycles (Milankovitch band and its modulations) in the volcanic record (e.g., Mason et al., 2004; Jupp et al., 2004; Crowley et al., 2015; Tolstoy, 2015).

The above studies collectively suggest a potential connection between astroclimatically paced sea-level and Earth's interior and surface processes, depending on the presence or absence of icehouse conditions (i.e., via the annual hydrological cycle, Mason et al., 2004). Such connection may operate via a direct or indirect control of sea-level in tune with seasonal/annual to Milankovitch scale variations. A direct control may be exerted by glacio-eustasy, acquifer-eustasy and/or thermo-eustasy (see Section 4.4). However, these mechanisms cannot explain the larger amplitudes of sea-level (hundred to several hundreds of meters), documented for the greenhouse periods. An indirect control may operate as feedbacks of Earth's interior to sea-level and Earth's surface perturbations from astronomical forcing. Earth's interior may resonate to these superficial perturbations in a similar fashion, as that suggested for the $100 \mathrm{kyr}$ climate-glacial Quaternary cycles (Crowley et al., 2015; Tolstoy, 2015).

Although we shed light on a continuum of astro-tectonically linked sea-level, from annual to 35 Myr cycle bands, with the available data it is hard to collectively envision the 
shorter, annual, and the longer, Myr to tens of Myr, timescales either in terms of sea-level magntitude or in terms of operating, forcing processes (e.g., Conrad, 2013). However, the Phanerozoic data allows the suggestion that magnitude of sea-level changes could be enhanced from higher to lower frequencies (energy-transfer process, Boulila et al., 2012), i.e., the longer climate-tectonic cycle the larger the sea-level magntitude is (Fig. 1). Therefore, low-frequency tectonic cycles and processes (Section 4.4), in response to climatically-driven mass changes on Earth's surface including rock accumulation and erosion (e.g., Calais et al., 2010; Sternai et al., 2016; Pesek et al., 2020), have the potential to explain larger sea-level magnitudes during greenhouse periods (e.g., Vail et al., 1977; Haq et al., 1987; Haq and Schutter, 2008; Müller et al., 2008; Conrad, 2013).

A

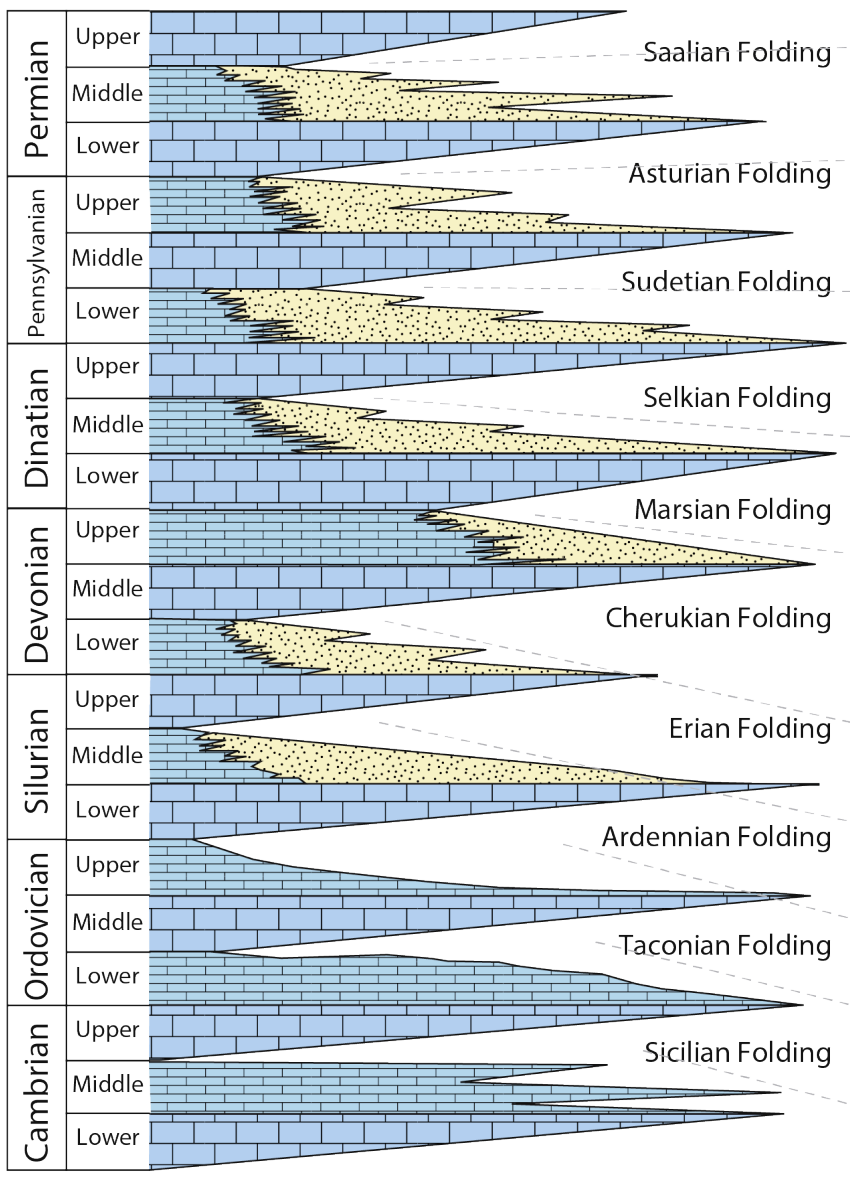

B

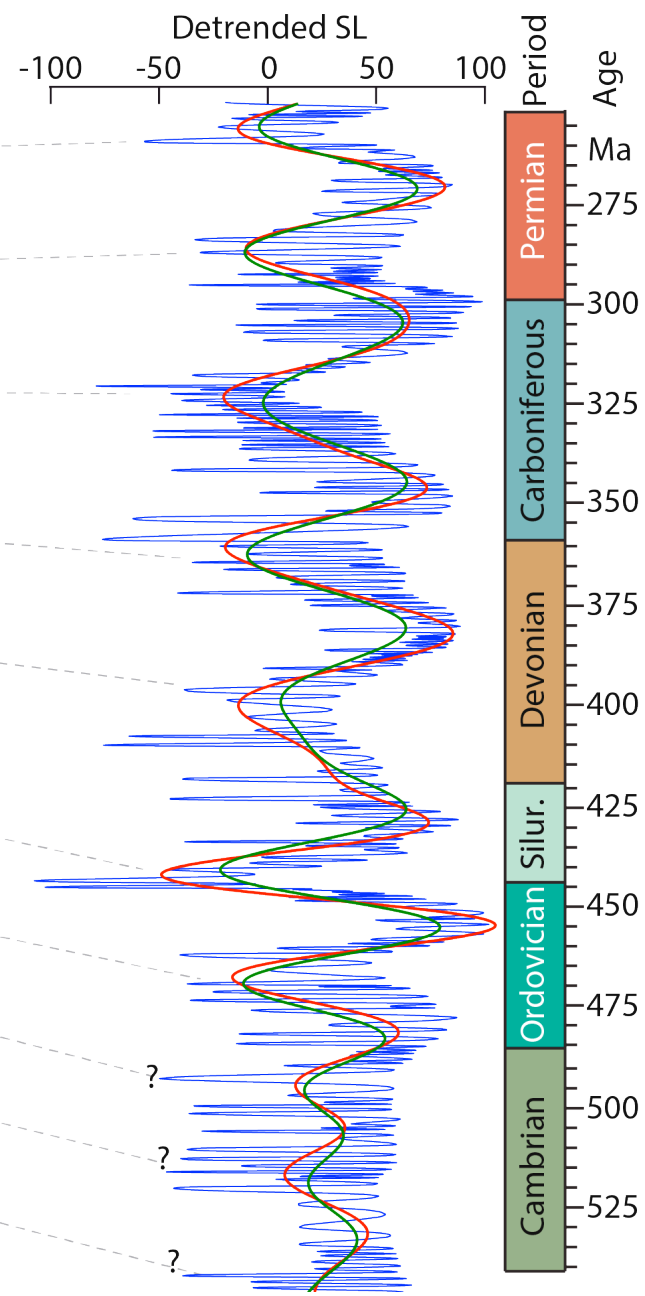

Figure 12: Paleozoic 35 Myr eustatic cycle. (A) Major global transgressions recognized by Grabau (1936) (modified after Simmons, 2012). (B) Detrended (Wilson Magacycle removed) Plaleozoic eustatic data of Haq and Schutter (2008) along with $35 \mathrm{Myr}$ bandpass filtering $(0.032 \pm 0.01 \mathrm{cycles} / \mathrm{Myr}$ in green and $0.032 \pm 0.02$ cycles/Myr in red) and potential correlation with 35 Myr equivalent cycles of Grabau (1936).

The 10 and 35 Myr cycles are common in Milankovitch, sea-level and subduction data. However, a dominant 25-26 Myr cyclicity has been detected in mid-ocean spreading data (Figs. 4 and 5, Cogné and Humler, 2006; Müller and Dutkiewicz, 2018). The 25-26 Myr cyclicity modulates the 10 Myr band in spreading and subduction data (Supplementary Information, Section 3.2). The present review points to a coupling between spreading and 
subduction at the 10 Myr band, but not at tens of Myr (Section 3.2). Such result should be further investigated in future geodynamic modeling efforts. Otherwise, one would expect that sea level oscillates in tune with mid-ocean spreading, given the potential link between them (e.g., Müller et al., 2008; see Conrad, 2013 for a review). However, subduction data also strongly correlate with sea level change (Figs. 13 and 14). We thus suggest that the longterm sea-level change is predominantly paced by the subduction processes. Recent studies of Earth's interior water cycling implies that the amount of water entering Earth's interior via subduction (Cai et al., 2018) greatly exceeds estimates of the amount being emitted by volcanoes including mid-ocean seafloor spreading (Parai and Mukhopadhyay, 2012), thus enhancing the importance of the subduction processes in the global water budget (Shillington, 2018). Nevertheless, changes to sea-level from both the spreading and subduction processes, which respond in turn to long-term (tens of Myr) perturbations in Earth's surface systems, is likely (Section 4.4). Reciprocally, substantial release of carbon dioxide $\left(\mathrm{CO}_{2}\right)$ from mid-ocean ridges (Müller and Dutkiewicz, 2018) and from subduction zones (Van Der Meer et al., 2014) could equally influence climate change at tens of Myr time scales.

\begin{tabular}{|c|c|c|c|c|}
\hline \multirow{2}{*}{ Order } & Suborder & $\begin{array}{c}\text { Mean period } \\
\text { (Myr) }\end{array}$ & Causal mechanism & Astronomy \\
\hline \multirow{2}{*}{ First } & Longer & $250-300^{*}$ & Tectonic, galactic? & Radial motion? \\
\cline { 2 - 5 } & Shorter & $91^{*}$ & Tectonic, galactic? & \\
\hline \multirow{3}{*}{ Second } & Longer & $36^{*}$ & Milankovitch, tectonic & Eccentricity-Obliquity \\
\cline { 2 - 5 } & Medium-2 & 18 & Milankovitch, tectonic & Eccentricity-Obliquity \\
\cline { 2 - 5 } & Medium-1 & $9.5^{*}$ & Milankovitch, tectonic & Eccentricity-Obliquity \\
\cline { 2 - 5 } & Shorter & 4.7 & Milankovitch, tectonic? & Eccentricity-Obliquity \\
\hline \multirow{2}{*}{ Third } & Longer & 2.4 & Milankovitch & Eccentricity (g4-g3) \\
\cline { 2 - 5 } & Shorter & 1.2 & Milankovitch & Obliquity (s4-s3) \\
\hline Fourth & & 0.405 & Milankovitch & Eccentricity (g2-g5) \\
\hline \multirow{2}{*}{ Fifth } & Longer & 0.173 & Milankovitch & Obliquity \\
\cline { 2 - 5 } & Shorter & 0.1 & Milankovitch & Eccentricity \\
\hline \multirow{2}{*}{ Sixth } & Longer & 0.04 & Milankovitch & Obliquity \\
\cline { 2 - 5 } & Shorter & 0.020 & Milankovitch & Precession \\
\hline
\end{tabular}

Table 1: Hierarchy of sea-level sequences and their potential causal mechanisms (modified after Boulila et al., 2011, 2018, 2020). ${ }^{*}$ Phanerozoic mean periodicity. Bold text indicates the updates. The $\sim 35 \mathrm{Myr}$ cyclicity has a very likely Milankovitch origin, which manifests as the modulator of the $10 \mathrm{Myr}$ orbital band (present study). Precise secular frequencies of the $4.7 \mathrm{Myr}$ orbital cycle are provided in Boulila (2019) and Boulila et al. (2020). The 9.5 Myr cycle originates from both the inclination and the eccentricity (Boulila, 2019) as well as the 4.7 Myr cycle (Boulila et al., 2012, 2020). Milankovitch forcing (eccentricity and inclination) by the 4.7, 9.5, 18 and $35 \mathrm{Myr}$ orbital cycles induce perturbations in Earth's surface processes, transferred to the deep solid Earth, and the latter resonates in turn to such superficial perturbations, thus explaining the conjoint astronomical-tectonic forcing on sea-level change. 

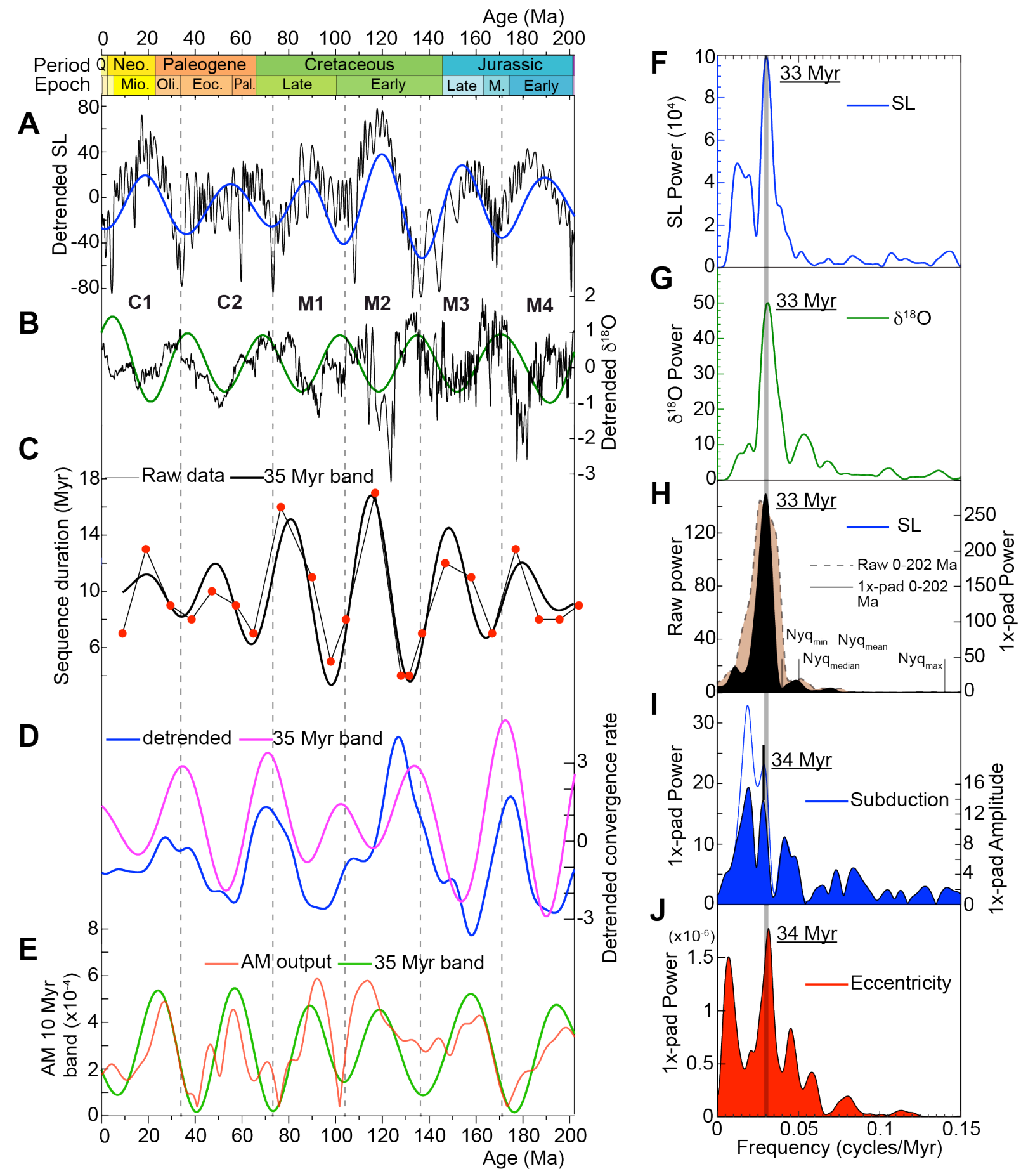

Figure 13: Time-series analysis of four geological datasets of the past $200 \mathrm{Ma}$ to highlight the $35 \mathrm{Myr}$ cyclicity. 'A', 'B', ' $F$ ' and ' $G$ ' are from Boulila et al. (2018). (A) Detrended eustatic reference data (Wilson megacycle removed), along with $35 \mathrm{Myr}$ bandpass filtering. (B) Detrended oxygen isotope data $\left(\mathrm{d}^{18} \mathrm{O}\right)$ (Wilson megacycle removed) along with $35 \mathrm{Myr}$ bandpass filtering. (C) Duration of major sequence boundaries through time (black curve), from the Canadian High Arctic Basin (Embry et al., 2019, see Fig. S1), and 35 Myr bandpass filtering (bold black curve). (D) Detrended convergence data of Müller et al. (2019) (blue, RC1, w = 25 Myr, step = 1 Myr) and 35 Myr bandpass filtering (pink, $0.0295 \pm 0.015$ cycles/Myr). (E) La2004 eccentricity amplitude modulation data (see Methods), along with a $35 \mathrm{Myr}$ bandpass filtering (0.0295 $\pm 0.015 \mathrm{cycles} / \mathrm{Myr}$, light green curve). (F) Power spectrum of data in 'A' (detrended). (G) Power spectrum of data in 'B'. (H) Power spectra of data in 'C'. (I) Power spectra of data in ' $D$ ' (see raw spectra in Fig. 4A and detail in Supplementary Fig. S15). (J) Power spectra of data in 'E' (see raw spectra in Supplementary Fig. S3). 

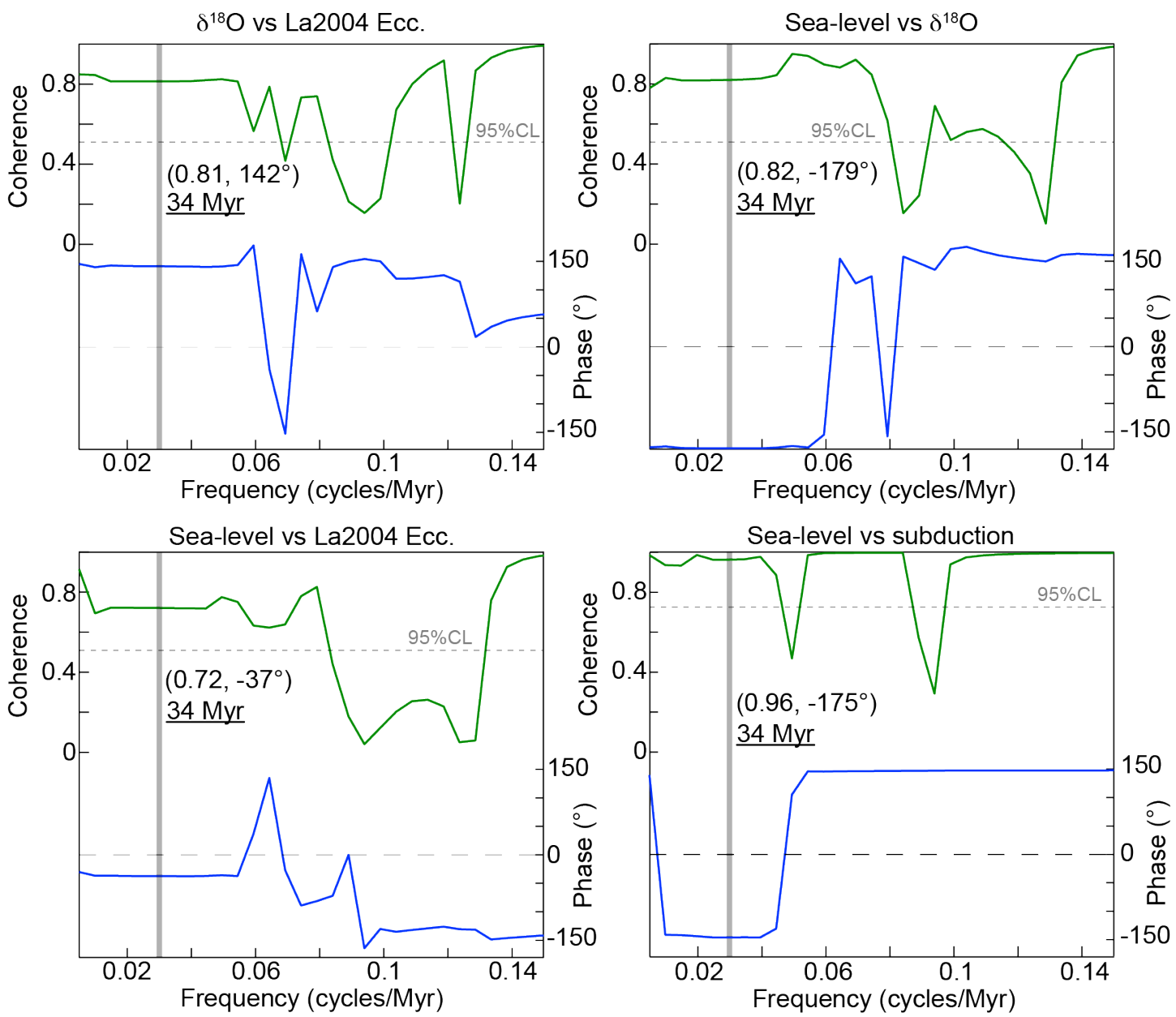

Figure 14: Cross spectral analysis of sea-level, $d^{18} \mathrm{O}$, La2004 eccentricity envelopes (La2004 Ecc.), and subduction data at the $34 \mathrm{Myr}$ cycle. Coherence and phase values for each cross spectrum are given between brackets. 

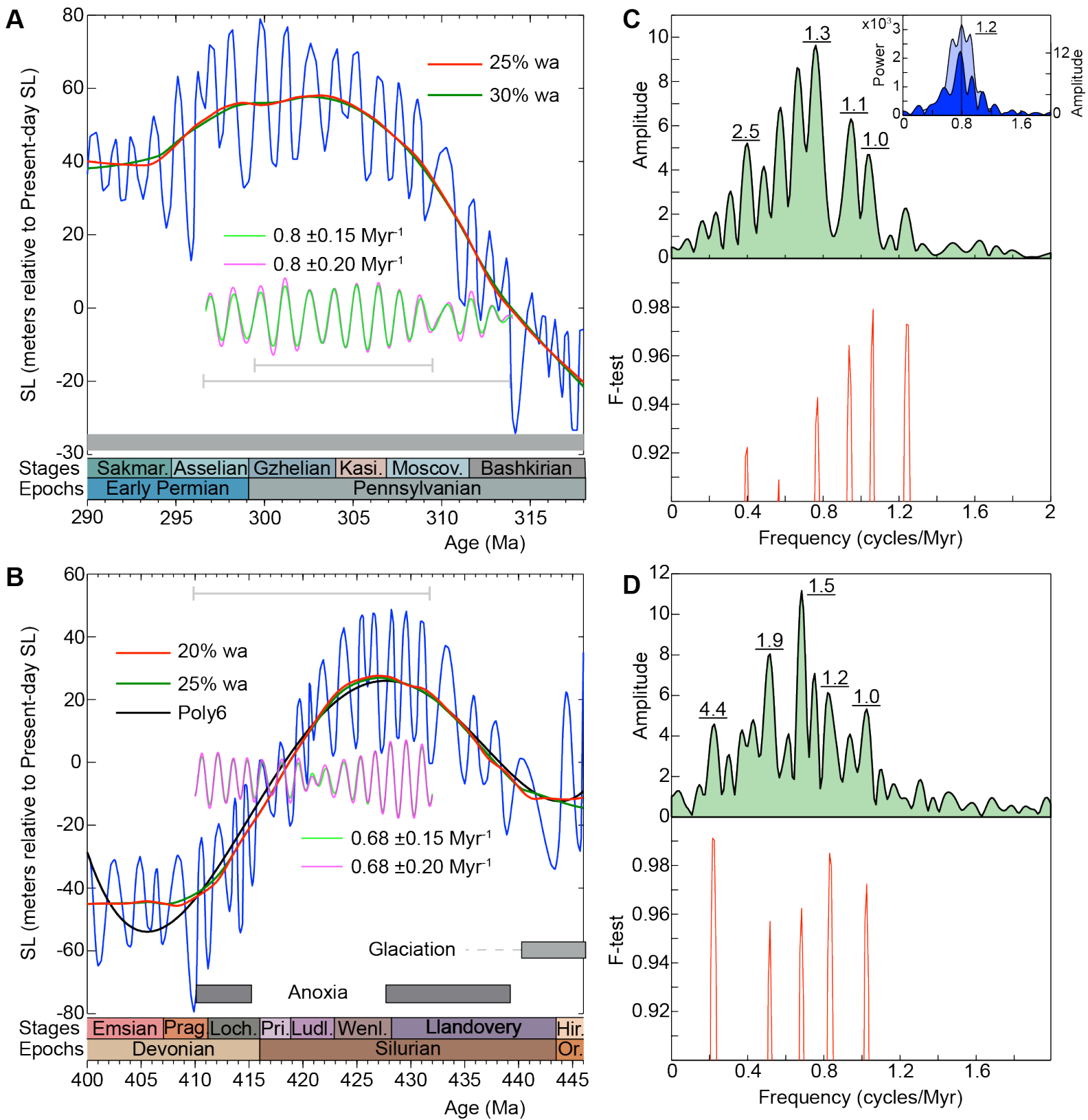

Figure 15: Time-series analysis of some Paleozoic glaciated and partially glaciated intervals to highlight the 1 Myr scale sea-level cyclicity (third-order sequences, Haq and Schutter, 2008). (A) Pennsylvanian to Early Permian p.p. interval. Raw data (bleu) along with smoothing weighted average (wa), and bandpass filtering of two intervals (indicated by horizontal grey double-arrows) showing regular 1.2 Myr scale cyclicity (see spectra in ' $C$ '). The grey horizontal bar indicates that all the interval is glaciated. (B) Silurian to Devonian p.p. interval. Raw data (bleu) along with smoothing weighted average (wa) and polynomial 6th order (Poly6), and bandpass filtering of one interval (indicated by horizontal grey double-arrow) showing regular 1.5 Myr scale cyclicity (see spectra in 'D'). The ligh-grey horizontal bar indicates the glaciated interval, and the dark-grey horizontal bar indicates the anoxic interval. (C) Spectrum of the interval from 296.7 to $314 \mathrm{Ma}$ and the significance F-test (upper and lower panels, respectively). Inset in the upper panel: spectra of a short interval from 299.5 to $309.5 \mathrm{Ma}$ showing a very regular cyclicity, depicted by a single strong peak centered on the period of $1.2 \mathrm{Myr}$. (D) Spectrum of the interval from 410 to $432 \mathrm{Ma}$ and the significance F-test (upper and lower panels, respectively). All values of periods indicated on spectral peaks are labelled in Myr. 


\section{Conclusions}

Superimposed on the tectono-eustatic Wilson megacycle (250-300 Myr in duration) are several long-term global sea level cyclicities of different amplitudes and origins. The most prominent ones are the $\sim 10$ and $\sim 35$ Myr cycles. Increasing evidence for Milankovitch orbital pacing of the $\sim 10$ Myr cyclicity has been demonstrated from various geological datasets and in the modulation of Milankovitch astronomical cycles. However, the origin of 35 Myr eustatic cyclicity has been controversial, which has been ascribed either to tectonics or climate from the solar system motion in the Galaxy.

Here we have reviewed the origin of $\sim 10$ and $~ 35$ Myr sea-level cycles based on amplitude modulation analysis of the compiled Phanerozoic sea-level data, together with additional geological datasets. We show that the 10 cycle band may be modulated by the $\sim 35$ Myr cyclicity in the sea-level record. We have tested the 10 and 35 Myr sea-level cyclicities for potential Milankovitch-forcing hypothesis since the $10 \mathrm{Myr}$ cycle arises from amplitude modulation of Milankovitch cycle band. Amplitude modulation analysis of Earth's orbital eccentricity variations indicates the modulation of the $\sim 10$ Myr cycles by the $\sim 35 \mathrm{Myr}$ cyclicity in different astronomical models. A correlation between sea-level and astronomical (insolation) variations at these two cyclicities provides a compelling evidence for a link between the two.

Additionally, the sea-level data support theoretical modeling that predicts the validity of astronomical models as far back as $45 \mathrm{Ma}$. We also show that the La2004 astronomical model provides the best fit with sea-level record compared to the more recent La2010d model. In particular, a good correlation between sea-level and La2004 astronomical data was established up to $50 \mathrm{Ma}$ at the $10 \mathrm{Myr}$ cycle, and even almost up to $150 \mathrm{Ma}$ for the $35 \mathrm{Myr}$ cycle, pointing to the robustness of La2004 model.

Our review suggests that it is unnecessary to invoke astronomically paced $35 \mathrm{Myr}$ cycle via cosmic ray flux from the vertical motion of solar system, unless insolation and cosmic ray are coupled through planetary and solar-system motions.

Finally, time-series analysis of subduction data from recent plate tectonic models also captures the 10 and $35 \mathrm{Myr}$ cyclicities. These tectonic cyclicities, especially the $35 \mathrm{Myr}$ cycle, correlated to sea-level and Milankovitch cycles. However, seafloor spreading data show a dominant cyclicity of 25-26 Myr. The interference of the 25-26 and 36 Myr (Phanerozoic mean period) tectonic cyclicities may explain a resulting third Phanerozoic sea-level cyclicity of a period that spans close to $91 \mathrm{Myr}(1 / 26-1 / 35)$.

The record of similar cyclicities in sea-level, $d^{18} \mathrm{O}$, Milankovitch and tectonic variations, and the correlations between them, especially at the $35 \mathrm{Myr}$ band, suggest a coupling between Earth's surface and interior processes. We thus hypothesize that Earth's interior processes resonate with astro-climatically (Milankovitch) driven perturbations of Earth's surface that include sea-level fluctuations. Our review augments the broad conclusion is that sea-level changes can respond directly to Milankovitch orbital forcing via glacioeustasy, thermo-eustasy and/or aquifer-eustasy or indirectly through feedbacks from tectonically-paced ocean-basin volume changes.

\section{Acknowledgments}

S.B., B.G. and G.C were supported by the ANR AstroMeso and ERC AstroGeo projects. B.U.H. acknowledges the support of his Sorbonne tenure through a doctoral funding by Total, and his sabbatical at Utrecht University in 2019 by Royal Dutch Academy of Sciences. N.C.H. acknowledges the financial support of the National Centre for Competence in Research of the Swiss National Science Foundation (SNSF). RDM was supported by the AuScope National Collaborative Research Infrastructure System (NCRIS) program. We thank Steve Puetz and an anonymous reviewer for their very helpful constructive comments. 


\section{References}

Abreu, V.S., Hardenbol, J., Haddad, G.A., Baum, G.R., Droxler, A.W., Vail, P.R., 1998. Oxygen isotope synthesis: A Cretaceous ice-house? In: de Graciansky, P.C., Jacquin, T., Hardenbol (Eds.), Mezozoic and Cenozoic Sequence Stratigraphy of European Basins. vol. 60. SEPM Special Publication, pp. 75-80 (Soc Sediment Geol, Tulsa, OK).

Austermann, J., Mitrovica, J.X., Latychev, K., Milne, G.A., 2013. Barbados-based estimate of ice volume at Last Glacial Maximum affected by subducted plate. Nat. Geosci. 6, 553-557.

Bacon, C.R., Lanphere, M.A., 2006. Eruptive history and geochronology of Mount Mazama and the Crater Lake region, Oregon. Geol. Soc. Am. Bull. 118, 1331-1359.

Baker, R.G.V., Flood, P.G., 2015. The Sun-Earth connect 3: lessons from the periodicities of deep time influencing sea-level change and marine extinctions in the geological record. SpringerPlus 4, 285.

Bailer-Jones, C.A.L., 2009. The evidence for and against astronomical impacts on climate change and mass extinctions: A review. International Journal of Astrobiology, 8, 213-239.

Beaufort, L., 1994. Climatic importance of the modulation of the $100 \mathrm{kyr}$ cycle inferred from $16 \mathrm{~m} . \mathrm{y}$. long Miocene records. Paleoceanography 9, 821-834.

Berger A., Loutre M.F., Mélice J.L., 2006. Equatorial insolation: from precession harmonics to eccentricity frequencies. Clim. Past 2, 131-136.

Bond, D.P., Grasby, S.E., 2017. On the causes of mass extinctions. Palaeogeogr. Palaeoclimatol. Palaeoecol. 478, 3-29.

Bornemann, A., Norris, R.D., Friedrich, O., Beckmann, B., Schouten, S., Damsté, J.S.S., Vogel, J., Hofmann, P., Wagner, T. 2008. Isotopic evidence for glaciation during the Cretaceous Supergreenhouse. Science 319, 189-192.

Boulila, S., 2019. Coupling between Grand cycles and Events in Earth's climate during the past 115 million years. Scientific Reports 9, 327. doi: 10.1038/s41598-018-36509-7.

Boulila, S., Brange, C., Cruz, A.M., Laskar, J., Gorini, C., Reis, T.D., Silva, C.G., 2020. Astronomical pacing of Late Cretaceous third- and second-order sea-level sequences in the Foz do Amazonas Basin. Marine and Petroleum Geology 117, 104382.

Boulila, S., Galbrun, B., Hinnov, L.A., Collin, P.Y., Ogg, J.G., Fortwengler, D., Marchand, D., 2010. Milankovitch and sub-Milankovitch forcing of the Oxfordian (Late Jurassic) Terres Noires Formation (SE France) and global implications. Basin Research 22, 717-732.

Boulila, S., Galbrun, B., Huret, E., Hinnov, L.A., Rouget, I., Gardin, S., Bartolini, A., 2014. Astronomical calibration of the Toarcian Stage: implications for sequence stratigraphy and duration of the early Toarcian OAE. Earth Planet Sci. Lett. 386, 98-111.

Boulila, S., Galbrun, B., Laskar, J., Pälike, H., 2012. A 9 myr cycle in Cenozoic $\delta 13 \mathrm{C}$ record and long-term orbital eccentricity modulation: Is there a link? Earth Planet. Sci. Lett. 317-318, 273281.

Boulila, S., Galbrun, B., Miller, K.G., Pekar, S.F., Browning, J.V., Laskar, J., Wright, J.D., 2011. On the origin of Cenozoic and Mesozoic "third-order" eustatic sequences. Earth-Sci. Rev. 109, 94-112.

Boulila, S., Laskar, J., Haq, B.U., Galbrun, B., Hara, N., 2018. Long-term cyclicities in Phanerozoic sea-level sedimentary record and their potential drivers, Global Planet. Change 185, 129-136.

Braun, J., 2010. The many surface expressions of mantle dynamics. Nature Geoscience 3 (12), 825833.

Cai, C., Wiens, D.A., Shen, W., Eimer, M., 2018. Water input into the Mariana subduction zone estimated from ocean-bottom seismic data. Nature 563, 389-392.

Calais, E., Freed, A.M., Van Arsdale, R., Stein, S., 2010. Triggering of New Madrid seismicity by latePleistocene erosion. Nature 466, 608-611.

Cerpa, N.G., Jones, D.W.R. and Katz, R.F., 2019. Consequences of glacial cycles for magmatism and carbon transport at mid-ocean ridges. Earth and Planetary Science Letters 528, p.115845.

Čižková, H. and Bina, C.R., 2015. Geodynamics of trench advance: Insights from a Philippine-Seastyle geometry. Earth and Planetary Science Letters 430, 408-415.

Clark, J.A., Farrell, W.E., Peltier, W.R., 1978. Global changes in postglacial sea level: A numerical calculation. Quaternary Research 9 (3), 265-287.

Cloetingh, S., Haq, B.U., 2015. Inherited landscapes and sea level change. Science 347, 393-403.

Cogné, J.-P., Humler, E., 2006. Trends and rhythms in global seafloor generation rate. Geochem. Geophys. Geosyst 7, Q03011, doi:10.1029/2005GC001148. 
Cogné, J.-P., Humler, E., 2008. Global scale patterns of continental fragmentation: Wilson's cycles as a constraint for long-term sea-level changes. Earth and Planetary Science Letters 273 (3-4), 251-259.

Cogné, J.-P., Humler, E., Courtillot, V., 2006. Mean age of oceanic lithosphere drives eustatic sealevel change since Pangea breakup: Earth and Planetary Science Letters 245 (1-2), 115-122.

Courtillot, V.E., Renne, P.R., 2003. On the ages of flood basalt events. C. R. Geosci. 335, 113-140.

Conrad, C.P., 2013. The solid Earth's influence on sea level. GSA Bulletin 125 (7/8), 1027-1052.

Conrad, C.P., 2015. How climate influences sea-floor topography. Science 347, 1204-1205.

Conrad, C.P., Gurnis, M., 2003. Seismic tomography, surface uplift, and the breakup of Gondwanaland: Integrating mantle convection backwards in time. Geochemistry Geophysics Geosystems 4, p. 1031, doi:10.1029/2001GC000299.

Conrad, C.P., Hager, B.H., 1997. Spatial variations in the rate of sea level rise caused by the presentday melting of glaciers and ice sheets. Geophysical Research Letters 24 (12), 1503-1506.

Conrad, C.P., Lithgow-Bertelloni, C., Louden, K.E., 2004. Iceland, the Farallon slab, and dynamic topography of the North Atlantic. Geology 32 (3), 177-180.

Crowley, J.W., Katz, R.F., Huybers, P., Langmuir, C.H., Park, S.-H., 2015. Glacial cycles drive variations in the production of oceanic crust. Science 347, 1237-1240.

Damon, P.E., 1971. The relationship between late Cenozoic volcanism and tectonism and orogenicepeirogenic periodicity, in Turekian, K.K., ed., The late Cenozoic glacial ages: New Haven, Conn., Yale University Press, p. 15-35.

Davis, M., Hut, P., Muller, R.A.., 1984. Extinction of species by periodic comet showers. Nature 308, 715-717.

Davies, A., Gréselle, B., Hunter, S.J., Baines, G., Robson, C., Haywood, A.M., Ray, D.C., Simmons, M.D., van Buchem, F.S.P., 2020. Assessing the impact of aquifer-eustasy on short-term Cretaceous. Cret. Res. 112, 104445.

DeCelles, P.G., Ducea, M.N., Kapp, P., Zandt, G., 2009. Cyclicity in cordilleran orogenic systems. Nat. Geosci. 2, 251-257.

Deynoux, M., Miller, J.M.G., Domack, E.W., Eyles, N., Fairchild, I.J., Young, G.M., 1994. Earth's Glacial Record. Cambridge University Press, Cambridge, p. 266.

Dinger, F., Bredemeyer, S., Arellano, S., Bobrowski, N., Platt, U., Wagner, T., 2019. On the link between Earth tides and volcanic degassing. Solid Earth 10, 725-740.

Dorman, F.H., 1968. Some australian oxygen isotope temperatures and a theory for a 30-million-year world-temperature. Journal of Geology 76, 297-313.

Embry, S., Beauchamp, B., Dewing, K., Dixon, J., 2019. Episodic tectonics in the phanerozoic succession of the Canadian high arctic and the "10-million-year flood". In: Piepjohn, K., Strauss, J.V., Reinhardt, L., McClelland, W.C. (Eds.), Circum-Arctic Structural Events: Tectonic Evolution of the Arctic Margins and Trans-arctic Links with Adjacent Orogens, vol. 541 Geological Society of America Special Paper. https://doi.org/10.1130/2018.2541(11).

Emter, D., 1997. Tidal triggering of earthquakes and volcanic events, in Tidal Phenomena, edited by S. Bhattacharji et al., pp. 293-309, Springer, New York.

Fang, Q., Wu, H., Hinnov, L.A., Jing, X., Wang, X., Jiang, Q., 2015. Geologic evidence for chaotic behavior of the planets and its constraints on the third-order eustatic sequences at the end of the Late Paleozoic Ice Age. Palaeogeography Palaeoclimatology Palaeoecology 440, 848-859.

Farrell, W.E., 1972. Deformation of the Earth by surface loads. Reviews of Geophysics and Space Physics 10 (3), 761-797.

Farrell, W.E., Clark, J.A., 1976. On postglacial sea level. Geophysical Journal of the Royal Astronomical Society 46 (3), 647-667.

Fischer, A.G., 1984. Two Phanerozoic supercycles. In: Berggren, W.A., Van Couvering, J.A. (Eds.), Catastrophes and Earth History. Princeton University Press, Princeton, pp. 129-150.

Fischer, A.G., Arthur, M.A., 1977. Secular variations in the pelagic realm. in Deep Water Carbonate Environments, H.E. Cook and P.Enos, eds., Soc. Econ. Paleontol. Mineral. Spec. Publ. 25, pp. 18-50.

Flament, N., Gurnis, M., Müller, R.D., 2013. A review of observations and models of dynamic topography. Lithosphere 5, 189-210.

Föllmi, K.B., 2012. Early Cretaceous life, climate and anoxia. Cretac. Res. 35, 230-257. 
Frakes, L.A., Francis, J.E., Syktus, J.L., 1992. Climate Modes of the Phanerozoic: The History of the Earth's Climate Over the Past 600 Million Years. Cambridge University Press, Cambridge, p. 274.

Gaffin, S., 1987, Ridge volume dependence on seafloor generation rate and inversion using long term sea level change. American Journal of Science 287 (6), 596-611.

Galeotti, S., Rusciadelli, G., Sprovieri, M., Lanci, L., Gaudio, A., Pekar, S., 2009. Sea-level control on facies architecture in the Cenomanian-Coniacian Apulian margin (Western Tethys): a record of glacio-eustatic fluctuations during the Cretaceous greenhouse? Palaeogeogr. Palaeoclimatol. Palaeoecol. 276, 196-205.

Ghil, M., Allen, R.M., Dettinger, M.D., Ide, K., Kondrashov, D., Mann, M.E., Robertson, A., Saunders, A., Tian, Y., Varadi, F., Yiou, P., 2002. Advanced spectral methods for climatic time series. Rev. Geophys. 40 (1), 3.1-3.41.

Goff, J.A., 2020. "Empirical Prewhitening" Spectral Analysis Detects Periodic but Inconsistent Signals in Abyssal Hill Morphology at the Southern East Pacific Rise. Geochemistry, Geophysics, Geosystems 21(11), p.e2020GC009261.

Goff, J.A., Zahirovic, S., Müller, R.D., 2018. No evidence for Milankovitch cycle influence on abyssal hills at intermediate, fast, and superfast spreading rates. Geophysical Research Letters 45(19), 10,305-10,313.

Grabau, A.W., 1936. Oscillation or pulsation? International Geological Congress Report on the $16^{\text {th }}$ Session, USA, 1933 1, 539-552.

Grabau, A.W., 1940. The rhythm of the ages. Henri Vetch Pub Peking China, 561p.

Gradstein, F.M., Ogg, J.G., Schmitz, M.D., Ogg, G., 2020. Geological Time Scale 2020. Elsevier, Amsterdam.

Gurnis, M., 1993, Phanerozoic marine inundation of continents driven by dynamic topography above subducting slabs. Nature 364 (6438), 589-593.

Haq, B.U., 2018. Triassic eustatic variations re-examined. GSA Today, 28, 4-9 + Online supporting material $16 \mathrm{pp}$. https://doi.org/10.1130/GSATG381A.1.

Haq, B.U., Al-Qahtani, A.-M., 2005. Phanerozoic cycles of sea-level change on the Arabian platform. GeoArabia 10 (2), 127-160.

Haq, B.U., Hardenbol, J., Vail, P.R., 1987. Chronology of fluctuating sea levels since the Triassic. Science 235 (4793), 1156-1167.

Haq, B.U., Schutter, S.R., 2008. A chronology of Paleozoic sea-level changes. Science 322 (5898), 64-68.

Harrison, C.G.A., 1990. Long-term eustasy and epeirogeny in continents, in Revelle, R.R., ed., SeaLevel Change: Washington, D.C., National Academy Press, p. 141-158.

Haskell, N.A., 1935. The motion of a fluid under a surface load. Physics Letters, Part B, 6, 265-269.

Hinnov, L.A., 2000. New perspectives on orbitally forced stratigraphy. Annual Review of Earth and Planetary Sciences 28, 419-475.

Hinnov, L.A., 2013. Cyclostratigraphy and its revolutionizing applications in the earth and planetary sciences. GSA Bulletin 125 (11/12), 1703-1734.

Huang, C., Hinnov, L.A., Fischer, A.G., Grippo, A., Herbert, T., 2010b. Astronomical tuning of the Aptian Stage from Italian reference sections. Geology 38, 899-902.

Huybers, P., Curry, W., 2006. Links between annual, Milankovitch and continuum temperature variability. Nature $441,329-332$.

Huybers, P., Denton, G., 2008. Antarctic temperature at orbital time scales controlled by local summer duration. Nat. Geosci. 1, 787-792.

Huybers, P., Langmuir, C., 2009. Feedback between deglaciation, volcanism and atmospheric CO2. Earth Planet. Sci. Lett. 286, 479-491.

Huybers, P., Langmuir, C. H., 2017. Delayed $\mathrm{CO}_{2}$ emissions from mid-ocean ridge volcanism as a possible cause of late-Pleistocene glacial cycles. Earth Planet. Sci. Lett. 457, $238-249$.

Immenhauser, A., 2005. High-rate sea-level change during the Mesozoic: New approaches to an old problem. Sedimentary Geology 175, 277-296.

Jacobs, D.K., Sahagian, D.L., 1993. Climate-induced fluctuations in sea level during non-glacial times. Nature 361, 710-712.

Jacobs, D.K., Sahagian, D.L., 1995. Milankovitch Fluctuations in Sea Level and Recent Trends in SeaLevel Change: Ice may not always be the answer, in: Haq, B.U. (Ed.), Sequence Stratigraphy and Depositional Response to Eustatic, Tectonic and Climatic Forcing. Springer Netherlands, Dordrecht, pp. 329-366. 
Jellinek, A.M., Manga, M., Saar, M.O., 2004. Did melting glaciers cause volcanic eruptions in eastern California? Probing the mechanics of dike formation. J. Geophys. Res., Solid Earth (19782012)109.

John, C.M., Karner, G.D., Mutti, M., 2004. $\delta^{18} \mathrm{O}$ and Marion Plateau backstripping: Combining two approaches to constrain latemiddleMiocene eustatic amplitude. Geology 32, 829-832.

Johnston, M., Mauk, F., 1972. Earth Tides and the Triggering of Eruptions from Mt Stromboli, Italy. Nature 239, 266-267.

Jupp, T.E., Pyle, D.M., Mason, B.G., Dade, W.B., 2004. A statistical model for the timing of earthquakes and volcanic eruptions influenced by periodic processes. J. Geophys. Res. 109, B02206, doi:10.1029/2003JB002584.

Kaiho, K., Saito, S., 1994. Oceanic crust production and climate during the last $100 \mathrm{Ma}$. Terra Nova 6, 376-384.

Karlsen, K.S., Conrad, C.P., Magni, V., 2019. Deep water cycling and sea level change since the breakup of Pangea. Geochem. Geophys. Geosyst. 20 (6), 2919-2935.

Kitchell, J.A., Pena, D., 1984. Periodicity of extinctions in the geologic past: deterministic versus stochastic explanations. Science 226(4675), 689-692.

Kominz, M.A., Browning, J.V., Miller, K.G., Sugarman, P.J., Mizintseva, S., Scotese, C.R., 2008. Late Cretaceous to Miocene sea-level estimates from the New Jersey and Delaware coastal plain coreholes: An error analysis. Basin Research 20, 211-226.

Kutterolf, S., Jegen, M., Mitrovica, J.X., Kwasnitschka, T., Freundt, A., Huybers, P., 2012. A detection of Milankovitch frequencies in global volcanic activity. Geology 41, 227-230.

Lagabrielle, Y., Goddéris, Y., Donnadieu, Y., Malavieille, J., Suarez, M., 2009. The tectonic history of Drake Passage and its possible impacts on global climate. Earth Planet. Sci. Lett. 279, 197-211.

Lamb, S., Davis, P., 2003. Cenozoic climate change as a possible cause for the rise of the Andes. Nature 425, 792-797.

Laskar, J., 1990. The chaotic motion of the Solar System: A numerical estimate of the size of the chaotic zone. Icarus 88, 266-291.

Laskar, J., 1999. The limits of the Earth orbital calculations for geological time-scale use. Philosophical Transactions of the Royal Society of London Series A 357, 1735-1759.

Laskar, J., Fienga, A., Gastineau, M., Manche, H., 2011. La2010: a new orbital solution for the long term motion of the Earth. Astronomy and Astrophysics 532, A89. doi: 10. 1051/0004$6361 / 201116836$.

Laskar, J., Joutel, F., Boudin, F., 1993. Orbital, precessional, and insolation quantities for the Earth from $-20 \mathrm{Myr}$ to $+10 \mathrm{Myr}$. Astronomy and Astrophysics 270, 522-533.

Laskar, J., Robutel, P., Joutel, F., Gastineau, M., Correia, A.C.M., Levrard, B., 2004. A long-term numerical solution for the insolation quantities of the Earth. Astronomy and Astrophysics 428, 261-285.

Li, M., Hinnov, L., Kump, L., 2019. Acycle: Time-series analysis software for paleoclimate projects and education. Computers \& Geosciences 127, 12-22.

Lieberman, B.S., and Melott, A.L., 2007. Considering the Case for Biodiversity Cycles: Reexamining the Evidence for Periodicity in the Fossil Record, PLoS One, 2(8): e759 doi:10.1371/journal.pone.0000759.

Liu, Y., Huang, C., Ogg, J.G., Algeo, T.J., Kemp, D.B., Shen, W., 2019. Oscillations of global sea-level elevation during the Paleogene correspond to 1.2-Myr amplitude modulation of orbital obliquity cycles. Planet Sci. Lett. 522, 65-78.

Lombard, A., Cazenave, A., Le Traon, P.-Y., Ishii, M., 2005. Contribution of thermal expansion to present day sea-level change revisited. Global and Planetary Change 47 (1), 1-16.

Lovell, B., 2010. A pulse in the planet: Regional control of high-frequency changes in relative sea level by mantle convection. Journal of the Geological Society of London 167 (4), 637-648.

Lund, D.C., Asimow, P.D., 2011. Does sea level influence mid-ocean ridge magmatism on Milankovitch timescales? Geochem. Geophys. Geosyst.12.

Maclennan, J., Jull, M., McKenzie, D., Slater, L., Grönvold, K., 2002. The link between volcanism and deglaciation in Iceland. Geochem. Geophys. Geosyst. 3, 1-25.

Mason, B.G., Pyle, D.M., Dade, W.B., Jupp, T., 2004. Seasonality of volcanic eruptions. J. Geophys. Res., 109, B04206, doi:10.1029/2002JB002293.

Matthews, R.K., 1984. Oxygen-isotopic record of ice-volume history: 100 million years of glacioeustatic fluctuations. AAPG Mem 36, 97-107. 
Matthews, R.K., Al-Husseini, M.I., 2010. Orbital-forcing glacio-eustasy: A sequence stratigraphic time scale. GeoArabia 15, 129-142.

McGuire, W.J., Howarth, R.J., Firth, C.R., Solow, A.R., Pullen, A.D., Saunders, S.J., Stewart, I.S., VitaFinzi, C., 1997. Correlation between rate of sea-level change and ency of explosive volcanism in the Mediterranean. Nature 389, 473-476.

McNutt, S.R., Beavan, R.J., 1981. Volcanic earthquakes at Pavlof Volcano correlated with the solid earth tide. Nature 294, 615-618.

Medvedev, M.V., Melott, A.L., 2007. Do extragalactic cosmic rays induce cycles in fossil diversity? Astrophys. J. 664, 879-889.

Melott, A.L., Bambach, R.K., 2010. Nemesis reconsidered. Monthly Notices of the Royal Astronomical Society Letters 407, L99-L102.

Melott, A.L., Bambach, R.K., 2014. Analysis of periodicity of extinction using the 2012 geological time scale. Paleobiology 40, 177-196 (2014).

Métivier, L., Greff-Lefftz, M., Altamimi, Z., 2010. On secular geocenter motion: The impact of climate changes. Earth and Planetary Science Letters 296 (3-4), 360-366.

Miller, K.G., Sugarman, P.J., Browning, J.V., Kominz, M.A., Hernandez, J.C., Olsson, R.K., Wright, J.D., Feigenson, M.D., Van Sickel,W., 2003. A chronology of Late Cretaceous sequences and sea-level history: glacioeustasy during the Greenhoouse World. Geology 31, 585-588.

Miller, K.G., Sugarman, P.J., Browning, J.V., Kominz, M.A., Olsson, R.K., Feigenson, M.D., Hernandez, J.C., 2004. Upper Cretaceous sequences and sea-level history, New Jersey Coastal Plain. Geological Society of America Bulletin 116, 368-393.

Miller, K.G., Kominz,M.A., Browning, J.V.,Wright, J.D.,Mountain, G.S., Katz,M.E., Sugarman, P.J., Cramer, B.S., Christie-Blick, N., Pekar, S.F., 2005a. The Phanerozoic record of global sea-level change. Science 310, 1293-1298.

Miller, K.G., Wright, J.D., Browning, J.V., 2005b. Visions of ice sheets in a greenhouse world. Marine Geology 217, 215-231.

Miller et al., 2020. Cenozoic sea-level and cryospheric evolution from deep-sea geochemical and continental margin records. Sci. Adv. 6, eaaz1346.

Mitrovica, J.X., Milne, G.A., 2002. On the origin of late Holocene sea-level highstands within equatorial ocean basins. Quaternary Science Reviews 21 (20-22), 2179-2190.

Mitrovica, J.X., Peltier, W.R., 1991. On postglacial geoid subsidence over the equatorial oceans. Journal of Geophysical Research-Solid Earth 96, 20,053-20,071.

Mitrovica, J.X., Peltier, W.R., 1993. Present-day secular variations in the zonal harmonics of Earth's geopotential. Journal of Geophysical Research-Solid Earth 98, 4509-4526.

Mitchell, R.N., Bice, D.M., Montanari, A., Cleavel, L.C., Christianson, K.T., Coccioni, R., Hinnov, L.A., 2008. Oceanic Anoxic Cycles? Orbital prelude to the Bonarelli Level (OAE 2). Earth and Planetary Science Letters 267, 1-16.

Mitchell, R.N., Spencer, C.J., Kirscher, U., He, X-F., Murphy, J.B., Li, Z-X., Collins, W.J., 2019. Harmonic hierarchy of mantle and lithospheric convective cycles: Time series analysis of hafnium isotopes of zircon. Gondwana Research 75, 239-248.

Mjelde, R., Wessel, P., Müller, R.D., 2010. Global pulsations of intraplate magmatism through the Cenozoic. Lithosphere 2, 361-376.

Molnar, P., England, P., 1990. Late Cenozoic uplift of mountain ranges and global climate change: chicken or egg?. Nature 346, 29-34.

Moucha, R., Forte, A.M., Mitrovica, J.X., Rowley, D.B., Quere, S., Simmons, N.A., Grand, S.P., 2008. Dynamic topography and long-term sea-level variations: There is no such thing as a stable continental platform. Earth and Planetary Science Letters 271 (1-4), 101-108.

Müller, R.D., Dutkiewicz, A., 2018. Ocean crustal carbon cycle drives 26-million years atmospheric carbon dioxide periodicities. Science Advances 4(2), eaaq0500.

Müller, R.D., Hassan, R., Gurnis, M., Flament, N. and Williams, S.E., 2018. Dynamic topography of passive continental margins and their hinterlands since the Cretaceous. Gondwana Research 53, 225-251.

Müller, R.D., Sdrollas, M., Gaina, C., Steinberger, B., Heine, C., 2008. Long-term sea-level fluctuations driven by ocean basin dynamics. Science 319, 1357-1362.

Müller, R.D., Seton, M., Zahirovic, S., Williams, S.E., Matthews, K.J., Wright, N.M., Shephard, G.E., Maloney, K.T., Barnett-Moore, N., Hosseinpour, M., Bower, D.J., Cannon, J., 2016. Ocean basin evolution and global-scale plate reorganization events since Pangea breakup. Annu. Rev. Earth Planet. Sci. 44, 107-138. 
Müller, R.D., et al., 2019. A Global Plate Model Including Lithospheric Deformation Along Major Rifts and Orogens Since the Triassic. Tectonics 38, 1884-1907.

Nakada, M., Lambeck, K., 1989. Late Pleistocene and Holocene sea-level change in the Australian region and mantle rheology. Geophys. J. Int. 96, 497-517.

Napier W.N., 1988. NEOs and impacts: The Galactic connection, Celestial Mechanics and Dynamical Astronomy 69, 59-75.

Nerem, R.S., Wahr, J., 2011. Recent changes in the Earth's oblateness driven by Greenland and Antarctic ice mass loss. Geophysical Research Letters 38 (13), L13501, doi:10.1029/2011GL047879.

Neuberg, J., 2000. External modulation of volcanic activity. Geophys. J. Int. 142, 232-240.

Nowell, D., Jones, C., Pyle, D., 2006. Episodic Quaternary volcanism in France and Germany. J. Quatern. Sci. 21, 645-675.

Olive, J.A., Behn, M.D., Ito, G., Buck, W.R., Escartín, J. and Howell, S., 2015. Sensitivity of seafloor bathymetry to climate-driven fluctuations in mid-ocean ridge magma supply. Science 350(6258), 310-313.

Paillard, D., Labeyrie, L., Yiou, P., 1996. Macintosch program performs timeseries analysis. Eos 77, 379.

Pälike, H., Norris, R.D., Herrle, J.O., Wilson, P.A., Coxall, H.K., Lear, C.H., Shackleton, N.J., Tripati, A.K., Wade, B.S., 2006. The Heartbeat of the Oligocene Climate System. Science 314, 18941898.

Parai, R., Mukhopadhyay, S., 2012. How large is the subducted water flux? New constraints on mantle regassing rates. Earth Planet. Sci Lett. 317-318, 396-406.

Peltier, W.R., Fairbanks, R.G., 2006. Global glacial ice volume and Last Glacial Maximum duration from an extended Barbados sea level record. Quat. Sci. Rev. 25, 3322-3337.

Pesek, M.E., Perez, N.D., Meigs, A., Rowden, C.C., Giles, S., 2020. Exhumation timing in the Oregon Cascade Range decoupled from deformation, magmatic, and climate patterns. Tectonics 39, e2020TC006078. https://doi.org/10.1029/2020TC006078.

Petersen, K.D., Nielsen, S.B., Clausen, O.R., Stephenson, R., Gerya, T., 2010. Small scale mantle convection produces stratigraphic sequences in sedimentary basins. Science 329 (5993), 827830.

Petrosino, S., Cusano, P., Madonia, P., 2018. Tidal and hydrological periodicities of seismicity reveal new risk scenarios at Campi Flegrei caldera. Sci. Rep. 8, 13808-13808.

Pitman, W.C., 1978, Relationship between eustasy and stratigraphic sequences of passive margins. Geological Society of America Bulletin 89 (9), 1389-1403.

Puetz, S.J., Borchardt, G., 2015. Quasi-periodic fractal patterns in geomagnetic reversals, geological activity, and astronomical events. Chaos Solitons and Fractals 81, 246-270.

Puetz, S.J., Ganade, C.E., Zimmermann, U., Borchardt, G., 2018. Statistical analyses of Global U-Pb Database 2017. Geoscience Frontiers 9, 121-145.

Rampino, RM., 2010. Mass extinctions of life and catastrophic flood basalt volcanism. Proc. Nat. Acad. Sci. USA 107 (no. 15), 6555-6556.

Rampino, M.R., 2015. Disc dark matter in the Galaxy and potential cycles of extraterrestrial impacts, mass extinctions and geological events. Monthly Notices of the Royal Astronomical Society 448, $1816-1819$.

Rampino, M.R., Caldeira, K., 1993. Major episodes of geologic change: correlations, time structure and possible causes. Earth Planet Sci. Lett. 114, 215-227.

Rampino, M.R., Caldeira, K., 2015. Periodic impact cratering and extinction events over the last 260 million years. Monthly Notices of the Royal Astronomical Society 454, 3480-3484.

Rampino, M.R., Caldeira, K., 2020. A 32-million year cycle detected in sea-level fluctuations over the last 545 Myr. Geoscience Frontiers 1029, doi: doi.org/10.1016/j.gsf.2020.06.005.

Rampino, M.R., Self, S., Fairbridge, R.W., 1979. Can rapid climatic change cause volcanic eruptions?. Science 206, 826-829.

Rampino, M.R., Stothers, R.B., 1984. Geological rhythms and cometary impacts. Science 226, 14271431.

Rampino, M.R., Stothers, R.B., 1988. Flood basalt volcanism during the past 250 million years. Science 241, 663-668.

Randal, L., Reece, M., 2014. Dark matter as a trigger for periodic comet impacts. Phys. Rev. Lett. 112 , 161301.1-161301.5. 
Rasmussen, C.E., Williams C.K.I., 2006. Gaussian Processes for Machine Learning, by. ISBN-13 9780-262-18253-9.

Raup, D.M., Sepkoski, J.J.Jr., 1984. Periodicity of extinctions in the geologic past. Proc. Nat. Acad. Sci. USA 81, 801-805.

Raup, D.M., Sepkoski, J.J.Jr., 1988. Testing for periodicity of extinction. Science 241, 94-96.

Ray, D.C., van Buchem, F.S.P., Baines, G., Davies, A., Gréselle, B., Simmons, M.D., Robson, C., 2019. The magnitude and cause of short-term eustatic Cretaceous sea-level change: A synthesis. Earth-Science Reviews 197, 102901.

Raymo, M., Ruddiman, W.F., 1992. Tectonic forcing of late Cenozoic climate. Nature 359, 117-122.

Raymo, M., Ruddiman, W.F., Froelich, P.N., 1988. Influence of Late Cenozoic mountain building on ocean geochemical cycles. Geology 16(7), 649-653.

Rich, J.E., Johnson, G.L., Jones, J.E., Campsie, J., 1986. A significant correlation between fluctuations in seafloor spreading rates and evolutionary pulsations. Paleoceanography 1, 85-95.

Rietbroek, R., Brunnabend, S.E., Kusche, J., and Schröter, J., 2012. Resolving sea level contributions by identifying fingerprints in time-variable gravity and altimetry. Journal of Geodynamics 59-60, 72-81.

Roy, K., Peltier, W.R., 2011. GRACE era secular trends in Earth rotation parameters: A global scale impact of the global warming process?. Geophysical Research Letters 38 (10), L10306, doi:10.1029/2011GL047282.

Royer, D.L., Berner, R.A., Montanez, I.P., Tabor, N.J., Beerling, D.J., 2004. CO2 as a primary driver of Phanerozoic climate. GSA Today 14, 4-10.

Sames, B., Wagreich, M., Conrad, C.P., Iqbal, S., 2020. Aquifer-eustasy as the main driver of shortterm sea-level fluctuations during Cretaceous hothouse climate phases. Geological Society London Special Publications 498, doi.org/10.1144/SP498-2019-105.

Sames, B., Wagreich, M., Wendler, J.E., Haq, B.U., Conrad, C.P., Melinte-Dobrinescu, M.C., Hu, X., Wendler, I., Wolfgring, E., Yilmaz, I., Zorina, S.O., 2016. Review: short term sea-level changes in a greenhouse world - a view from the Cretaceous.

Schindlbeck, J.C., Jegen, M., Freundt, A., Kutterolf, S., Straub, S.M., Mleneck-Vautravers, M.J., McManus, J., 2018. 100-kyr cyclicity in volcanic ash emplacement: Evidence from a $1.1 \mathrm{Myr}$ tephra record from the NW Pacific. Scientific Reports. https://doi.org/10.1038/s41598-018-225950 .

Shackleton, N.J., Imbrie, J., 1990. The $\delta^{18} \mathrm{O}$ spectrum of oceanic deepwater over a 5-decade band. Clim Change 16, 217-230.

Shillington, 2018. Water takes a deep dive into the Mariana Trench. Nature 563, 335-336.

Siddall, M., Hönisch, B., Waelbroeck, C., Huybers, P., 2010. Changes in deep Pacific temperature during the mid-Pleistocene transition and Quaternary. Quaternary Science Reviews 29, 170-181.

Simmons, M.D., 2012. Sequence stratigraphy and sea-level change. In: In: Gradstein, F.M., Ogg, J.G., Schmitz, M.D., Ogg, G.M. (Eds.), The Geologic Time Scale 2012, vol. 1. pp. 239-267.

Simmons, M.D., Miller, K.G., Ray, D.C., Davies, A., van Buchem, F.S.P., Gréselle, B., 2020. Phanerozoic eustasy. In: In: Gradstein, F.M., Ogg, J.G., Schmitz, M.D., Ogg, G.M. (Eds.), The Geologic Time Scale 2020 (in press). v.x, pp. xxx-xxx.

Spasojevic, S., and Gurnis, M., 2012, Sea level and vertical motion of continents from dynamic Earth models since the Late Cretaceous: American Association of Petroleum Geologists Bulletin 96 (11), 2037-2064.

Sprovieri, M., Sabatino, N., Pelosi, N., Batenburg, S.J., Coccioni, R., lavarone, M., Mazzola, S., 2013. Late Cretaceous orbitally-paced carbon isotope stratigraphy from the Bottaccione Gorge (Italy). Palaeogeogr. Palaeoclimatol. Palaeoecol. 379-380, 81-94.

Sternai, P., Caricchi, L., Castelltort, S., Champagnac, J.-D., 2016. Deglaciation and glacial erosion: A joint control on magma productivity by continental unloading. Geophysical Research Letters, 43, 1632-1641.

Sternai, P., Caricchi, L., Pasquero, C., Garzanti, E., van Hinsbergen, D.J.J., Castelltort, S., 2020. Magmatic forcing of Cenozoic climate? Journal of Geophysical Research: Solid Earth 125, e2018JB016460. https://doi.org/10.1029/2018JB016460.

Stigler, S.M., Wagner, M.J., 1987. A substantial bias in nonparametric tests for periodicity in geophysical data. Science 238, 940-945.

Stigler, S.M., Wagner, M.J., 1988. Testing for periodicity of extinction: response. Science 241, 96-99.

Stoll, H.M., Schrag, D.P., 1996. Evidence for glacial control of rapid sea level changes in the Early Cretaceous. Science 272, 1771-1774. 
Stoll, H.M., Schrag, D.P., 2000. High-resolution stable isotope records from the Upper Cretaceous rocks of Italy and Spain: glacial episodes in a greenhouse planet? Geol. Soc. Am. Bull. 112, 308319.

Stothers, R.B., 1998. Galactic disk dark matter, terrestrial impact cratering and the law of large numbers. Mon. Not. R. Astron. Soc. 300, 1098-1104.

Strasser, A., Hilgen, F.J., Heckel, P. H., 2006. Cyclostratigraphy - concepts, definitions, and applications. Newsletters on Stratigraphy 42(2), 75-114.

Svensmark, H., 2006. Imprint of Galactic dynamics on Earth's climate. Astron. Nachr. AN 327 (9), 866-870.

Svensmark, H., 2007. Cosmoclimatology: a new theory emerges. Astron. Geophys. 48, 1.18-1.24.

Thomson, D.J., 1982. Spectrum estimation and harmonic analysis. IEEE Proc. 70, 1055-1096.

Tolstoy, M., 2015. Mid-ocean ridge eruptions as a climate valve. Geophys. Res. Lett.42, 1346-1351.

Vail, P.R., Mitchum, R.M., and Thompson, S., 1977. Seismic stratigraphy and global changes of sea level: Part 4. Global cycles of relative changes of sea level, in Payton, C.E., ed., Seismic Stratigraphy; Applications to Hydrocarbon Exploration. American Association of Petroleum Geologists Memoir 26, p. 83-97.

Van Der Meer, D.G., Zeebe, R.E., van Hinsbergen, D.J.J., Sluijs, A., Spakman, W., Torsvik, T.H., 2014. Plate tectonic controls on atmospheric CO2 levels since the Triassic. PNAS 111(22), 43804385.

Wagreich, M., Lein, R., Sames, B., 2014. Eustasy, its controlling factors, and the limno-eustatic hypothesis e concepts inspired by Eduard Suess. Austrian Journal of Earth Sciences 107 (1), 115-131.

Walcott, R.I., 1972. Past sea levels, eustasy and deformation of the Earth. Quaternary Research 2 (1), $1-14$.

Wendler, J.E., Wendler, I., Vogt, C., Kuss, J., 2016. Link between cyclic eustatic sea-level change and continental weathering: evidence for aquifer-eustasy in the Cretaceous. Palaeogeogr. Palaeoclimatol. Palaeoecol. 441 (3), 430-437.

Wendler, J.E., Wendler, I., 2016. What drove sea-level fluctuations during the mid-Cretaceous greenhouse climate? Palaeogeography, Palaeoclimatology, Palaeoecology 441, 412-419.

Whiteside, J.H., Olsen, P.E., Eglinton, T., Brookfield, M.E., Sambrotto, R.N., 2010. Compound-specific carbon isotopes from Earth's largest flood basalt province directly link eruptions to the endTriassic mass extinction. Proc Natl Acad Sci USA 107(no. 15), 6721-6725.

Wiemer, D., Schrank, C.E., Murphy, D.T., Wenham, L., Allen, C.M., 2018. Earth's oldest stable crust in the Pilbara Craton formed by cyclic gravitational overturns. Nature Geoscience 11, 357-361.

Wise, D.U., 1974. Continental margins freeboard and the volumes of continents and oceans through time. In: Burh C.A. \& Drake, C.L., eds, Geology of the continental margins Springer Verlag Heidelberg Germany, p. 45-58.

Wolfram, L.C., Weinberg, R.F., Nebel, O., Hamza, K., Hasalová, P., Míková, J., Becchio, R., 2019. A $60-$ Myr record of continental back-arc differentiation through cyclic melting. Nat. Geosci. 12, 215219.

Wright, N.M., Seton, M., Williams, S.E., Whittaker, J.M. and Müller, R.D., 2020. Sea level fluctuations driven by changes in global ocean basin volume following supercontinent break-up. EarthScience Reviews 208, p.103293.

Zachos, J.C., Pagani, M., Sloan, L., Thomas, E., Billups, K., 2001. Trends, rhythms, aberrations in global climate $65 \mathrm{Ma}$ to present. Science 292, 686-693.

Zucker, S., 2018. Detection of periodicity based on independence tests - III. Phase distance correlation periodogram . Monthly Notices of the Royal Astronomical Society: Letters, Volume 474, Issue 1, p.L86-L90. 
Supplementary Information on:

\title{
Potential encoding of coupling between Milankovitch forcing and Earth's interior processes in the Phanerozoic eustatic sea-level record
}

\author{
Slah Boulila ${ }^{\text {a,b, }}$, Bilal U. Haq ${ }^{\text {a,c }}$, Nathan Hara ${ }^{\text {d }}$, R. Dietmar Müller ${ }^{\mathrm{e}}$, \\ Bruno Galbrun ${ }^{a}$, and Guillaume Charbonnier ${ }^{a}$
}

\footnotetext{
a Sorbonne Université, CNRS, Institut des Sciences de la Terre Paris, ISTeP, F-75005 Paris, France.

b ASD/IMCCE, CNRS-UMR8028, Observatoire de Paris, PSL University, Sorbonne Université, 77 Avenue Denfert-Rochereau, 75014 Paris, France.

${ }^{c}$ Smithsonian Institution, Washington DC, USA

${ }^{d}$ Département d'astronomie, Université de Genève, 51 chemin des Maillettes, 1290 Versoix, Suisse.

e EarthByte Group, School of Geosciences, University of Sydney, Sydney, New South Wales 2006, Australia.
}



Supplementary Figure S1: Correlation of Canadian sedimentary sequences and the reference 36 Myr eustatic cycle. (A) Variations of durations of large-magnitude sedimentary sequences through time, from the Canadian High Arctic Basin (Embry et al., 2019). (B) Detrended (Wilson Magacycles removed) Phanerozoic eustatic data, along with 36 Myr bandpass filtering, and potential correlation (shaded lines) with Canadian sequences. A 36 Myr bandpass filter was also applied to the Canadian data (see Fig. 13 for spectral analysis). Note that the durations of Canadian sequences (9.5 Myr mean cyclicity, see Fig. 3) evolves cyclically through time, and this resulting modulation cyclicity captures the 36 Myr eustatic cycle. The shaded interval is statistically detailed in Fig. 13. 


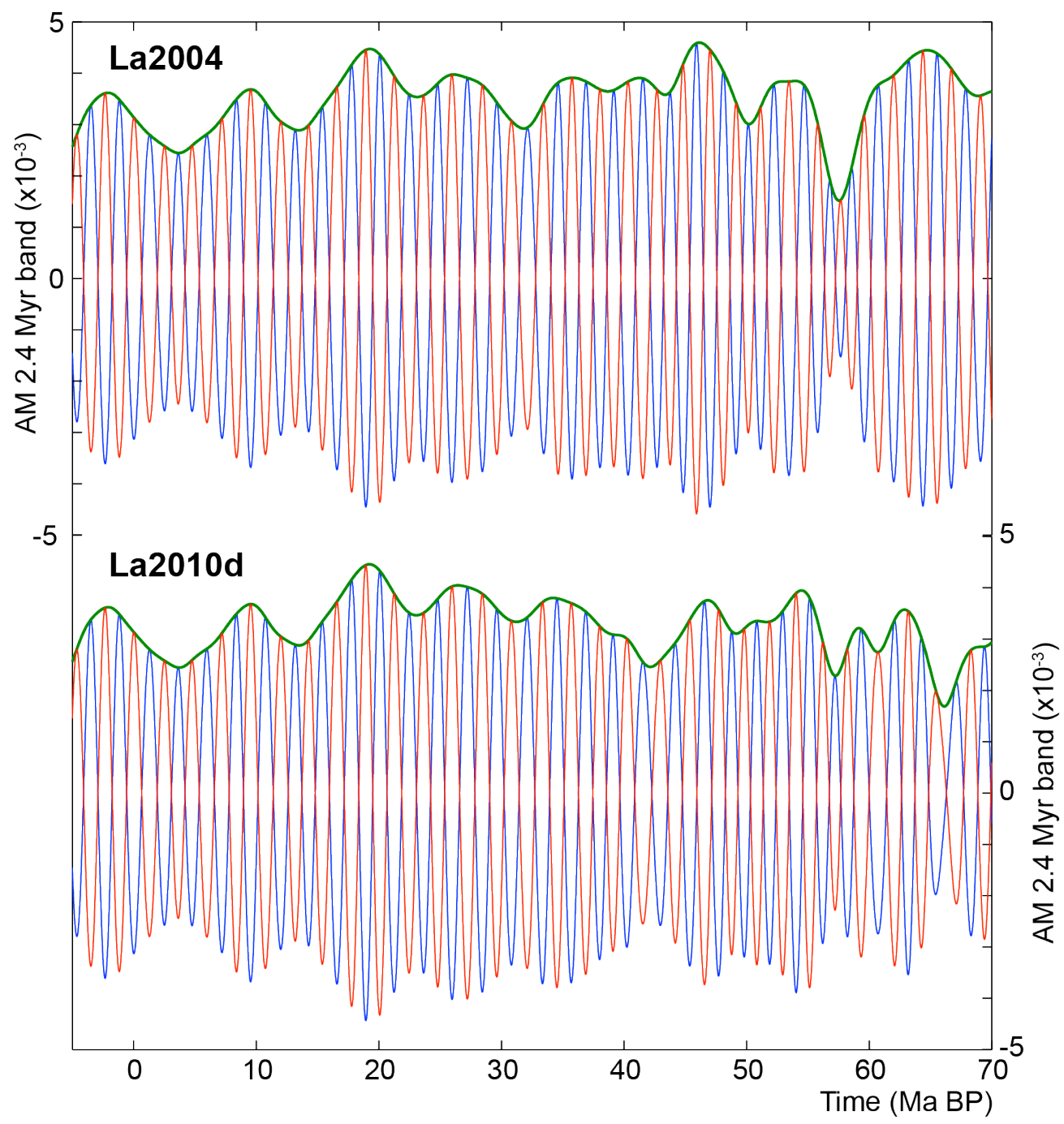

Supplementary Figure S2: Amplitude modulation of the 2.4 Myr eccentricity cycle band $(0.43 \pm 0.15$ cycles/Myr) from the two astronomical models La2004 and La2010d (Laskar et al., 2004, 2010). 9.5 Myr envelopes are in green, 2.4 Myr eccentricity cycle in blue, and inverted 2.4 Myr eccentricity cycle in red.

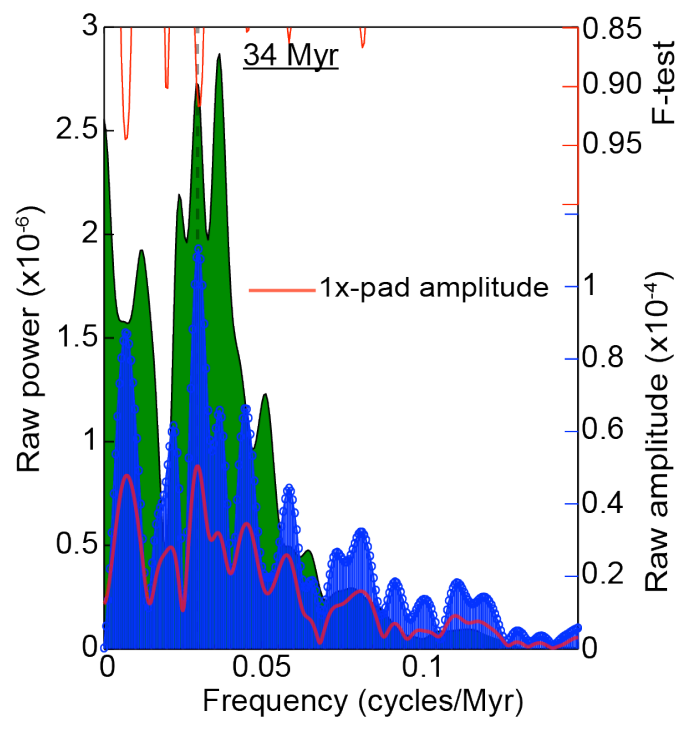

Supplementary Figure S3: Power spectra of La2004 eccentricity amplitude modulation over the interval 0-202. 2pi-MTM raw power spectrum in green-shaded area. 2pi-MTM raw amplitude spectrum in blue-shaded area. 2piMTM 1x-pad amplitude spectrum in red line. Note the strong $34 \mathrm{Myr}$ peak in the three spectral outputs. 2pi-MTM 1x-pad power spectrum is provided in Fig. 13J. 


\section{Myr-scale cyclicity in the Paleozoic glacioeustatic intervals}

The irregular sea-level variations in some Paleozoic intervals (Fig. 15) are possibly related to not-yet astronomically tuned Paleozoic strata, since dating of sea-level data was mainly based on biostratigraphy (see Haq and Schutter, 2008). Biostraigraphy generally does not offer the required temporal resolution (e.g., Boulila et al., 2008) for the study and a precise quantification of sea-level periodicities (e.g., Boulila et al., 2010).

Some Paleozoic intervals document with high fidelity both third- and fourth-order sealevel sequences (Haq and Schutter, 2008). Fourth-order has been ascribed to the $405 \mathrm{kyr}$ eccentricity cycle (Haq and Schutter, 2008; Boulila et al., 2011). A method to precisely assess the duration of third-order sequences is to tune to a $405 \mathrm{kyr}$ periodicity and the 405 kyr eccentricity term is relatively stable over a large part of the Phanerozoic era, and therefore could be used to calibrate Phanerozoic third-order sequences (Laskar et al., 2004). For instance, the Gzhelian Stage contains 10 cyclothem groupings (Strasser et al., 2006), each one has been ascribed to the $405 \mathrm{kyr}$ eccentricity cycle (fourth-order sequences, Haq and Schutter, 2008; Boulila et al., 2011). The same interval, i.e. Gzhelian Stage, contains exactly three and a half third-order sequences (Fig. 15A,C, Haq and Schutter, 2008), the duration of which could be tuned to a mean period of $\sim 1.2 \mathrm{Myr}$ based on the $405 \mathrm{kyr}$ periodicity. Thus, third-order sea-level sequences could be attributed to the 1.2 Myr obliquity modulation cycle within the glaciated Paleozoic intervals (Boulila et al., 2011).

Assuming that the fourth- and third-order sequences were genetically related via orbital pacing by the $405 \mathrm{kyr}$ eccentricity and $1.2 \mathrm{Myr}$ obliquity periodicities, recalibration of duration of well-constrained third-order sequences using the stable $405 \mathrm{kyr}$ periodicity (Laskar et al., 2004) would provide constraints on the s4-s3 orbital frequency in Paleozoic deep times.

\section{New time-series methods of the sea-level data}

To unveil potential frequencies in the sea-level data, we analyzed it with a phase distance correlation periodogram (PDC periodogram), as defined in Zucker (2018). This tool searches for statistical independence between an angle rotating with a certain frequency and the data. As such, the method is weakly dependent on the shape of the periodic signal. The PDC periodogram of the raw sea-level data is represented in blue in Fig. S5. The maximum is attained at $342 \mathrm{Myr}$ (highlighted by the dashed blue line), but this periodicity is not well defined because of limited cycle repetitions in the data. This perodicity could range from ca. 250 to $342 \mathrm{Myr}$ (Fig. S5), and corresponds to the two mega-oscillations present in the data. We fitted polynomials of increasing order and compute the $x^{2}$ of the fit as a function of the degree (see Figure S6, right panel). Once the $X^{2}$ reaches a plateau, we adopted the corresponding degree, the polynomial is fitted to the data (represented by blue points, see Figure S6). The fitted model (orange curve) is then subtracted from the data and the PDC periodogram is computed on the residuals. The orange curve (Fig. S5) is obtained, with a maximum at $91.3 \mathrm{Myr}$.

We repeated the search for a suitable polynomial fit of the data, but this time on the data phase-folded at 91.3 Myr. We further imposed a constraint of derivability of the polynomial. We selected a polynomial of degree 3 , then subtracted from the data. We repeated the process so as to obtain in successive iterations the green and red PDC periodogram with maxima respectively at periods $37 \mathrm{Myr}$ and $54 \mathrm{Myr}$. The fit onto the phasefolded data is shown in figures S7 and S8 respectively. We repeated the procedure and found peaks at $40.30,33.83,119.15,60.90,114.187500,24.2522$ Myr. 
Successive phase distance correlation periodograms

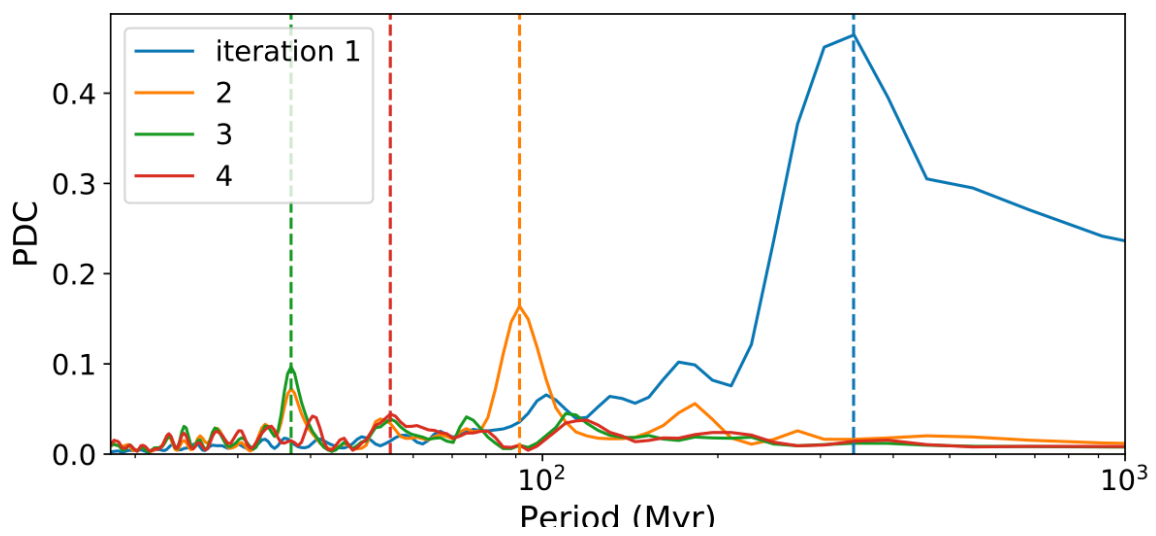

Supplementary Figure S4: Successive phase distance correlation periodograms obtained by computation on the residuals, after removal of the periodicities previously found.
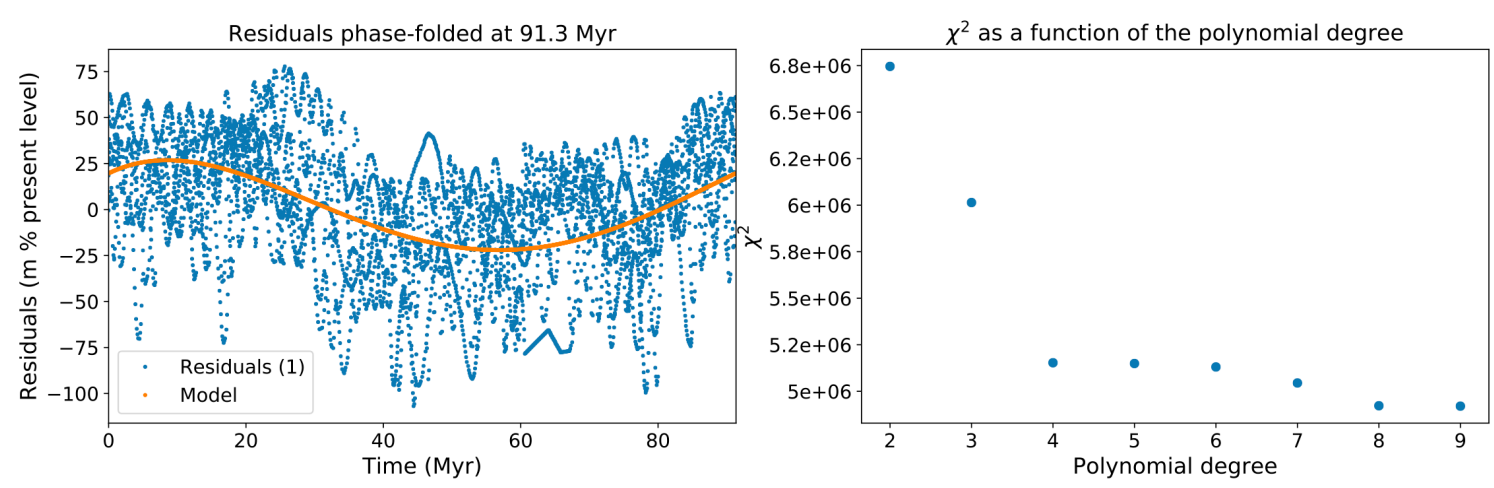

Supplementary Figure S5: left sea-level data (blue) and 6-th order polynomial model (orange). Right: $\chi^{2}$ fit of the data as a function of the degree of the polynomial fitted.
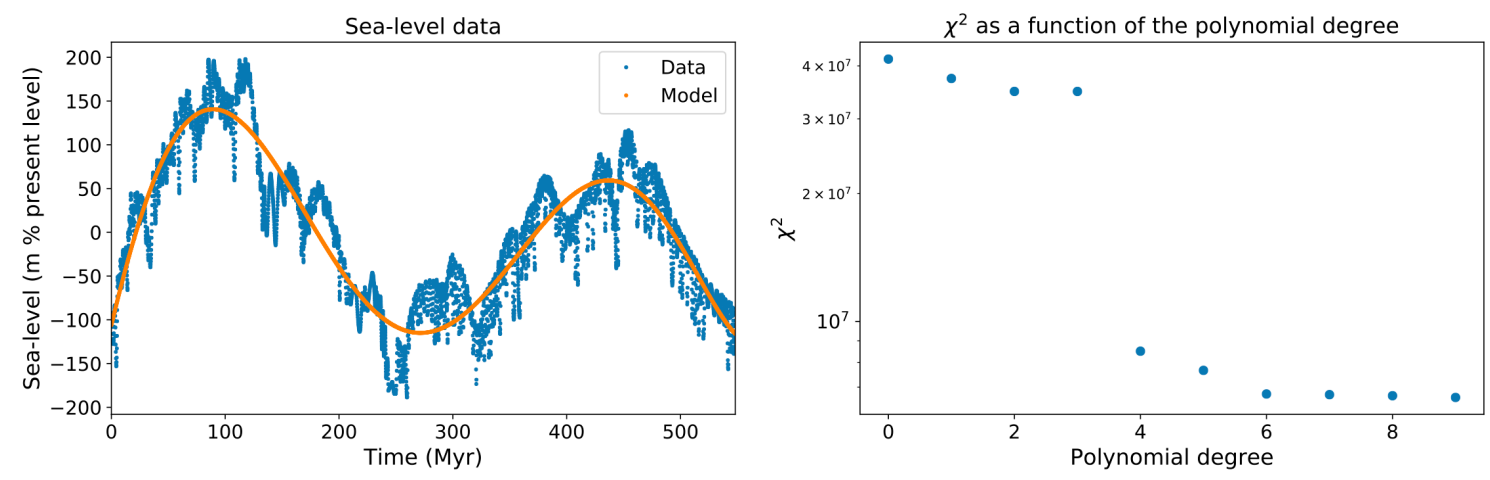

Supplementary Figure S6: left sea-level residual data after subtraction of a six order polynomial fitted (blue) and 3-rd order polynomial model (orange). Right: $\chi^{2}$ fit of the data as a function of the degree of the polynomial fitted. 

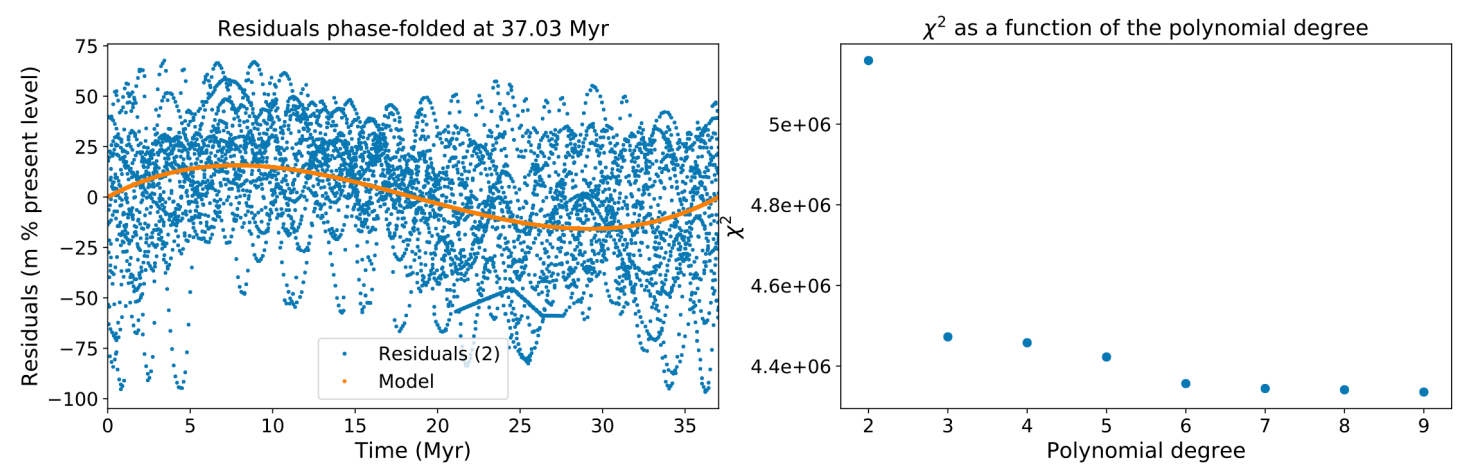

Supplementary Figure S7: left sea-level residual data after subtraction of a fitted six order polynomial and the 91 Myr periodicity (blue) and 3-rd order polynomial model (orange). Right: $\chi^{2}$ fit of the data as a function of the degree of the polynomial fitted.
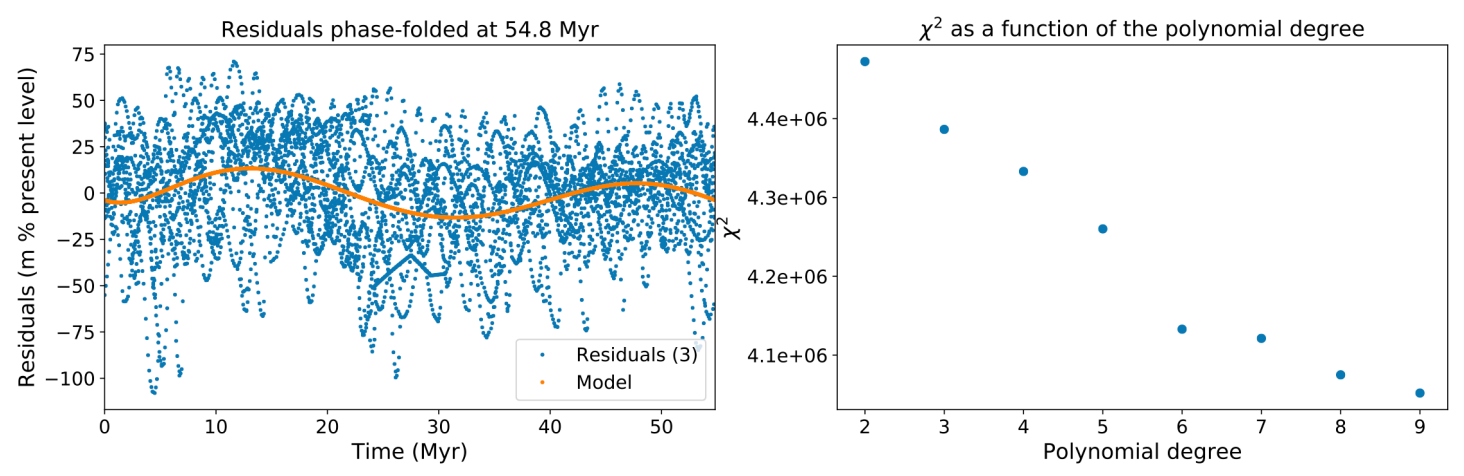

Supplementary Figure $\mathbf{S 8}$ left sea-level residual data after subtraction of a fitted six order polynomial and the 91 Myr periodicity (blue) and 6-th order polynomial model (orange). Right: $\chi^{2}$ fit of the data as a function of the degree of the fitted polynomial.

It is unclear at this point whether, besides 91.3 and 37 Myr which have been found significant with other methods, are significant, or whether these are traces of phase, frequency and amplitude modulations of other the 91.3 and 37 Myr signal. To explore this aspect, we considered Gaussian process models of the data (Rasmussen and Williams, 2006). We considered the data as a sum of three stochastic processes, corresponding to stochastically driven harmonic oscillators (SHO) with fundamental frequencies 1/342, 1/91.3 and 1/37.03 cycle/Myr. Such processes have been suggested for instance in Foreman-Mackey et al. (2017). They are defined by a fundamental frequency, a quality factor $Q$ parametrising the speed of the response of the oscillator and an amplitude A. We used the Gaussian process implementation of Delisle et al. (2020). The frequencies are supposed fixed and we perform a maximum likelihood fit of the the quality factor $Q$ as well as the amplitude $A$ defining the SHO gaussian processes with constraints $Q>100$ and A less than the standard deviation of the data.

The predictive mean of the resulting Gaussian process is over-plotted on Figure S10. In Figure S11, we represent in purple the Gaussian process model of the SHO model with period 37 Myr only. The orange curve represents the sum of the successive models obtained 
by the iterative PDC periodogram procedure, starting from the second iteration. Indeed, the first two iterations were modelling the megacycle as well as the $91 \mathrm{Myr}$ cycle. It then appears that the sum of the successive terms is close to the Gaussian process model. As a conclusion, it appears that the periodicities found in the iterative procedure can be explained by a stochastic process exhibiting a peak in the power spectrum at 37 Myr. We finally subtracted the Gaussian process with three harmonic oscillator from the data and perform a PDC periodogram on the residuals, shown in Fig. S12 in blue. We found the highest peaks at 2.556, 4.095, 4.50 and 9.46, $12.45 \mathrm{Myr}$, which is compatible with the previous analyses.

The result of such period search depends on the way the detrending of the low frequencies is undertaken. For comparison, we performed this detrending by fitting a polynomial. To select its degree, we computed the $\chi^{2}$ as a function of the degree of the fitted polynomial, as shown in Figure S13. It appears there are sudden drops at degrees 4-6, 20 and 45. If such drops correspond to fits of periodic functions, one would expect them to appear at approximately three times the number of oscillations present in the data. Degree 6 corresponds to $\sim 6 / 3$ oscillations, that is a period of $548 \mathrm{Myr}$ (the total timespan of the observations) / $2=274 \mathrm{Myr}$. The second drop to $\sim 45 / 3=15$ oscillations, or $\sim 36.5$ Myr periodicity. These orders of magnitude are compatible with the periodicities found so far. In Figure S14, we represent the PDC periogogram of the residuals after a fit of polynomial of degree 48 . The periodicities at 2.556, 4.095 and $12.45 \mathrm{Myr}$ still appear, the 9.5 one is absent, and we find additionally 18.35 , 22.5, 28.2 Myr.
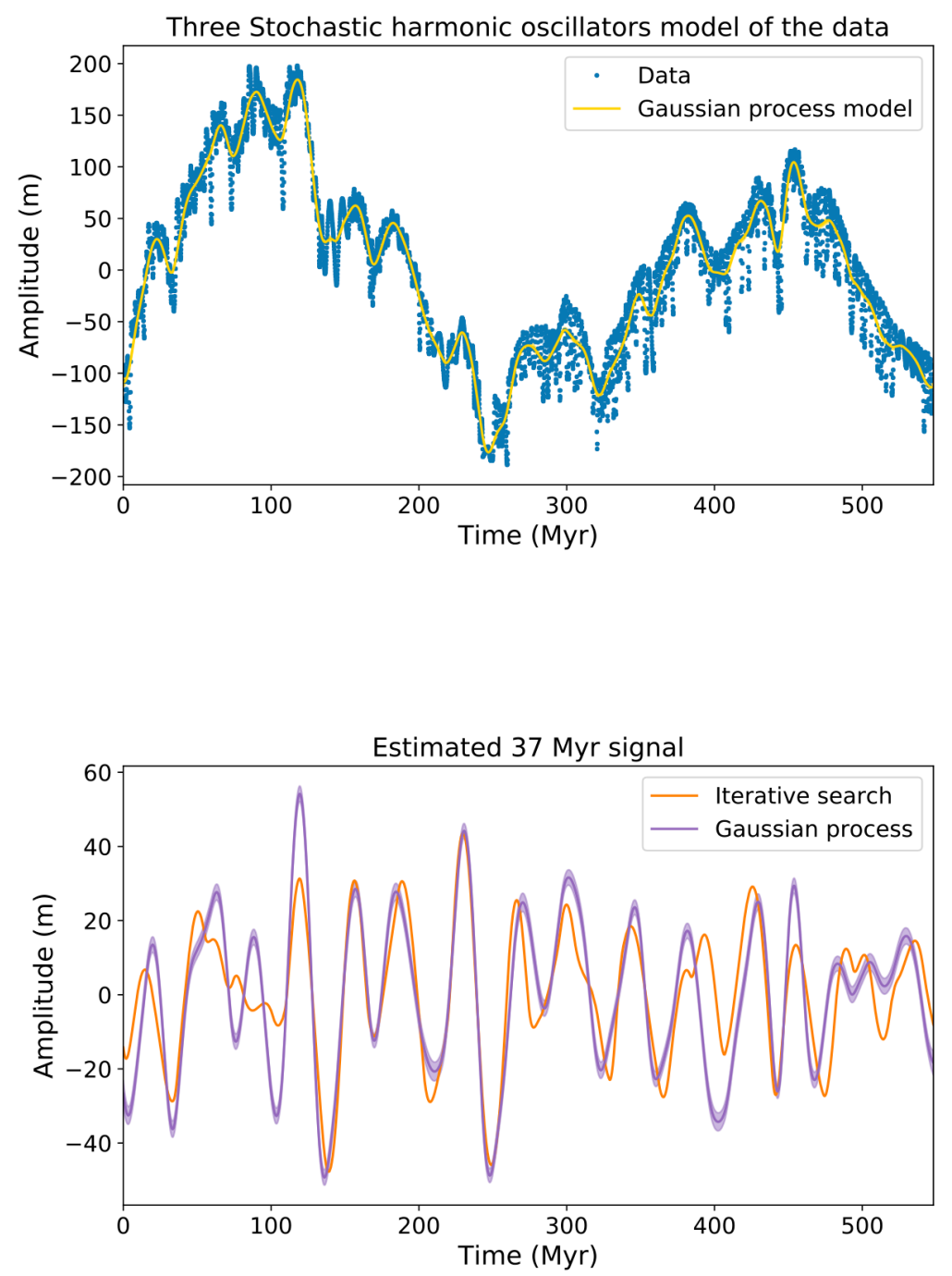

Supplementary Figure S9 In blue: raw sea-level data with mean subtracted. In yellow: three stochastic harmonica oscillators model of the data.

Supplementary Figure S10 In orange: sum of the contributions of the model components successively found in sea-level data. 


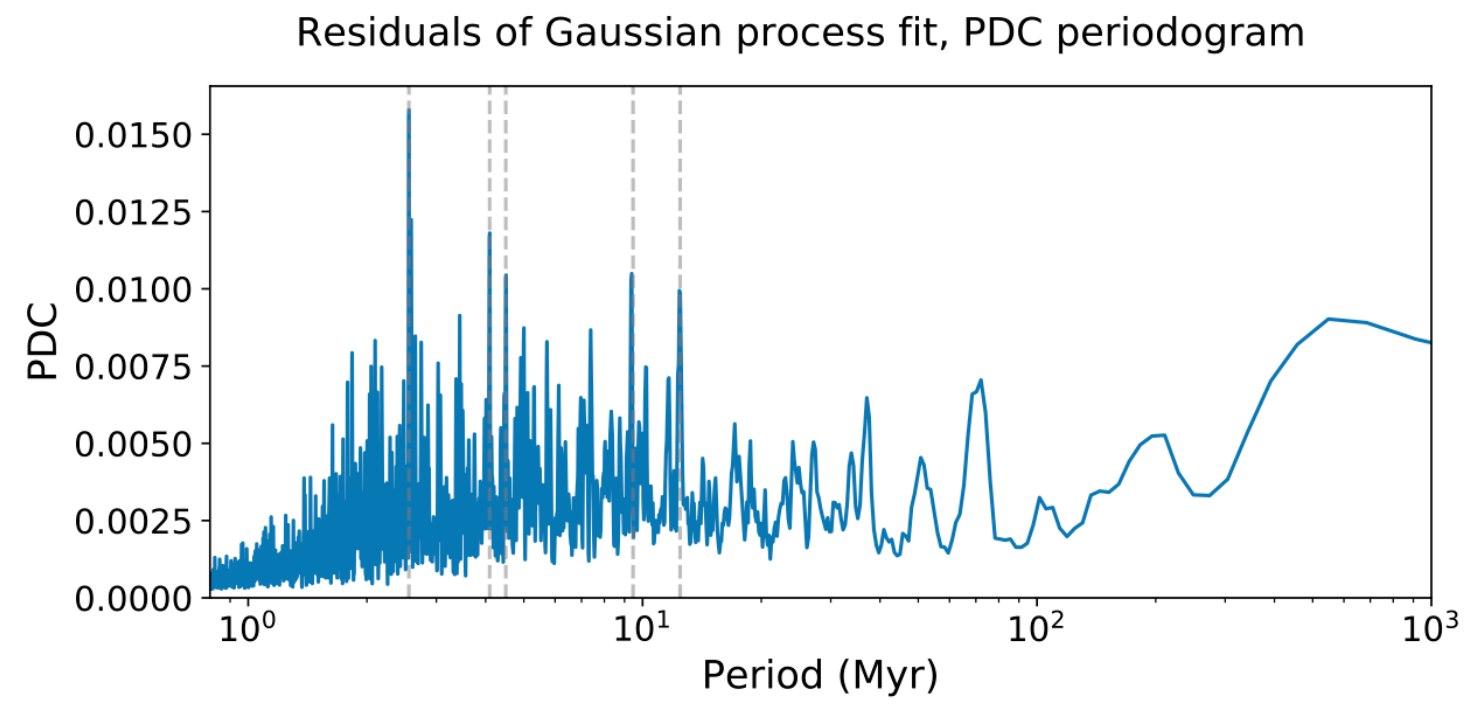

Supplementary Figure S11 Phase distance correlation periodogram after subtraction of the Gaussian process model (in blue) in sea-level data. The grey dashed lines indicate periods at 2.556, 4.095, 4.50 and 9.46, $12.45 \mathrm{Myr}$.

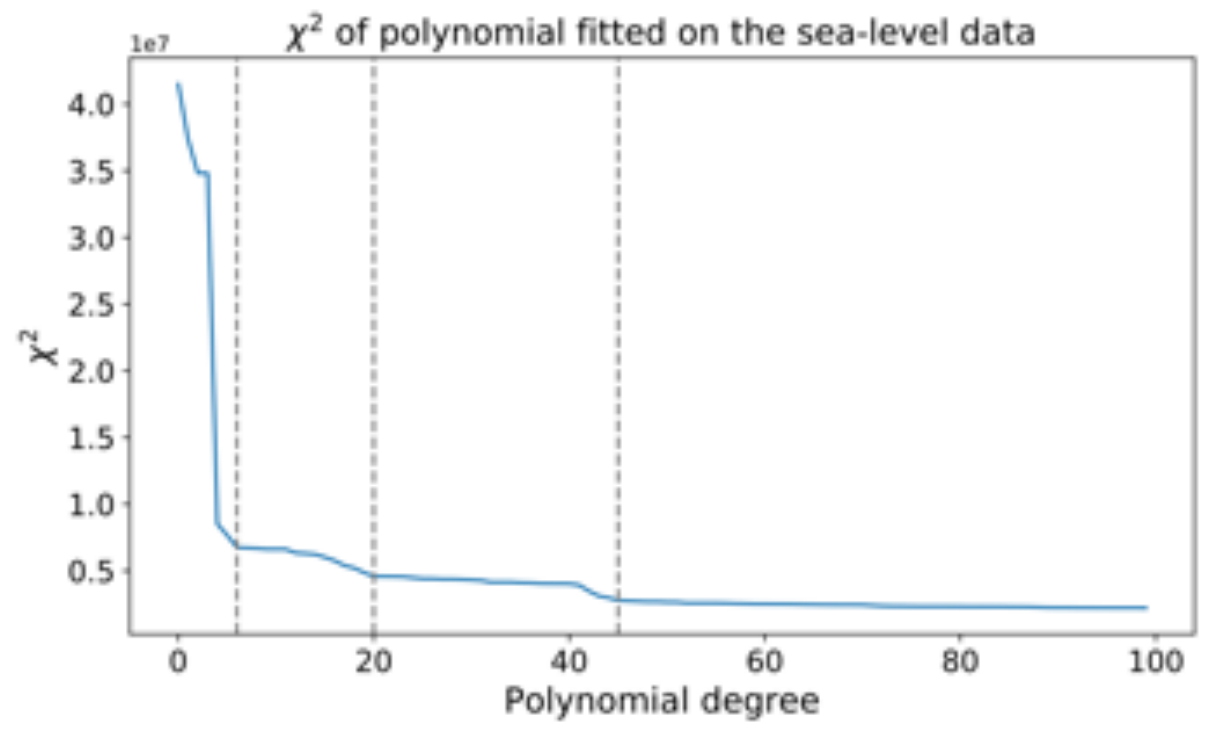

Supplementary Figure $\mathbf{S 1 2} \mathbf{X}^{2}$ of the residuals after a polynomial fit with increasing degree in sealevel data. The grey dashed lines indicate apparent drops in the $\chi^{2}$ at degree 6, 20 and 45 . 


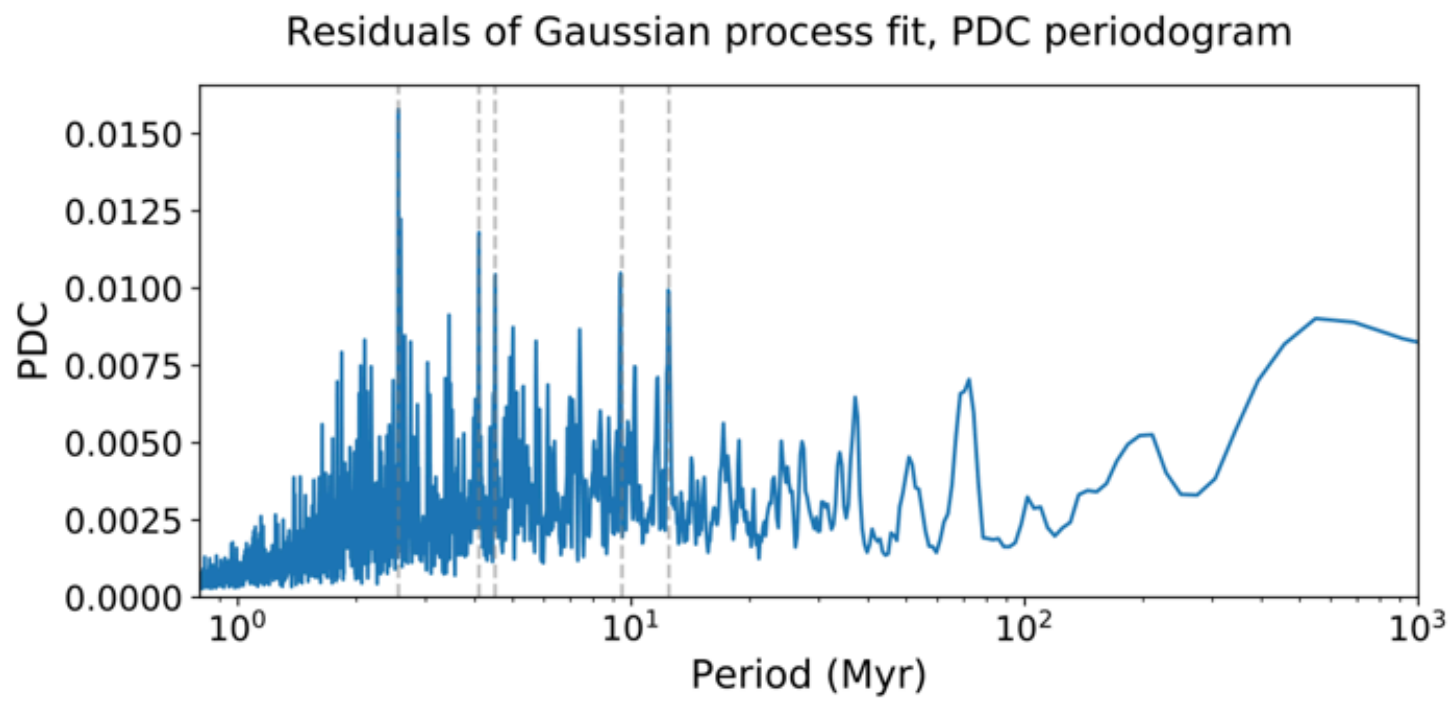

Supplementary Figure S13 Phase distance correlation periodogram after subtraction of the Gaussian process model (in blue) in sea-level data. The grey dashed lines indicate periods at 2.556, 4.095, $12.45,18.35,22.5,28.2$ Myr.

\section{Time-series analysis of Müller et al.'s 2016 datasets}

Spectral analysis of subduction data (rate and plate boundary length) shows evidence for the $35 \mathrm{Myr}$ cycle (Fig. S15). However, this $35 \mathrm{Myr}$ cyclicity in subduction rate and that in plate boundary length are phase shifted by only 1.5 to $2.7 \mathrm{Myr}$ in the lower part of the signal, i.e. before $140 \mathrm{Ma}$, but then become significantly phase shifted by 3.2 to $5 \mathrm{Myr}$ up to $65 \mathrm{Ma}$. The phasing could be explained by the delayed response time of plate boundary length. The phase change after 140 Ma could be due to continental rifting and new ocean basin formation at that time (e.g., Müller et al., 2008).

Spectral analysis of spreading rate data detects a dominant 25-26 Myr cyclicity (Fig. S16, see also Cogné and Humler, 2006; Müller and Dutkiewicz, 2018). Additionally, midocean ridge plate boundary length show very long-term irregular variations riding two main cyclicities of 12.3 and 17.1 Myr (Fig. S16). The most regular is the $12.3 \mathrm{Myr}$ cyclicity, which is characterized by a shorter mean period of 10.3 Myr for the interval 20-100 Ma. Amplitude modulation of this $10 \mathrm{Myr}$ band detects the $26 \mathrm{Myr}$ cycle observed in the original spreading rate data.

Finally, convergence rate data shows, in addition to the prominent $35 \mathrm{Myr}$ cycle, some short-term oscillations, considered here with caution because of their low statistical significance (modeling resolution, error on timescales, etc). Spectral and amplitude modulation AM analyses of these short-term swings indicate that they most likely match the 10 Myr cycle band, and they are modulated by a dominant cyclicity of 26 Myr (Fig. S17). The exploratory search applied to subduction rate data also yields the detection of the $35 \mathrm{Myr}$ cycle (Figs. S18 and S19).

The phase relationship, at the 26 Myr cycle band, between spreading and subduction rates is provided in Fig. S16E. Subduction leads spreading rate by $\sim 5.4 \mathrm{Myr}$ (coherence $=$ $0.75, \phi=-75^{\circ}$ at $25.8 \mathrm{Myr}$, Fig. S16E), which corresponds approximately to the half period of the modulation cyclicity, i.e., the two signals are almost in phase quadrature. We have also noticed that this phase lead/lag is more important after $140 \mathrm{Ma}$. This result is beyond the scope of the present review, and needs further investigation via geodynamic modeling.

Since the convergence and spreading rates are Earth's interior coupled processes they share some frequencies. The main 25.9 Myr cyclicity seen in spreading rate data (e.g., Cogné and Humler, 2006; Müller and Dutkiewicz, 2018) could be retrieved in the 
convergence rate data as the modulator of the $10 \mathrm{Myr}$ cycle band, but convergence clearly leads the spreading rate (Fig. S16D). An increase in spreading rate forces old lithosphere to subduct more rapidly into the mantle interior, where it enhances mantle downwelling (Conrad, 2013).

In summary, the $35 \mathrm{Myr}$ periodicity is particularly well expressed in the global subduction data (Fig. S15), revealing that this cyclicity may originate from the episodicity in slab rollback and advance. This process would involve profound rhythmic changes in subduction deepwater cycling, and thus could explain the $35 \mathrm{Myr}$ sea-level cyclicity inferred from the sedimentary record (see Discussion). The potential impact of deep mantle water recycling on sea-level oscillations has already been raised by Cloetingh and Haq (2015).

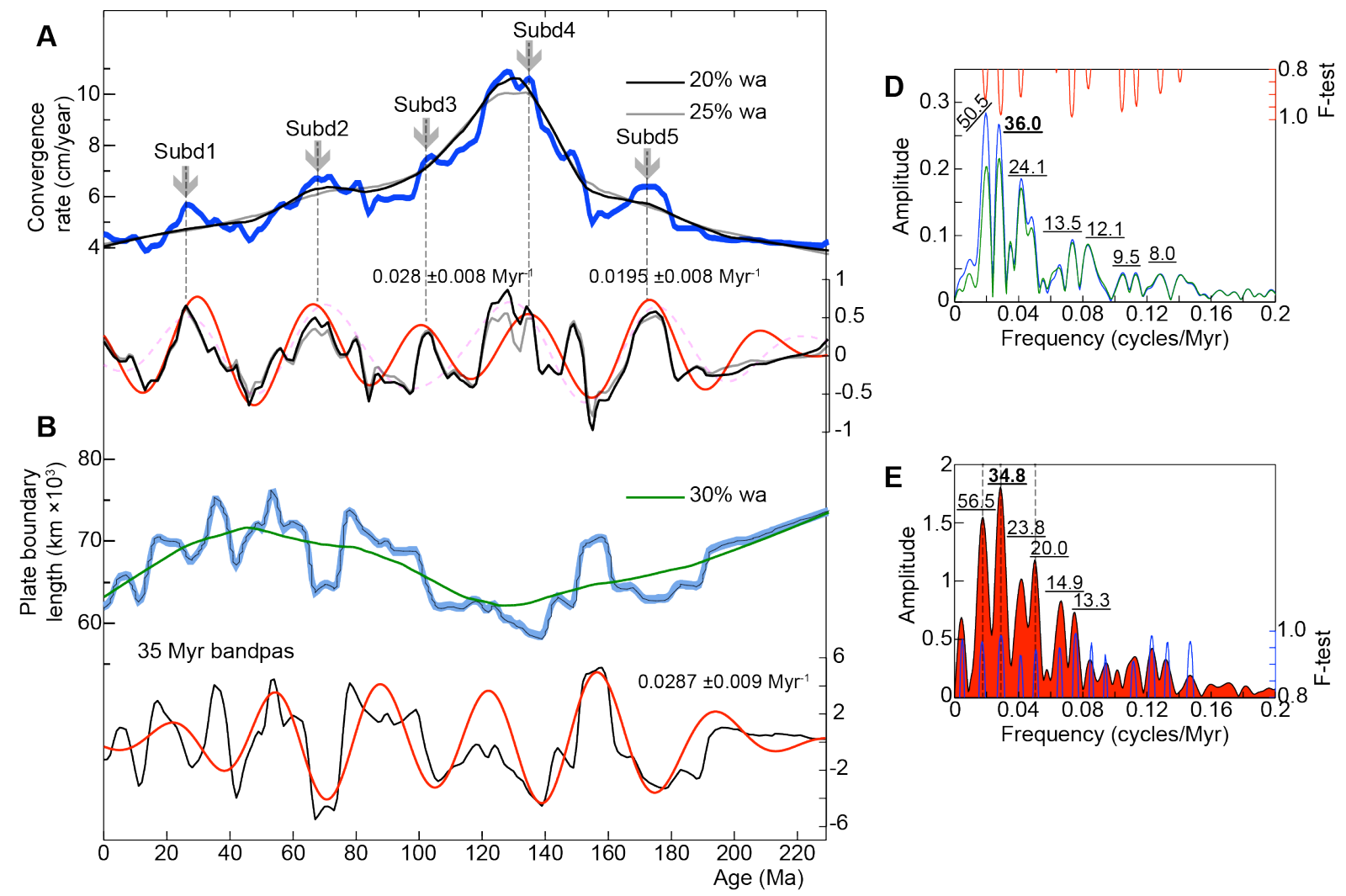

Supplementary Figure S14: Time-series analysis of plate convergence data of Müller et al. (2016) and Müller and Dutkiewicz (2018). (A) Raw convergence rate data (blue curve) along with weighted average (wa) smoothing (grey and lack curves) to remove long-term trends (shown below the raw data with similar corlor codes, along with a $35 \mathrm{Myr}$ bandpass filter $(0.028 \pm 0.008 \mathrm{cycles} / \mathrm{Myr})$ in red and 50 Myr bandpass filter (0.0195 \pm 0.008 cycles/Myr) in pink-dashed curve). Maxima of subduction rate related to the 36 Myr cycle are indicated by arrows and labelled 'Subd1' through 'Subd5'. (B) Raw convergence zone plate boundary length data (blue curve) along with weighted average (wa) smoothing (green curvs) to remove long-term trends (shown below the raw data, along with a $35 \mathrm{Myr}$ bandpass filter (0.0287 \pm 0.009 cycles/Myr). (C) Amplitude spectra of the detrended convergence rate data (20\% wa in blue and $25 \%$ wa in green). (D) Amplitude spectrum of the $30 \%$ wa detrended convergence zone plate boundary length data. 

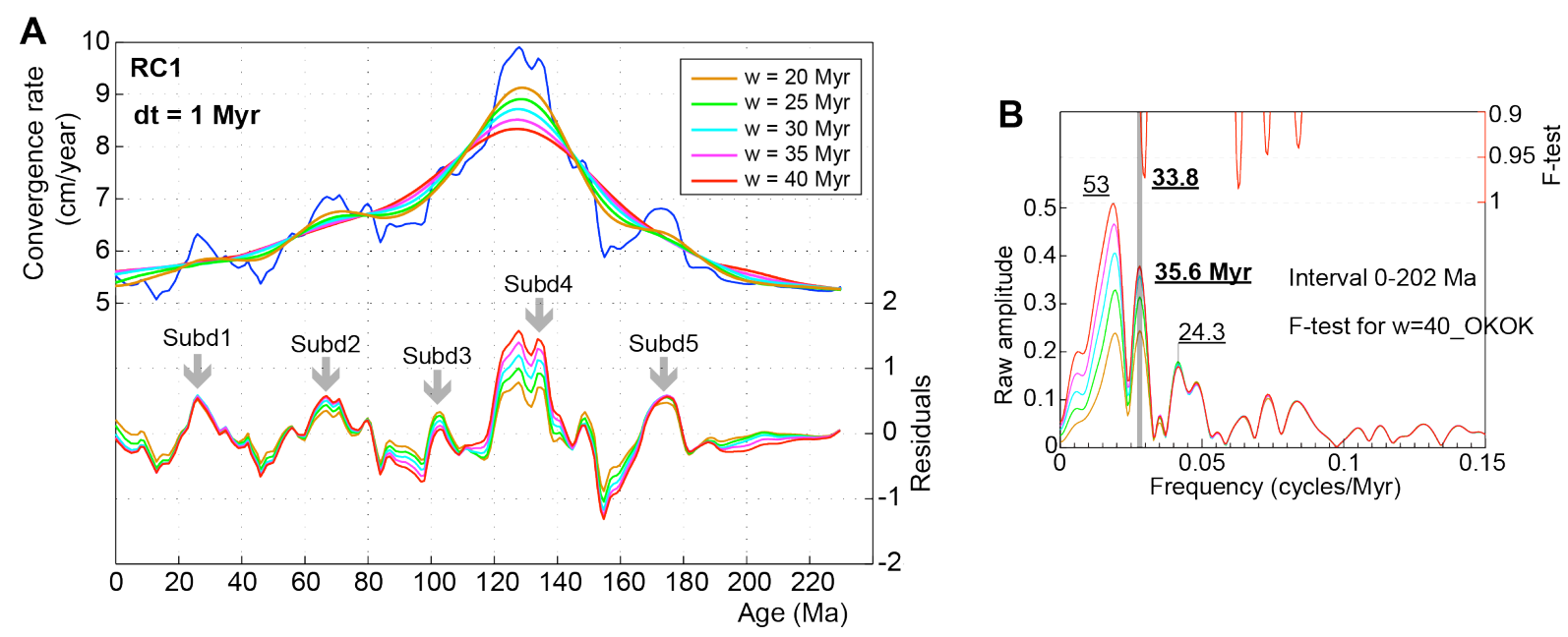

Supplementary Figure S15: Power spectra of the convergence rate data over the interval 0-202 (Müller et al.'s 2016 data). (A) SSA detrends. Subd1 through Subd5 are $35 \mathrm{Myr}$ scale convergence maxima. (B) 2pi-MTM amplitude spectra of the detrended data (see respective color codes for each detrend). Note that the $35 \mathrm{Myr}$ peak is not affected by the detrend process. 2pi-MTM 1x-pad power spectrum is provided in Fig. 14l.
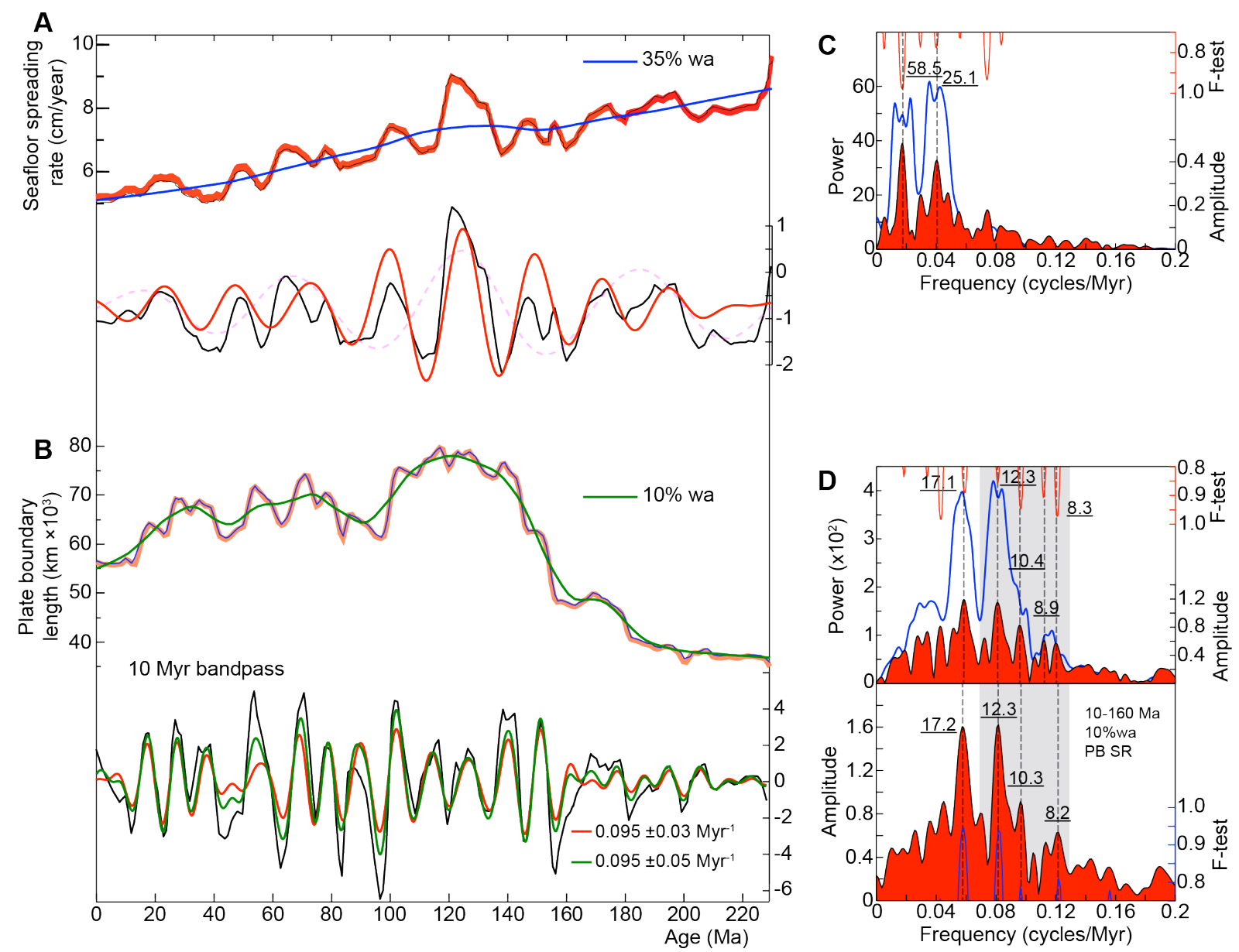

Supplementary Figure S16: Time-series analysis of spreading rate data of Müller et al. (2016) and Müller and Dutkiewicz (2018). (A) Spreading rate data (red curve) along with weighted average (wa) smoothing (blue curve) to remove long-term trends (shown below the raw data with black color, along with a $25 \mathrm{Myr}$ bandpass filter $(0.04 \pm 0.01 \mathrm{cycles} / \mathrm{Myr})$ in red and $50 \mathrm{Myr}$ bandpass filter $(0.017 \pm 0.008$ 
cycles/Myr) in pink-dashed curve). (B) Raw mid-ocean ridge plate boundary length data (blue curve) along with weighted average (wa) smoothing (green curve) to remove long-term trends (shown below the raw data, along with a $10 \mathrm{Myr}$ bandpass filters (0.095 $\pm 0.03 / 0.05$ cycles/Myr). (C) Amplitude and power spectra of the detrended spreading rate data. (D) Amplitude spectra of the detrended midocean ridge plate boundary length data, upper panel for all the data, lower panel for the interval 20$160 \mathrm{Ma}$

A

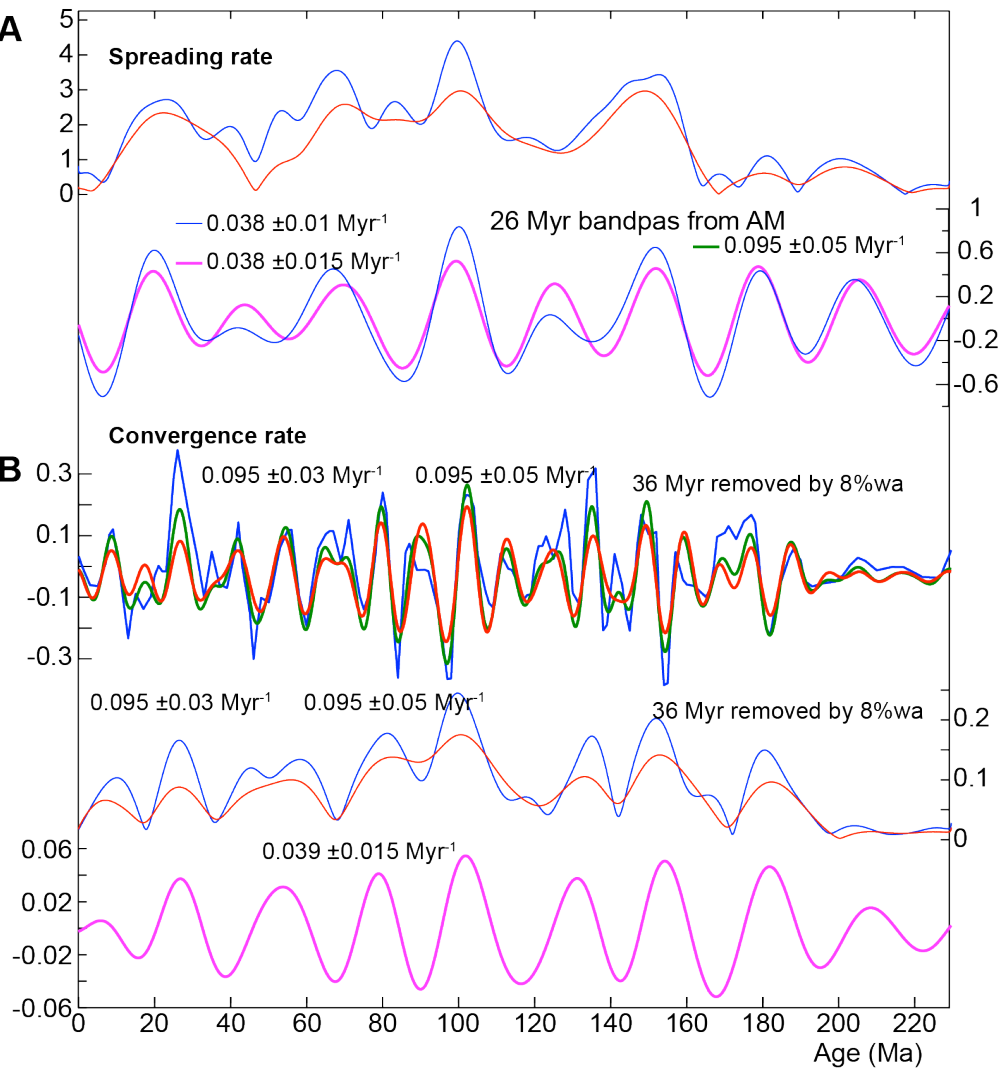

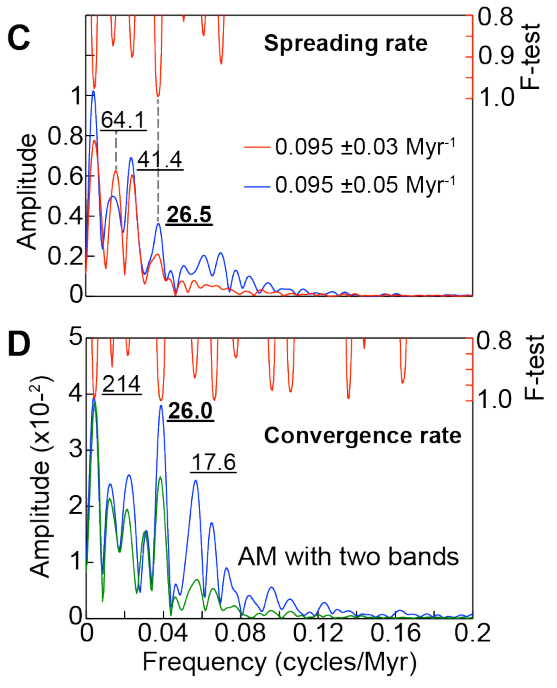

E

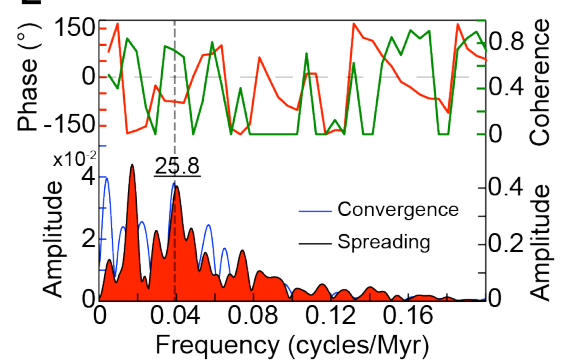

Supplementary Figure S17: Amplitude modulation analysis of 10 Myr cycle band from geodynamic data of Müller et al. (2016) and Müller and Dutkiewicz (2018). (A) Amplitude modulation results of spreading rate data using large and moderate bands $(0.095 \pm 0.05 / 0.03$ cycles/Myr $)$ along with bandpass filters at the $26 \mathrm{Myr}$ cycle band $(0.038 \pm 0.01$ in blue and $0.038 \pm 0.015$ in pink). (B) Amplitude modulation results of convergence rate data using large and moderate bands $(0.095$ $\pm 0.05 / 0.03$ cycles $/ \mathrm{Myr})$ along with bandpass filter of the $26 \mathrm{Myr}$ cycle $(0.038 \pm 0.015$ in pink). Note that the $10 \mathrm{Myr}$ cycles in convergence rate are not as regular as those in spreading rate, and therefore should be considered with caution because of several constraints (resolution, error in timescales, acyclic transferred processes, etc). (C) Amplitude spectra of amplitude modulation outputs of spreading rate data with the two respective bands (indicated). (D) Amplitude spectra of amplitude modulation outputs of convergence rate data with the two respective bands (indicated). (E) Crossspectra between raw spreading rate and $10 \mathrm{Myr}$ band amplitude modulation of convergence rate data. Note the coherence (0.75) of the two signals at $26 \mathrm{Myr}$ band, phased by $75^{\circ}$. 


\section{New time-series methods of geodynamic data}

Successive phase distance correlation periodograms

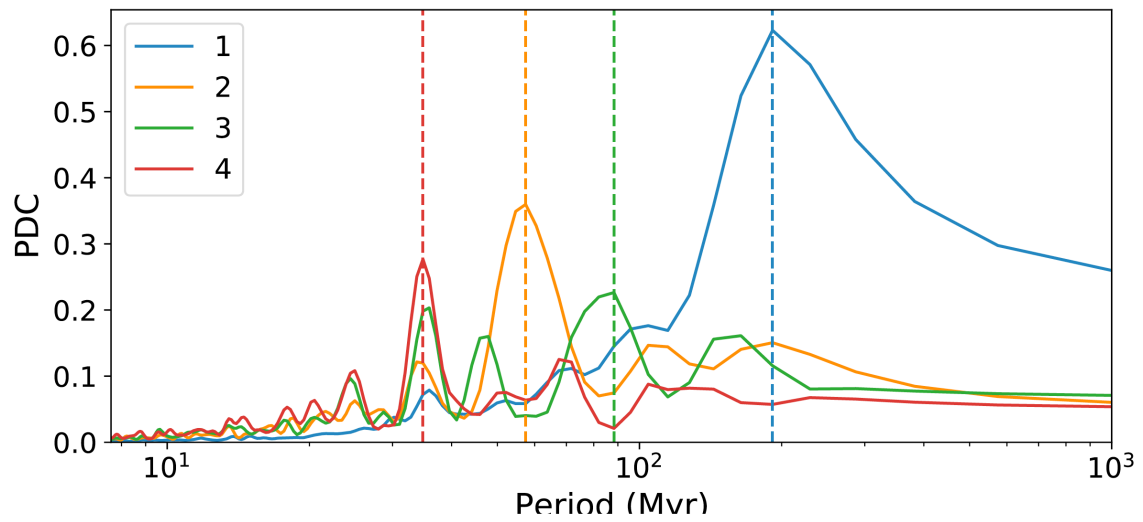

Supplementary Figure S18: Successive phase distance correlation periodograms obtained by computation on the residuals, after removal of the periodicities previously found in subduction data (Müller et al.'s 2016 model). The detected periodicities are 57.4, 88.3 and 34.8 Myr (repectively green, orange, and red vertical-dashed lines).

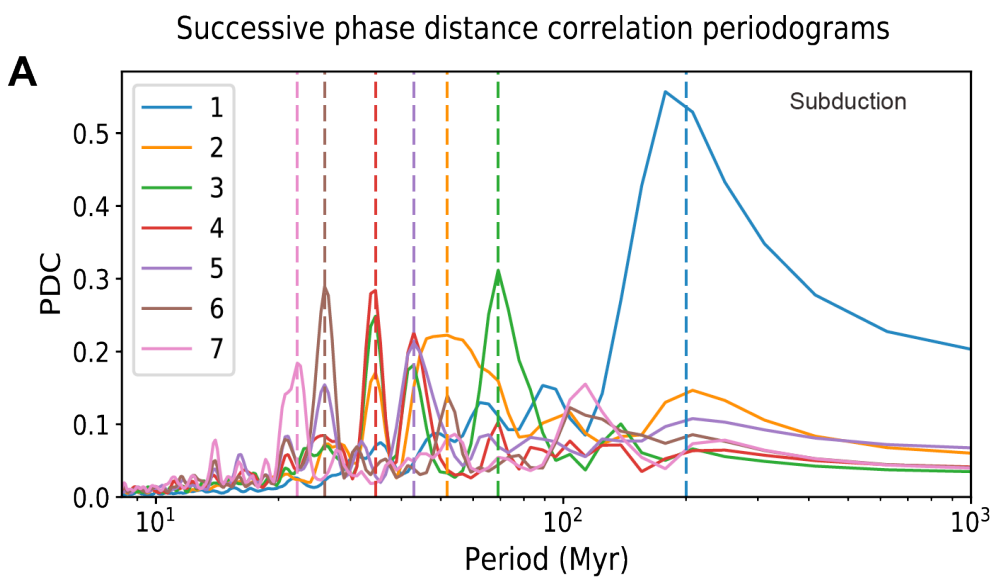

Successive phase distance correlation periodograms

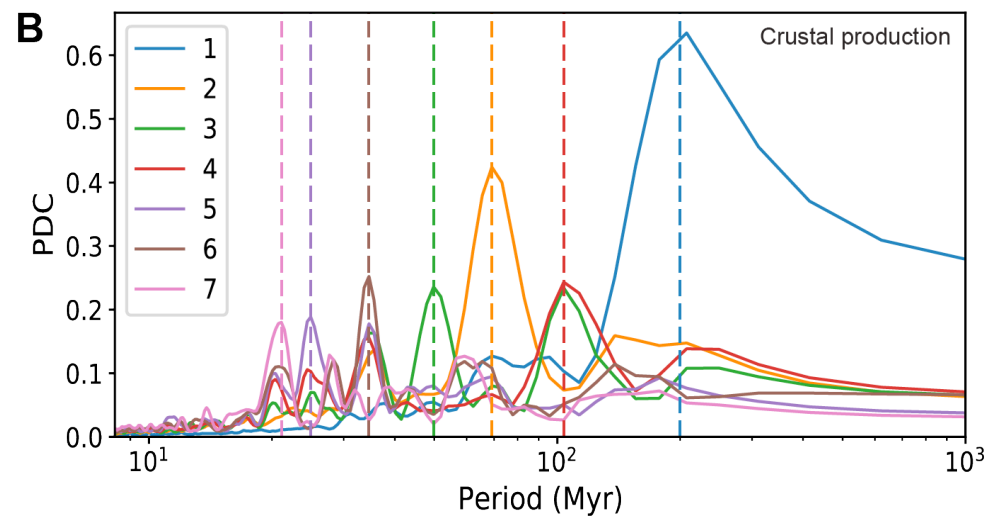

Supplementary Figure S19: Successive phase distance correlation periodograms obtained by computation on the residuals, after removal of the periodicities previously found in geodynamic data (Müller et al.'s 2019 model). (A) Subduction data. The successive detected periodicities are 51.9, 69.2, 34.6, 42.9, 25.9 and 22.2 Myr. (B) Crustal production data. The successive detected periodicities are 69.2, 49.8, 24.9, 34.6, and 22.1 Myr. 
Visual inspection and filtering of the 26 and 35 Myr cycles in spreading and subduction data:

A

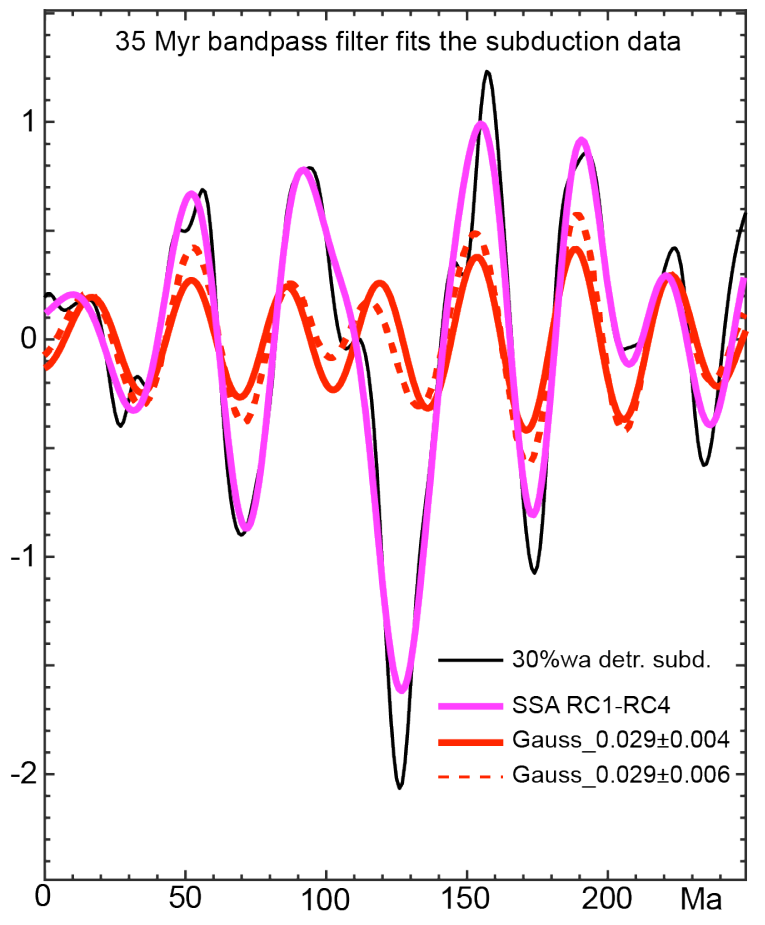

C

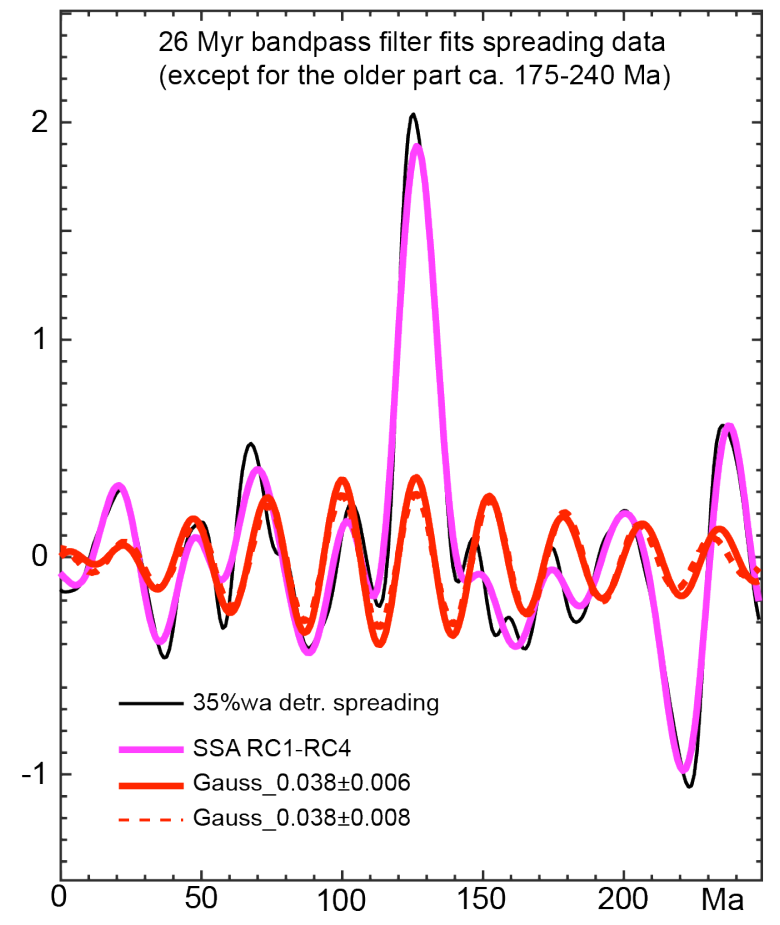

B

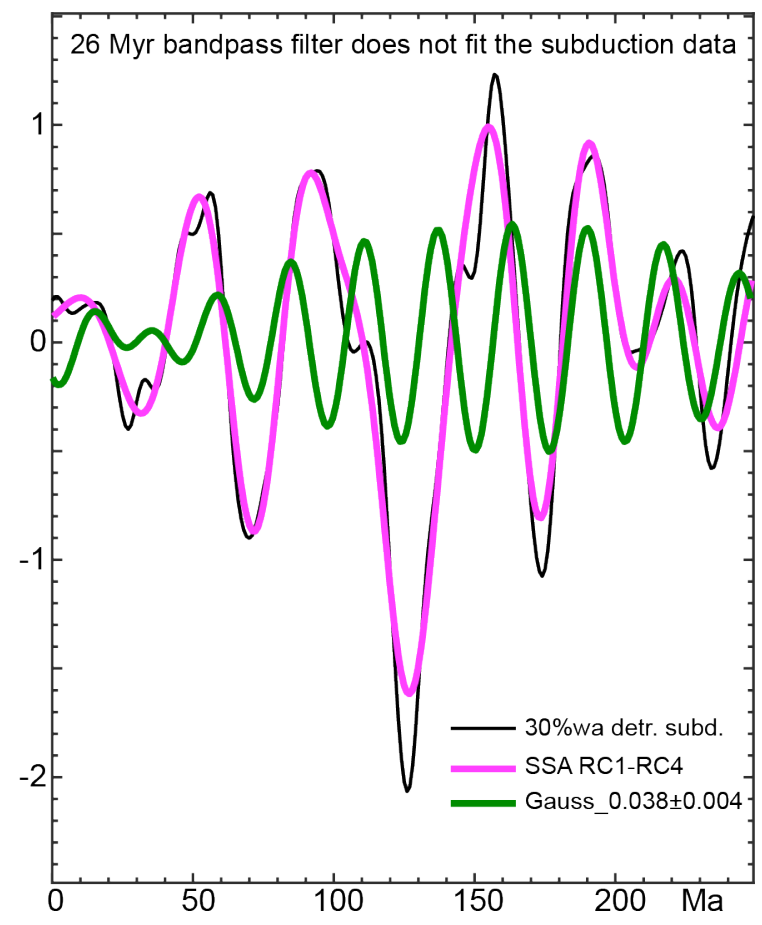

D

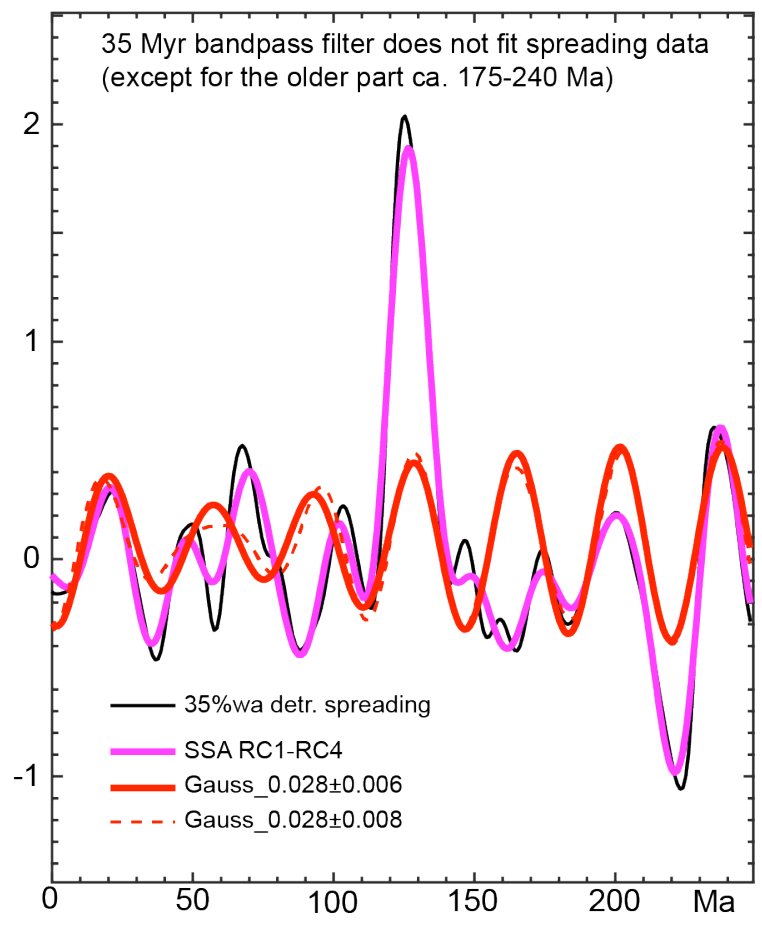

Supplementary Figure S20: (A) and (B) for subduction data, and (C) and (D) for spreading data. 


\section{Cited references:}

Boulila, S., Galbrun, B., Hinnov, L.A., Collin, P.Y., Ogg, J.G., Fortwengler, D., Marchand, D., 2010. Milankovitch and sub-Milankovitch forcing of the Oxfordian (Late Jurassic) Terres Noires Formation (SE France) and global implications. Basin Research 22, 717-732.

Boulila, S., Galbrun, B., Miller, K.G., Pekar, S.F., Browning, J.V., Laskar, J., Wright, J.D., 2011. On the origin of Cenozoic and Mesozoic "third-order" eustatic sequences. Earth-Sci. Rev. 109, 94-112.

Boulila, S., Hinnov, L.A., Huret, E., Collin, P.Y., Galbrun, B., Fortwengler, D., Marchand, D., Thierry, J., 2008. Astronomical calibration of the Early Oxfordian (Vocontian and Paris basins, France): consequences of revising the Late Jurassic time scale. Earth and Planetary Science Letters 276, $40-51$.

Delisle, J. B., Hara, N., Ségransan, D. Efficient modeling of correlated noise. II. A flexible noise model with fast and scalable methods, Astronomy \& Astrophysics, Volume 638, id.A95, 10 pp.

Embry, S., Beauchamp, B., Dewing, K., Dixon, J., 2019. Episodic tectonics in the phanerozoic succession of the Canadian high arctic and the "10-million-year flood". In: Piepjohn, K., Strauss, J.V., Reinhardt, L., McClelland, W.C. (Eds.), Circum-Arctic Structural Events: Tectonic Evolution of the Arctic Margins and Trans-arctic Links with Adjacent Orogens, vol. 541 Geological Society of America Special Paper. https://doi.org/10.1130/2018.2541(11).

Foreman-Mackey, Daniel; Agol, Eric; Ambikasaran, Sivaram; Angus, Ruth. Fast and Scalable Gaussian Process Modeling with Applications to Astronomical Time Series. The Astronomical Journal, Volume 154, Issue 6, id.220

Haq, B.U., Schutter, S.R., 2008. A chronology of Paleozoic sea-level changes. Science 322 (5898), 64-68.

Laskar, J., Robutel, P., Joutel, F., Gastineau, M., Correia, A.C.M., Levrard, B., 2004. A long-term numerical solution for the insolation quantities of the Earth. Astronomy and Astrophysics 428, 261-285.

Laskar, J., Fienga, A., Gastineau, M., Manche, H., 2011. La2010: a new orbital solution for the long term motion of the Earth. Astronomy and Astrophysics 532, A89. doi: 10. 1051/0004$6361 / 201116836$.

Rasmussen C.E. and Williams C.K.I, Gaussian Processes for Machine Learning, by. ISBN-13 978-0262-18253-9.

Strasser, et al., 2006. Cyclostratigraphy - concepts, definitions, and applications. Newsletters on Stratigraphy $42(2), 75-114$.

Zucker 2018: Detection of periodicity based on independence tests - III. Phase distance correlation periodogram Monthly Notices of the Royal Astronomical Society: Letters, Volume 474, Issue 1, p.L86-L90. 